\title{
THE CHALLENGE OF NONIONIZING RADIATION: A PROPOSAL FOR LEGISLATION
}

\author{
KAREN A. MASSEY*
}

* Project Attorney, Natural Resources Defense Council, Inc., New York, New York; B.A., Middlebury College 1974; J.D., Yale University 1978.

The author wishes to thank Jeff Thaler, Louis Slesin and Zorach Glaser for their helpful comments and editorial advice, and the staff at NRDC for their support. The opinions in this Article are those of the author and do not necessarily represent the views of the reviewers or of NRDC.

THE FOLLOWING CITATIONS WILI BE USED IN THIS ARTICLE:

Radiation Control for Health and Safety Act of 1967: Hearings on S. 2067 Before the Senate Comm. on Commerce, 90th Cong., 1st Sess. (1967) [hereinafter cited as Hearings on S. 2067];

Radiation Health and Safety: Hearings Before the Senate Comm. on Commerce, Science \& Transportation, 95th Cong., 1st Sess. (1977) [hereinafter cited as 1977 Hearings];

Advisory Committee on the Biological EfFects of Ionizing Radiation, Nat'

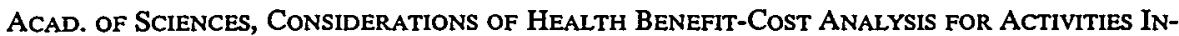
volviNg IONIZING RADIATION EXPOSURE AND ALTERNATIVES (1977) [hereinafter cited as BEIR II REPORT];

S. BARANSKI \& P. CZERSKI, Biological EFfects of Microwaves (1976) [hereinafter cited as BARANSKI];

P. Brodeur, The Zapping of America: Microwaves, Their Deadly Risk, aNd the COVER-UP (1977) [hereinafter cited as BRODEUR];

EPA, ENVIRONMENTAL EXPOSURE to NoNIONIzing RAdiation (1973) [hereinafter cited as ENVIRONMENTAL EXPOSURE];

General accounting Office, Report to Congress, The Environmental Protection Agency Needs Congressional Guidance and Support to Guard the Public in a Period of Radiation Proliferation (1978) [hereinafter cited as Radiation Proliferation];

K. MARHA, J. MUSil \& M. TuHA, Electromagnetic FieldS AND the Life ENVIRONMENT (1971) [hereinafter cited as MARHA];

Office of Radiation Programs, EPA, Radiation Protection activities (1976) [hereinafter cited as Radiation Protection Activities 1976];

Office of Telecommunications Policy, Fourth Report on "Program for Control of Electromagnetic Pollution of the Environment: The Assessment of Biological HaZARDS OF Nonionizing Radiation" (1976) [hereinafter cited as OTP, Fourth ANNUAL REPORT];

Office of Telecommunications Policy, Report on "Program for Control of Electromagnetic Pollution of the Environment: The Assessment of the Blological HAZARDS OF NoNIONIZING ElECTROMAGNETIC RADIATION" (1973) [hereinafter cited as OTP, First ANNUAL REPORT];

Office of Telecommunications Policy, The Radio Frequency Spectrum, U.S. USE AND MANAGEMENT (1975) [hereinafter cited as RADIo FreQUENCY SPECTRUM];

Tyler, Overview of Electromagnetic Radiation Research: Past, Present and Future, in Biologic EfFects of Nonionizing Radiation, 247 ANNALS N.Y. ACAD. SCI. 6 (1975) [hereinafter cited as Tyler]. 
I. INTRODUCTION.................................. 108

II. BACKGROUND................................ 109

A. Description of Nonionizing Radiation as a Biologically Active Agent ................................ 109

B. The Benefits of Nonionizing Radiation Use (Sources of Human Exposure) ............................. 110

1. Early Uses ............................. 110

2. Spectrum Distribution of Uses................ 111

3. Sources of Light-like Radiation ............... 112

4. Sources of Extra-low Frequency Radiation ........ 112

5. Sources of Radio Frequency and Microwave Radiation .......................................... 113

6. Future Uses ............................ 114

C. Adverse Effects of Electromagnetic Radiation on Man and His Environment ................................ 115

1. Bioeffects ............................. 115

(a) Thermal effects and the American protection guidelines ............................ 115

(b) Low-level ("nonthermal') effects ........... 118

(c) Uncertainties-parameters of nonionizing radiation $\ldots \ldots \ldots \ldots \ldots \ldots \ldots \ldots \ldots \ldots \ldots \ldots . \ldots \ldots, 121$

(i) Power density .................. 121

(ii) Intensity and relative phase of all field components....................... 122

(iii) Specific frequency................. 123

(iv) Waveform characteristics ............ 123

(v) Exposure regimes ................. 124

(vi) Specific occupations................ 124

(vii) Level of control over exposed populations ....................... 124

(viii) Individual differences .............. 124

(ix) Presence of other environmental stressors ........................ 125

2. Interference Effects ......................... 126

3. Environmental Measurements .................. 126

D. Present Governmental Activities in Nonionizing Radiation Protection ....................................... 130

1. Federal Agencies ......................... 130

(a) Agencies with coordination and oversight functions ...................................

(i) Department of Commerce-The National Telecommunications and In- 
(ii) Environmental Protection Agency (EPA) ....................... 132

(b) Agencies with regulatory authority .......... 135

(i) Department of Health, Education and Welfare (HEW).................. 135

(ii) Department of Labor (DOL)Occupational Safety and Health Administration (OSHA) .............. 138

(iii) Department of Defense (DOD) ....... 140

(iv) Federal Communications Commission (FCC) $\ldots \ldots \ldots \ldots \ldots \ldots \ldots \ldots \ldots . \ldots \ldots$

(v) Other agencies with regulatory power 143

(c) Other research-nonregulatory agencies and authorities................................ 144

2. State and Municipal Activities ................ 145

III. The NeEd for Legislation $\ldots \ldots \ldots \ldots \ldots \ldots \ldots \ldots \ldots, 148$

A. Legislation for Prevention ...................... 148

1. Timing ............................... 148

2. The Logic of Prevention Policy ................ 150

B. Legislation for National Policy Directives............ 152

C. Legislation for Research ........................ 153

D. Legislation for Regulation ...................... 156

1. The Trouble with EPA ..................... 156

2. Clarification of Agency Roles ................. 158

3. Reexamining the Federal Radiation Council Concept

4. The Changing Picture ..................... 161

IV. Formulating a Legislative Response .............. 161

A. Developing Policy and Strategy .................. 162

1. Health Protection-Setting Standards ........... 162

(a) The definition of health ................. 162

(b) The benefits of nonionizing electromagnetic radiation (NEMR) and the need for a standard .. 164

2. Welfare Policy............................. 167

(a) Determining the scope of the problem ....... 168

(b) Weighing the costs and benefits-the limits of economic analysis ...................... 170

3. Policy Implementation-Choosing Pollution Control Strategies ................................. 171

(a) Control of government sources ............ 172

(b) Control of private broadcast sources ........ 173 
(c) Control through expanded spectrum management .................................. 175

B. Restructuring the Institutions .................. 178

1. The Research Program-Choosing a Coordinator.. 178

(a) Office of Management and Budget (OMB) ... 179

(b) Office of Science and Technology Policy (OSTP) ........................... 181

(c) Council on Environmental Quality (CEQ) .... 182

2. The Regulatory Program .................... 183

(a) A new Federal Radiation Council for nonionizing radiation ........................... 183

(b) Redefinition of the EPA role .............. 186

(c) Other agencies-OSHA .................. 186

(d) Federal-state relationships............... 187

(e) Adjudication of agency jurisdictional disputes . 188

V. Conclusion......................................... 189

\section{INTRODUCTION}

Nonionizing radiation is an important factor in the life of every member of an advanced technological society. This is particularly true of American society with its space program, its sophisticated weapons systems, its highly developed electronics products, and the world's most advanced national communications system - all of which use nonionizing radiation, generally in the microwave and radio frequency ranges. Most Americans are probably unaware of either the pervasiveness of nonionizing radiation or the controversy surrounding its status as a pollutant and a health hazard. In the last decade, however, both the scientific community and the United States Congress have begun to pay more attention to this form of energy and its impact on our lives. Very recently, their concerns have begun to trickle into the general public domain, popularized by a series of articles in the New Yorker by Paul Brodeur, recently expanded and published in his book, The Zapping of America. ${ }^{1}$ Unfortunately, America's inventors and entrepreneurs nove much more swiftly than its scientists, politicians and publicists; while the latter investigate and deliberate, the American public is presented with an array of consumer products such as CB radios and microwave ovens. Once again, progress threatens to roll right over the regulators, leaving them to clean up the mess, as has been the case with air and water pollution.

The purpose of this Article is to assemble the available informa-

1. BRODEUR. 
tion on radio frequency and microwave radiation in a systematic way, and to present it accurately as both a primary agent of progress in the second half of the twentieth century and a potential threat to inan's environment. The Article atteinpts to assess the immediate need for a regulatory system that would control nonionizing radiation in the public interest and offers a critique of the existing system, or lack thereof, for controlling such radiation. It makes a plea for a legislative solution and offers soine suggestions for dealing with what may be the most complex yet in a line of pollution problems that tax the imdividual talents of both the scientists and the policymakers, as well as their ability to bridge the gap between their two spheres of action.

\section{BACKGROUND}

The following background information is provided in some detail because nonionizing electromagnetic radiation constitutes a very complex pollution problem, and the subject is one on which hittle has been written for the lay person. Those articles that do exist tend to oversimplify the scientific disputes and neglect the questions concerning governmental efforts to control norionizing radiation. The first portion of this Article atternpts to overcome these deficiencies. Part A describes nonionizing radiation, distinguishing it from ionizing radiation, with which it is solnetimes confused. Part B identifies the sources that emit this radiation and the benefits that derive from its use. Part $\mathrm{C}$ describes the harm that individuals and society may incur from present and continued use of these sources. Finally, Part D outlines current governinental research and regulatory activities in the field of nonionizing radiation.

\section{A. Description of Nonionizing Radiation as a Biologically Active Agent.}

The electromagnetic spectrum can be divided and subdivided in many ways, but the most basic division as to biological effects is that between the ionizing and noinonizing portions of the spectrum. The zone designated as ultraviolet radiation (UV) ${ }^{2}$ separates the higher fre-

2. Some authorities refer to the whole spectrum of nonionizing radiation generally as "radio frequency (RF) radiation" or the "radio-wave band," e.g., "[a]ccording to another system of classification, the radio-wave band includes all coherent radiation even at wavelengths below . . 0.3 $\mathrm{mm}$, which would include laser radiation." MARHA 1.

The Electromagnetic Spectrum

\section{$f$ in cycles $/ \mathrm{sec} \longrightarrow$}

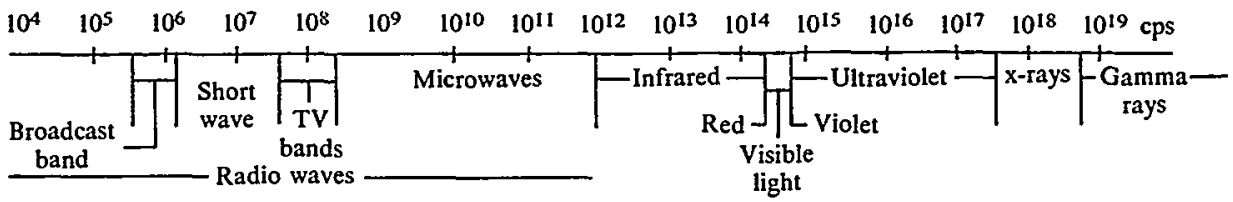

Reprinted from J. Ovear, Fundamental Physics 40 (2d ed. 1967). 
quency, shorter wavelengths of ionizmg radiation from the lower frequency, longer wavelengths of nonionizing radiation. ${ }^{3}$ Ionizing radiation (also known as high-energy radiation) is so named because "[t]he primary effect of its interaction with living inatter is ionization" - the production of electrically charged atoms or molecules. This process causes physical and chemical changes within the cells of the radiated biological matter that may ultimately lead to mutations, malignancies, diseases and the like. In contrast, nonionizing radiation, because of its lower frequency, does not possess sufficient energy per quantum to ionize nrolecules. ${ }^{5}$ The exact manner im which nonionizing radiation interacts with biological inaterial is not fully understood at the present time, but, like all issues related to nonionizing radiation, the subject is highly controversial. Nevertheless, experiments and praetical experience have deinonstrated that there is an interaction that can be injurious to human health. ${ }^{6}$

\section{B. The Benefits of Nonionizing Radiation Use (Sources of Human Exposure).}

1. Early Uses. Shortly after the discovery of nonionizing radiation fields, experimenters noted that when the body is exposed to these fields it experiences a heating sensation. ${ }^{7}$ In the early part of this century, this knowledge was put to medical use in a technique called radiodiatherny, which rehed on the deep-heating capabilities of radio waves. ${ }^{8}$ Simultaneously, other scientists and imventors, notably Guglielmo Marconi, were rapidly adapting this newly discovered electroinagnetic energy to communications, resulting in the development of wireless telegraph, telephone and radio broadcast. ${ }^{9}$

Developinents in the ionizing radiation field were also proceeding apace. Because of the rapid adaptation of this form of radiation to widespread nedical use, physicians and others soon discovered its adverse effects on hunian health. ${ }^{10}$ Perhaps because of the concentration of inedical research efforts in this field, there was relatively hittle re-

3. 'Far' or higher frequency ultraviolet radiation (UV) produces biological effects similar to those of ionizing radiation, while 'near' UV is more like nonionizing radiation in this respect. BARANSKI 11.

4. Id.

5. MARHa 1.

6. 1977 Hearings 11-12 (statement of Dr. Stefen O. Schiff).

7. See, e.g., Hearings on S. 2067 at 354 (report of Warren H. Donnelly); Brodeur 17 (experiments of Nikola Tesla and Jacques Arsene D'Arsonval); MARHA 2. See generally Brodeur 131 (a layman's history of developments in radiation).

8. Hearings on S. 2067 at 354.

9. BRODEUR 1-5.

10. Id. 17-22. 
search into the bioeffects of nonionizing radiation ${ }^{11}$ until the late 1950 s, when the Departnent of Defense sponsored the "Tri-Service" research progran1. ${ }^{12}$ The new interest stemmed front the widespread proliferation in the post-war period of electronics devices. The result was an increase in nonionizing radiation emissions and growing concern about the health risks associated with the new equipinent-particularly with the operation of radar systenis. Radar was first developed by the British in the mid-1930s and was further developed by the military during World War II. The armed forces and their contractors have been improving it ever snice, rapidly increasnig its power output. There has also been a constant increase in the number of radar installations, both military and civilian. ${ }^{13}$

2. Spectrum Distribution of Uses. Considering that radio broadcasts, communications systens and radio-diathermy were virtually the only manmade sources of nonionizing electromagnetic radiation prior to World War II, the growth in the number of sources and the variety of applications in the post-war period has been phenoinenal. These uses span the spectrun of nonionizing frequencies and nay be roughly divided into four classes (in descending frequencies): light-like radiation [near UV, visible and infrared]; ${ }^{14}$ microwave radiation $[300 \mathrm{MHz}$ (megahertz) - $300 \mathrm{GHz}$ (gigahertz)]; radio frequency radiation $[30 \mathrm{kHz}$ (kilohertz)-300 MHz]; ${ }^{15}$ and lower frequency radiation, including very low frequency radiation (VLF) $[3-30 \mathrm{KHz}]$ and extra-low frequency radiation (ELF) [direct current to $3 \mathrm{kHz}$ ]. ${ }^{16}$

This Article will concentrate primarily on the radio frequency-microwave range of electrolnagnetic radiation. The development of new sources of radiation in these frequencies has been particularly rapid. Also, incidents such as the irradiation of the Moscow Embassy have brought the question of increasing exposures into the public eye, re-

11. There was some preliminary research on the bioeffects of nonionizing radiation in the 1930s, but this research was abruptly terminated by World War II. These programs were not reinstigated after the war because such research was once again overshadowed by the intense research on ionizing radiation prompted by the radiation health disaster-and radiobiology research boom-in the aftermath of Hiroshima and Nagasaki. See MARHA 2-3; Tyler 6-7.

12. Tyler 7. See text accounpanying note 44 infra.

13. BARANSKI 14-15.

14. Hearings on $S .2067$ at 364-66 (report of Warren H. Donnelly).

15. BARANSKI 13; MARHA 4. But see Tell, Environmental Nonionizing Radiation Exposure: $A$ Preliminary Analysis of the Problem and Continuing Work within EPA, in ENvironMENTAL ExPOSURE 49. Tell extends the "microwave" spectrum down to $30 \mathrm{Mhz}$, beginning the "radiofrequency" spectrum there.

16. Marha 4; OTP, Fourth AnNual RePORT, Figure 4. These frequencies are also referred to as the "audiofrequency radiation band," but should not be confused with sonic-sound wave radiation. 
vealing the extent of scientific uncertainty in this area. Thus, 1nuch of the citizen concern and the bulk of recent scientific research deals with this portion of the spectrum, and it is in this area that information and legislative reform are nost needed. Although it is true that certain health effects may be soinewhat frequency-dependent, ${ }^{17}$ inany of the observed adverse effects nay be induced by exposure to electronnagnetic radiation in either of these frequency ranges. ${ }^{18}$ However, because all nonionizing radiation is usually lumped together for administrative purposes, and should properly be dealt with on this broad level for legislative purposes, soine mention inust be made of the higher and lower ends of the nonionizing spectrum as well.

3. Sources of Light-like Radiation. One source of light-like radiation that has attracted particular attention due to its potential danger to health is the UV radiation used in inercury vapor and inercury arc lamps. ${ }^{19}$ These lainps provide general illumination for highways and parking lots, stores, auditoriums and gymnasiums. ${ }^{20}$ Ultraviolet radiation is also cominonly used in sunlamps and germicidal lainps. A third application of light-like radiation that spans the frequency range of this portion of the nonionizing spectruin is lasers. First developed in the late 1950s and early 1960s, this technology and its uses have developed quite rapidly in a very short time. ${ }^{21}$ Lasers are used in range finding, surveying, coinputer memory devices, cominumications, weapons, surgery, welding and drilling, ${ }^{22}$ as well as in laser art shows.

4. Sources of Extra-low Frequency Radiation. At the other end of the scale, in the ELF range, are the $60 \mathrm{~Hz}$ electric fields that surround the controversial but increasingly cominon extra-high voltage (EHV) power lines strung across the nation. ${ }^{23}$ Another projected use of ELF electromagnetic energy is a Navy cominunications system known as Project SEAFARER (formerly Project SANGUINE), designed to

17. Tyler 11.

18. BARANSKI 15.

19. See, e.g., Radiation Protection Activities 1976 at 106 . For a brief general discussion of the practical applications of radiation in all zones of the electromagnetic spectrum (ionizing as well as nonionizing), see Hearings on S. 2067 at 350-55 (report of Warren H. Donnelly). See also BARANSK1 16, Table 3.

20. Personal commumication with Henry J.L. Rechen, Division of Electronic Products, Bureau of Radiological Health, FDA, HEW (Dec. 13, 1977).

21. Hearings on S. 2067 at 365 (report of Warren H. Donnelly).

22. Id. 352 .

23. EHV refers to voltages above 345 kilovolts. Radiation Protection Activities 1976 at 105. EHV lines carrying 765 kilovolts of power are already in use, and lines carrying 1100 or 1500 kilovolts are proposed. Marino \& Becker, High Voltage Lines, Hazard at a Distance, EnvironMENT, Nov. 1978, at 6. 
transmit signals to submerged nuclear submarines from a mammoth antenna system buried six feet underground in the American Midwest. $^{24}$

5. Sources of Radio Frequency and Microwave Radiation. Microwave and radio frequency radiation uses range from walkie-talkies and burglar alarms to the huge earth terminals of satellite commumications systems (SATCOMS), our highest-powered sources. ${ }^{25}$ These uses may be classified into five major categories: ${ }^{26}$ defense; transportation-cominunications; medical; industrial; and commercial and consumer products. These classifications should make it clear that products producing nonionizing radiation are an integral part of American life at the individual, national and imternational levels. In the defense category are high-powered military radar tracking weapons and guidance systems ${ }^{27}$ such as the PAVE PAWS ${ }^{28}$ radar installations under constrnction (and under increasing environmental scrutiny by citizens) at Otis Air Force Base on Cape Cod, Massachusetts, and at Beale Air Force Base in Yuba County, California. In addition to these radars, the military uses marine and aerial navigation radars. Although the military has its own communications imstallations, it also relies on other government and general use communications networks.

In the field of civilian transportation and communications, "microwave serves broadcast stations, communication common carriers, aviation, marime, railroad, motor carriers, public utility, forestry, other business, and inunicipal and state agencies including police and fire departments. It carries voice, teletype, telemetering, facsimile, and digital data, serves inobile and other control functions, and relays TV programs." 29 The primary medical use is for medical diatheriny, but other medical uses imclude electro-coagulation (cautery), nerve stimulation (including dental applications), and cancer therapy (still im the experimental stage). The major imdustrial use of radio frequency and microwave energy is in mduction and dielectric heatimg systems, which are

24. Brodeur 75; McClintock, Rissman \& Scott, Talking to Ourselves, Environment, Sept. 1971, at 16; McClintock \& Scott, Sanguine, Environment, July-Aug. 1974, at 27.

25. EPA, Radiological Quality of THE ENVIRoNMENT 193 (1976).

26. Of course, there is some overlap among categories. For example, radiation-emitting communications devices are an important component of the defense and, to some extent, the consumer electronics categories.

27. See generally BRODEUR' 239-41.

28. PAVE PAWS is an acronym for Precision Acquisition of Vehicle Entry Phased Array Warning Systems radars.

29. FCC, 32D ANNUAL RePORT FOR THE FISCAL YEAR 1966 at 47 (1966), quoted in Hearings on $S .2067$ at 353 (report of Warren H. Donnelly). 
employed in countless industrial processes. ${ }^{30}$ Consumer uses generally involve lower-powered emitters, but they are extremely varied. The most publicized and one of the fastest growing is the microwave oven; ${ }^{31}$ among the most ubiquitous is the ignition system of the internal combustion engine automobile. ${ }^{32}$ Other emitters include radars of private boats and planes and citizen-band radio antennas. ${ }^{33}$

6. Future Uses. Projected and liypothetical uses of nonionizing electromagnetic radiation stagger the mragmation. It might be used for transmitting power to an unmanned helicopter in flight, ${ }^{34}$ new types of computer communications, ${ }^{35}$ collision avoidance and automatic braking systems in cars, beaming energy from solar power generators in space, ${ }^{36}$ or any process triggered by 1notion-froin setting off shoplifting alarms to controlling the thickness of latex applied to the backs of carpets. ${ }^{37}$ Any new applications would be in addition to the proliferation of existing sources. In 1976, the Environmental Protection Agency (EPA) noted that radio frequency and microwave sources alone are estimated to be increasing at the rate of fifteen percent annually. Within certain frequency ranges, sucli as those allotted to radio and television stations, spectrun 1 crowding is a problem. While the growth rate in the nuinber of new stations inay be starting to level off, ${ }^{38}$ existing stations are increasing their power outputs in an attempt to reacls larger audiences and avoid interference. ${ }^{39}$

Thus, in the last thirty-five years man lias significantly changed his physical environment, producing a "type of man-made radiation [that] has no counterpart in inan's evolutionary background; it was relatively negligible prior to World War II."40 Unfortunately, as is the case witl

30. See generally MARHA 60-68.

31. See, e.g., EPA, Radiation Program Statement 17 (1976).

32. Tell, supra note 15 , at 62 .

33. Radiation Program Statement, supro note 31, at 17.

34. Hearings on S. 2067 at 353 (report of Warren H. Donnelly). 86.

35. Frey, Growth of Microwave Systems and Applications, in ENVIRONMENTAL EXPOSURe 85-

36. Glaser, Space Solar Power: An Option for Power Generation, in Environmental ExPoSURE 105.

37. Hearings on S. 2067 at 87 (report of Warren H. Donnelly).

38. In 1945, there were six television stations and 930 radio stations in the United States. By 1969, the numbers had increased to 847 and 6,442, respectively. OTP, FIRST ANNUAL REPORT Figure 2.

39. Radiation Program Statement, supra note 31, at 15.

40. OTP, First ANNUAL RePort app. A, at 1.

Electromagnetic fields do occur in nature, primarily in the form of pulsed electromagnetic waves ahead of a cold front or during electrical storms. MarHA 43, 59; cf. Browne, Experts Debate the Amount of Microwave Radiation that Can Cause Danger to Health, N.Y. Times, Dec. 27, 
many forms of chemical pollution, scientific research on the biological effects of this agent has not kept pace with technological developments and with the proliferation of emissions sources.

\section{Adverse Effects of Electromagnetic Radiation on Man and His Environment.}

Nonionizing electromagnetic radiation (NEMR) can affect human health adversely in two ways. First, these electromagnetic waves may penetrate the human body and interact with the hiving system. Second, such radiation causes interference with, and physical degradation of, electronic systems.

1. Bioeffects. (a) Thermal effects and the American protection guidelines. One of the few points on which there is widespread agreement among researchers is that exposure to high levels of noinionizing radiation causes "thermal" effects (reactions induced by the heating of tissues). ${ }^{41}$ If uncontrolled-that is, outside of the medical therapy context-these effects can be hazardous. Armed with this knowledge, in 1953 the United States Air Force adopted a standard of $10 \mathrm{~mW} / \mathrm{cm}^{2}$ for occupational exposure to nonionizing radiation. ${ }^{42}$ At the time, very little research had been done in this country on the bioeffects of this radiation, and much of the foreign hiterature was either untranslated or unexamined. Thus, the standard was based largely on theoretical projections of the thermal effects that were calculated, and to some extent demonstrated, to be hazardous at levels of $100 \mathrm{~mW} / \mathrm{cm}^{2}$. A safety factor of ten was incorporated ${ }^{43}$ to arrive at the standard. With this background, the military conducted its four-year Tri-Service Research Program, which consisted primarily of an investigation of the nature of thermal bioeffects. The program included no studies of possible effects from low-level power densities of nonionizing radiation. In retrospect,

1977, at 23, col. 2 ("[o]thers [scientists] said . . . that the man-made 'electronic smog' already enveloping Americans is millions of times more intense than any natural microwave radiation").

41. This heating results from the conversion of absorbed energy into "electronic excitation" causing "molecular vibration and rotation." EPA, RADIOLOGICAL QUALITY OF THE ENFIRONMENT IN THE UNITED STATES, 1977 at 275 (1977).

42. Ten milliwatts per centimeter squared-a measurement of the amount of power that passes through a square centimeter of space during each second.

43. Tyler 7. See also BARANSKI 170-73. Incorporation of a "safety factor" of one order of magnitude or more is a common practice in setting protection standards for environmental pollutants. These safety factors are supposed to cover any number of scientific uncertainties, including margims of error in experimental evidence or theoretical calculations, and the differential response of individuals to the same level of environmental stress. Cf. Society of Plastics Indus., Inc. v. OSHA, 509 F.2d 1301, 1308 (2d Cir. 1975) (quoting testimony of Dr. Kraybill, National Cancer Institute, supporting the use of a safety factor of 100 when setting health standards for pollution agents that are noncarcinogens). 
one Navy scientist summed up the program and its effects as follows: Although Tri-Service research addressed essentially only the problem of thermal hazard, the idea that the sole hazard was thermal beeame dominant, and in the early 1960's, an air of complacency settled over this country. At the end of the Tri-Service Program im 1960, United States research decreased to a very low level and remained there for the next decade. ${ }^{44}$

Meanwhile, research efforts in the Soviet Union and Eastern Europe continued at a steady pace, and the Soviets, concerned with "nonthermal" 45 as well as thermal bioeffects, developed a maximum safety standard of $10 \mu \mathrm{W} / \mathrm{cm}^{2}$ exposure, ${ }^{46}$ averaged over the working day. ${ }^{47}$ This Soviet standard is stricter than the only existimg American exposure standard by a factor of $1000 .^{48}$ This fact was one topic of consideration when, in the late 1960 s and the 1970 s, spurred by a strong national environmental movement and by the congressional hearings that resulted in the passage of the Radiation Control for Health and Safety Act of 1968,49 Umited States scientists increased their research into the question of the bioeffects of nonionizing radiation.

Over the years, there was some refinement in knowledge of thermal effects. For example, thermal effects were classified as either primary or secondary. Primary effects are caused by the heating of the irradiated body itself, in either a generalized or localized fashion, or by the "activation of thermoregulatory compensatory mechamsms." Secondary effects are those that may result from the heating of organs that control body processes, such as the glands, the liver, the kidneys and the nervous systein. ${ }^{51}$

Experiments on mice, rats, rabbits and dogs proved that exposure to very high-power densities leads to death of the irradiated animals,

44. Tyler 7.

45. See text accompanying notes $69-92$ infra.

46. A inicrowatt ( $\mu \mathrm{W})$ is $1 / 1000$ of a milliwatt ( $\mathrm{mW}$ ).

47. This standard was adopted in the Soviet Union in 1958, accoinpanied by higher maximums for lesser exposure times: $100 \mu \mathrm{W} / \mathrm{cm}^{2}-2 \mathrm{hrs}$./day; $1 \mathrm{~mW} / \mathrm{cm}^{2}-15-20 \mathrm{~min} . /$ day. An additional safety factor of ten was introduced for a general population exposure standard of 1 $\mu \mathrm{W} / \mathrm{cm}^{2}\left(.001 \mathrm{~mW} / \mathrm{cm}^{2}\right)$.

48. In 1966 the United States of America Standards Institute (USASI), now the American National Standards Institute (ANSI), a private organization, adopted the $10 \mathrm{~mW} / \mathrm{cm}^{2}$ standard, the recommended exposure level used by the military since 1953. ANSI C95.1 (1966), (reaffirmed and modified slightly in 1974). In 1971 this standard becaine the Occupational Safety and Health Administration (OSHA) Standard, 29 C.F.R. $\$ 1910.97$ (1976). See RAdiarion PRotection ACTIVITIES 1976 at 92 . OSHA's "standard" has since been declared unenforceable; it is therefore only a guideline. See text accompanying note 202 infra.

49. 42 U.S.C. $\S \S 263 b-263 n$ (1976).

50. BARANSKI 73. An example of an "activation of thermoregulatory coinpensatory mechanisms" is an increase in blood flow as the heat is dissipated without a rise in temperature. Id.

51. Id. $73-74$. 
and that the lethal power density varies with respect to the species and the radiation frequency. At lower, but still lethal power densities, the survival time before death lengthens. ${ }^{52}$ Of course, man is not immune to this lethal phenomenon, but it should be noted that "[m]an is characterized by the high efficiency of his thermoregulatory mechamsms." 53 One author's extensive literature search of publications from all nations in the years 1938 to 1972 uncovered only one report attributing a human death to microwave overexposure (from a high-power radar source), and that attribution was later denied. ${ }^{54}$ The only recorded injuries from acute exposure found in the same survey were microwave cataracts. $^{55}$

This points to one of the many problems that have plagued nonionizing radiation research-the problem of extrapolation or "scaling" from animal experiments to allow predictions about bioeffects on man. Because it is ethically impossible to experiment on humans with power densities known to be potentially dangerous, it is important that scientists develop methods of "scaling," that is, of predicting levels of radiation hazardous to human health from results obtamed at various frequencies and power densities in animal experiments. Such extrapolations are "particularly bothersome in the field of microwave radiation"56 because of the differences in heat regulation between man and furbearing animals, in response of animals of different sizes to different radiation frequencies, ${ }^{57}$ and in laboratory experimental conditions and average human exposure conditions. ${ }^{58}$

Despite these and other problems in nonionizing radiation research, ${ }^{59}$ considerable knowledge has been accumulated on thermal bioeffects since America's first exposure guideline was formulated on the basis of a crude theory concerning the thermal interaction of radiation with human tissue. This further research has shown that the threshold level for thermal bioeffects is lower than the $100 \mathrm{~mW} / \mathrm{cm}^{2}$ level of known adverse effects on which the American National Standards Institute (ANSI) based its occupational exposure standard-a standard subsequently adopted by the United States Air Force and the

52. Id. 78-79.

53. Id. 88 (footnotes omitted). See Weiss \& Mumford, Microwave Radiation Hazards, 5 Health Physics 160, 162-63 (1961).

54. BARANSKI 157 .

55. Id.

56. 1977 Hearings 83 (statement of Daniel Cahill).

57. Id. 200-01 (statement of Dr. John Osepchuk).

58. Id. 7-8 (statement of Dr. Stefen O. Schiff).

59. See discussion of other difficulties that attend all scientific research on nonionizing radiation at text accompanying notes 93-145 infra. 
Occupational Safety and Health Administration (OSHA)..$^{60}$ EPA has reported three ranges of microwave power densities: first, greater than $10 \mathrm{~mW} / \mathrm{cm}^{2}$ (high level), in which distinct thermal effects predominate; second, $1 \mathrm{nW} / \mathrm{cm}^{2}$ to $10 \mathrm{~mW} / \mathrm{cm}^{2}$ (intermediate range), $\mathrm{m}$ which there are weak but noticeable thermal effects as well as direct field effects and other effects of an uncertain nature; and third, less than $1 \mathrm{nW} / \mathrm{cm}^{2}$ (low level), in which thermal effects are improbable. ${ }^{61}$

Specific documented bioeffects associated with thermal reaction include cataract formation, heat stress, cardiovascular effects, testicular effects, brainwave pattern changes, ${ }^{62}$ burns and necrosis of the skin, lesions of the nervous system, ${ }^{63}$ subcutaneous burns, ${ }^{64}$ heinorrhaging of internal organs ${ }^{65}$ and birth defects. ${ }^{66}$ These radiation effects are increasingly probable as power densities rise above the "threshold" for thermal effects. The presence of inetal implants in the body (such as inetal pins in bones) may concentrate the absorption of radiation at the location of implantation, inducing thermal effects froin lower power densities than would ordinarily cause such harm. ${ }^{67}$ In addition, research imto the bioeffects of lasers and other hight-like radiation has docuinented the fact that cataracts and other serious eye dainage, ulceration or burning, and bhistermg and infection of the skin are associated thermal hazards. ${ }^{68}$

(b) Low-level ("nonthermal") effects. Currently the inost basic question is whether or not there are "nonthermal" or "athermal"

60. See note 48 supra.

61. Office of Radiation Programs, epa, Review of Radiation Protection activiTIES 1974 at 81 (1975). See also BARANSKI 83-84 (a similar division proposed).

62. Radiation Protection Activities 1976 at 90 (citing Cleary, Uncertainties in the Evaluation of the Biological Effects of Microwave and Radiofrequency Radiation, 25 HEALTH PHYSICS 387-404 (1973)).

63. Hearings on S. 2067 at 367 (report of Warren H. Donnelly).

64. BARANSK1 51.

65. MARHA 29.

66. Id. 35. See also Browne, supra note 40.

67. See Hearings on S. 2067 at 367 (report of Warren H. Donnelly); id. 714-15 (statement of Dr. Herbert P. Schwan); Baranski 107. See also Palm, Electronic Smog, New Haven Advocate, Jan. 25, 1978, at 10, col. 1. (reporting pain and severe traumatization of a woman's uterus from a "Copper T" IUD when she walked past a microwave oven; the article did not note whether or not the oven was functioning properly).

68. Hearings on S. 2067 at 364-66 (report of Warren H. Donnelly).

69. Although such terms as "nonthermal" and "athermal" are widely used, many scientists object to them because the terms are confusing (though they themselves employ the terms). E.g., Baranski 51; Review of Radiation Protection Activities 1974, supra note 61, at 82; Tyler 9. Marha offers the following criticism:

The majority of authors understand this concept to mean the effect of electromagnetic waves of a field intensity so low that they do not produce a significant increase in the 
mechanisins that produce adverse health effects in persons chronically exposed to NEMR of $10 \mathrm{~mW} / \mathrm{cm}^{2}$ or less. If such effects do exist, then it must be determined what they are and how they are produced. The first problem-identifymg health effects-is more important to the policymaker, but it is the second that caused American scientists to halt their own research on nonionizing radiation and that was partially responsible for their dismissal of Soviet and Eastern European research in the field. ${ }^{70}$ As one researcher and commentator described the situation, "It has been said that present physical laws do not account for any 'nonthermal' effects and unless new laws are discovered, there can be no possible effects of electrolnagnetic radiation on biologic systems. This statement is slightly contrary to good science."71 It may be more than "slightly" contrary to good science. Knowledge of mechanisins or pliysical laws explaining phenomena is obviously very important, particularly for its predictive value. But to say that there are no effects when effects are in fact observed, simply because the effects cannot be explamed, is like saying no apples fell until Newton discovered the law of gravity. For a long while American scientists could not have observed such effects because, believing only thermal inechanisms had biologic effect, they did not experiment at below-thermal levels. Their Soviet counterparts, believing they had discovered such effects, set their exposure standard accordingly. ${ }^{72}$

Recently, scientists have developed several theories of possible mechanisms for direct (nonthermal) interaction of microwaves with biosystems. ${ }^{73}$ In addition, the United States and the Soviet Union have concluded a research agreement, and the United States is trying to rep-

temperature of an irradiated object. This is of course a highly unobjective definition and does not provide any explanation of the basis of the phenomenon.

Marha 47. Some authors do use a more objective definition with the result that "nonthermal" effects have been noted at power densities above $10 \mathrm{~mW} / \mathrm{cm}^{2}$. See Hearings on $S .2067$ app., at 964. (report of experiment by R.L. Carpenter and C.A. Van Ummerson). Nevertheless, it can generally be said that at high power densities thermal effects predominate, while at low densities reactions are primarily nonthermal in nature. MARHA 41.

70. Other reasons for the rejection of this research include problems with dosimetry, 1977 Hearings 64 (statement of Sherwin Gardner), and with translations and reporting standards of the experiments, Tyler 7. Also, $m$ the important area of effects on the central nervous system induced by low-level radiation exposures, some Western scientists tended to distrust Soviet conclusions based on behavioral (Pavlovian) experiments, perhaps caused by a lack of familiarity with the methodology used in conditioned-reflex experiments. See BARANSKI 115.

71. Tyler 9 .

72. The Soviet safe exposure limit was based largely on "the results of evaluation of clinical syunptoms of microwave professional exposure, as compared to an analysis of working conditions." BaRANSKI 177 (relying on Z. GORDON, VOPROSY GIGIENY TRUDA I BIOLOGITCHESKOGO DIETJSTVUA ELECTROMAGNITNYCH POLEI SVERCHVYSOKICH TCHASTOT (1966)). These clinical symptoms are set forth in the text accompanying note 84 infra.

73. See, e.g., BARANSKI 66-72. 
licate and corroborate some of the Soviet experiments. ${ }^{74}$ So far these efforts have produced mixed results. ${ }^{75}$ In general, however, evidence is increasing that low-level bioeffects do exist. These effects mclude nervous system and behavioral effects, ${ }^{76}$ including a reduction in learning facility; ${ }^{77}$ desadaptive effects; ${ }^{78}$ damage to the chemical barrier that prevents blood toxins from entering the bram; ${ }^{79}$ inhibition of lymphocyte development (part of the immunological system $)^{80}$; and, possibly, genetic defects, birth defects ${ }^{81}$ and general effects on growth and aging processes. ${ }^{82}$

In addition, Soviet surveys of occupationally exposed persons have identified a chronic exposure syndrome based on subjective evidenceworkers' coniplaints. ${ }^{83}$ This syndrome includes headache, eyestrain and tearing, fatigue and weakness, vertigo, sleeplessness at night and drowsmess during the day, n1oodiness, irritability, hypochondria, paranoia, either nervous tension or mental depression and inemory impairment. After longer periods of exposure, additional coinplaints may include sluggishness, mability to make decisions, loss of hair, pain im muscles and in the heart region, breathlessness, sexual problems and even a decrease in lactation im nursing mothers. Clinically observed effects in persons voicing these complaimts include trembling of the eyelids, fingers and tongue, mcreased perspiration of the extremities, rash, ${ }^{84}$ and, at exposures im the 1 to $10 \mathrm{~mW} / \mathrm{cm}^{2}$ range, changes $\mathrm{m}$ electroencephalogram (EEG) patterns. ${ }^{85}$ Researchers also have noted a more specific response-preconvulsive discharges and convulsions or

74. 1977 Hearings 669 (statement of Donald I. McRee).

75. See id.; id. 85 (statement of Daniel Cahill).

76. See Rowe, National Environmental Radiation Strategy and Plan of EPA, in HEW, 5TH annual National Conference on Radiation Control, Planning for Protection 262 (1974). See generally BARANSKI 100-05.

77. BARANSKI 101.

78. Desadaptivity is found experimentally when animals that have ceased to respond to a particular environmental stress over a period of time by adapting to it again respond im characteristic fashion to this stress after being irradiated with microwaves at low-power densities. For example, rabbits exposed to imfrared radiations responded mitially with a rise in blood pressure. After sevcral sessions of exposure to the stimulus, they no longer exhibited this response. Yet after irradiation with $1 \mathrm{~mW} / \mathrm{cm}^{2}$ of microwave power (which does not by itself induce any change in blood pressure), the rabbits again responded to infrared exposure with a significant rise in blood pressure. This was true even on the third day after the microwave irradiation. BARANSKI 118.

79. 1977 Hearings 7 (statement of Dr. Stefen O. Schiff); Browne, supra note 40.

80. 1977 Hearings 7 (statement of Dr. Stefen O. Schiff). See also EPA, Radiation ProtecTION ACTIVITIES 1975 at 131 (1975).

81. Hearings on S. 2067 at 713-14 (statement of H.P. Schwan); BRODEUR 89-91.

82. See Tyler 12.

83. Marha 30 (levels of exposure not indicated).

84. Id.

85. BARANSKI 163. 
shock-upon intravenous administration of a drug ${ }^{86}$ that produces no effect in a normal adult male. ${ }^{87}$ Regenerative processes seem to cause most of these subjective and objective effects to disappear within several weeks after radiation exposure ends. ${ }^{88}$

Finally, after surveying the literature on eye pathology, one Eastern European expert concluded that microwaves cause eye defects (sucl as retinal lesions, lenticular opacities and lenticular defects) at sufficiently low levels to warrant the setting of exposure standards lower than $10 \mathrm{~mW} / \mathrm{cm}^{2}{ }^{89}$ Other extensive experiments suggest that "nonthermal" inechanisins may be involved in cataractogenesis ${ }^{90}$ and that effects are cumulative. ${ }^{91}$ These experiments indicate, however, that the threshold for this response may be well above $10 \mathrm{~mW} / \mathrm{cm}^{2}$ and, encouragingly, that these opacities may regress upon termination of microwave exposure regimes. ${ }^{92}$

(c) Uncertainties-parameters of nonionizing radiation. In this country, experimentation on chromic low-level effects is, in many areas, still in the preliminary stage. Because of the rapid expansion of knowledge about the properties of the electromagnetic waves themselves, earlier experiments must be reevaluated and often repeated in light of new knowledge, either controlling for certain newly identified variables and distortimg influences or usmg new, nore sensitive, measuring devices. Indeed, the great mcrease in experimentation in this field has raised many new questions but has answered few of the old ones.

Many of these questions concern exactly which parameters of this

86. $500 \mathrm{mg}$ of cardiazole (Metrazol) in $10 \mathrm{ml}$ saline ( 1 milliliter every 30 seconds).

87. BARANSKI $163-64$.

88. MARHA 30-31.

89. BARANSKI 167-68 ("for prolonged periods of occupational exposure a safe limit of 1 $\mathrm{mW} / \mathrm{cm}^{2}$ or less should be observed"). See id. 176 ("Ericson AB in Sweden reccntly lowered their safe exposure limit from 10 to $5 \mathrm{nW} / \mathrm{cm}^{2}$ in view of retmal lesions found in workers in one factory"). Sweden has since lowered its occupational standard again to $1 \mathrm{nW} / \mathrm{cm}^{2}$. See Dodge \& Glaser, Trends in Nonionizing Electromagnetic Radiation Bioeffects Research and Related Occupational Health Aspects, 12 J. Microwave Power 319, 322 Table 1 (1977).

90. Hearings on S. 2067 app., at 964 (report on experiment by R.L. Carpenter and C.A. Van Ummerson).

91. Id. app., at 1010-13, 1044 (report on experiment by R.L. Carpenter).

92. Id. app., 1013. But $f f$. Z. Glaser, P. Brown \& M. Brown, Bibllography of Reported Biological Phenomena ('EFfects') and Clinical Manifestations attributed to MiCROWAVE AND RADIOFREQUENCY RADIATION: COMPILATION AND INTEGRATION OF REPORT AND Seven Supplements, SePTEMBer 1976 app., at 174 (1976) (lists "cataractous lesions" as a nonreversible effect of heating of the lens of the eye by microwave/radio frequency radiation). This Appendix is reprinted from an earlier bibliography and lists all effects of microwave and radio frequency radiation reported in the world scientific literature in that comprehensive index through 1971. 
pollution agent influence its interactions with biosystems. The more parameters that are deemed to have a significant impact, the more diffcult it is to formulate proper safety standards for health protectionone of the goals of the current American research program. ${ }^{93}$ This program has identified nine variables whose impacts need to be determined: power density, imtensity and relative phase of all field components, specific frequency ranges, waveform characteristics, exposure regimes, specific occupations, level of control over exposed populations, individual differences (age, sex, health, specific predisposing factors) and presence of other environinental stressors. ${ }^{94}$

The present Umited States guideline- $10 \mathrm{~mW} / \mathrm{cm}^{2}-$ specifies only power density. Nomonizing radiation research to date suggests not only that this threshold may need to be changed because of the possibility of chronic low-level effects, but also that an accurate standard would need to be keyed to these eight other parameters as well. For a suminary understanding of the significance of these other variables, consider the discussions below, which deal with discoveries made in recent experiments concerning these variables.

(i) Power density. This parameter is the only one generally considered with respect to the health impact of nonionizing radiation. ${ }^{95}$

(ii) Intensity and relative phase of all field components. In the radio frequency band the two components of the electroinagnetic field, $\mathrm{E}$ (electric) and $\mathrm{H}$ (magnetic), may be differentially absorbed ${ }^{96}$ the magnetic component gaiming in influence as frequency decreases into the low megahertz and kilohertz range. ${ }^{97}$ Exposure standards for this range should perhaps be expressed as values for $E$ and $H$ rather than as a simple power density. This nay be particularly true for the "near-field zone" close to the antenna; ${ }^{98}$ although $\mathrm{E}$ and $\mathrm{H}$ have a defined relationship in the far field (radiation field), ${ }^{99}$ this relationship is

93. This is an interagency research program formerly coordinated by the Office of Telecoinmunications Policy (OTP) through the Electroinagnetic Radiation Management Advisory Council. See text accompanymg notes 146-55 infra. The other goal of OTP's prograin was to accomplish this first goal (health protection) while "assuring optimal use of radiatimg equipment and avoiding unnecessary limitation or withdrawal of equipment." OTP, FIRST ANNUAL REPORT 1.

94. Id. 29.

95. See notes $42-43$ supra and accompanying text.

96. MARHA 79.

97. Tyler 12.

98. BARANSKI 30.

99. "The electric and magnetic coinponents of a field are mutually perpendicular and both are also perpendicular to the direction of propagation." MARHA 5 . The magnitude of the compo- 
distorted in the near field. ${ }^{100}$

(iii) Specific frequency. Discovery that certain radiation-induced bioeffects appeared frequency-dependent led to the development of the theory of resonance. A resonant frequency or frequency range is the range in which there is maximun penetration and absorption of the radiated power by the irradiated body. Resonance depends on the size, shape and orientation of the irradiated body. Resonance is, generally speaking, species specific, ${ }^{101}$ and imdividual body organs have their own resonance ranges (dimensional resonance). ${ }^{102}$ It is postulated that the "whole body" resonant frequency range for man is in the VHF range at about $68 \mathrm{MHz}$ for a 1.75 ineter man. ${ }^{103}$ This closely corresponds to the frequencies used for FM and television broadcasting, ${ }^{104}$ for some common radar guidance systenn ${ }^{105}$ and for $\mathrm{CB}$ and mobile radio commumications. ${ }^{106}$ General thermal effects may also vary with frequency because of the different electrical properties of the tissues (for example, water content). ${ }^{107}$

(iv) Waveform characteristics. Research to date indi-

nents varies sinusoidally along the direction of propagation, and the sinusoidal parts repeat periodically. Id. The far field relationship then is one in which there is a polarization of the $\mathrm{E}$ and $\mathrm{H}$ vectors.

100. Id. 9. See also id. 14-15; BARANSKI 30. Even in the far field, and in the microwave as well as in the radio frequency range, simple power density ineasurements inay be distorted by reflection, dispersion and interference caused by the presence of other conducting objects in the vicinity of the source (such as telephone lines, metal fences and the like) that influence the configuration of electromagnetic fields. Indeed, the biological target or targets theinselves may cause such field distortions. BARANSKI 43.

101. 1977 Hearings 210 (stateinent of Dr. John M. Osepchuk).

102. This phenomenon occurs when the dimension of the irradiated body or organ is an integral inultiple of half of the wave length, causing "standing waves" in the irradiated body or organ. MARHA 30-31.

103. OTP, Fourth ANNUAL REPort 36.

104. 1977 Hearings 210 (statement of Dr. John M. Osepchuk). The FM Band is 88-108 MHz; VHF-TV-30-300 MHz.

105. Airport instrument landing radars operate at $110 \mathrm{MHz}$.

106. 1977 Hearings 234 (answers to prehearing questions by the Institute for Electrical and Electronics Engineers (IEEE)).

107. Several authors have noted that while there is nore general concern with the higher microwave frequencies, the lower frequency, longer waves may actually be inore dangerous. These waves penetrate more deeply into the body and, for this reason, there is no surface heating sensation to warn persons that they are being exposed to high levels of such radiation. See BARANSKI 115-16 (specifying frequencies of a few megahertz as perhaps the most dangerous and identifying industrial equipment, radio communication, radionavigation, and broadcasting (AM) as falling in this range). See also MARHA 29 ("But longer-wave irradiation . . . generates the highest temperature in deep-lying muscles"). But see id. 41 ("II]t nnay be said in general that tissue heating increases [on the surface?] with frequency. Many other effects are also more pronounced at the higher frequencies"). 
cates that, particularly at low radiation levels, pulsed waves (as in radars) may be significantly more effective in producing certain adverse reponses than contimuous wave radiation of the same average field intensity. ${ }^{108}$ This indicates that the current practice of averaging power densities of pulsed fields in relation to a power density safety standard may be insufficient for purposes of health protection. One commentator notes that "whether this enhanced effort is due to the pulsing, repetition rate or peak power is still unclear; certainly there is a need for additional information in this area." 109

(v) Exposure regimes. The exposure regime unay be determined by the character of the radiation as indicated above; thus exposure is continuous with fixed contimuous wave radiation, such as that from a twenty-four hour radio broadcast tower, while it is intermittent from a scannimg radar (pulsed). It has been postulated that the irradiation cycle rate, that is the time interval or rhythm of repetitious intermittent exposure from, for exaunple, a scanning radar, inay be an important factor. ${ }^{110}$

If further experimentation should indicate that all of these factors are inportant, then the question of exposure standards could becoine coinplicated imdeed. It inight be desirable to develop a table of coinbinations of repetition rates correlated to peak powers and wave amplitudes of various average power densities, $\mathrm{E}$ and $\mathrm{H}$ phases, and frequencies relative to their differential effectiveness in producing biological changes. Such a formidable undertaking could be accoinphished only after years of experimenttion.

(vi) Specific occupations.

(vii) Level of control over exposed populations.

(viii) Individual differences. These areas of investigation all represent an attempt to link the adverse effects that result from radiation of defined paraineters to the persons who are potentially subject to such radiation. Identification of occupationally exposed groups and the conditions of exposure involves surveying persoimel, observimg their physical environments and nneasuring radiation levels therein. ${ }^{111}$ The determination of individual differences, however, requires a com-

108. This phenomenon is fairly well documented and is difficult to explam solely on the basis of "thermal" mechanisms. MARHA 42. See Hearings on S. 2067 app., at 969 (report of experiments of Russell L. Carpenter).

109. Tyler 12.

110. BARANSK1 43.

111. EPA is presently performing environmental measurements to determine conditions of exposure of the general population (as opposed to specific occupatioual groups). In this case the 
bination of many research techniques, including retrospective epidemiology, which is very difficult because "the methods of measuring exposure are faulty and the scientific basis of the specific medical consequences of exposure is in its infancy."112 Researchers must also confront the basic problems that attend any study of low-level effects, such as the problem of locating an exposed population of a size sufficient for statistical significance and the problem of naking causal connections between radiation and health effects that may have resulted from some other pollutant, drug or event. ${ }^{113}$ The literature includes only a few experiments directed at or useful in identifying the most sensitive populations.

(ix) Presence of other environmental stressors. It is generally accepted that the biological impact of a given power density of NEMR increases when temperature and humidity are high; thus ANSI recommends appropriate adjustinent of their safety standard under these adverse environmental conditions to avoid possible heat stress of einployees. ${ }^{114}$ There is also evidence indicating that radio frequency and X-radiations act synergistically on a biological object, producing more severe adverse reactions than would be expected from independent actions of the two stresses. ${ }^{115}$ Similarly, experiments combining exposure to electromagnetic radiation with diverse chenrical substances such as caffein, ${ }^{116}$ adrenaline ${ }^{117}$ and soine medicines ${ }^{118}$ produced biological responses indicating synergistic interactions. Finally, a question has arisen concerning the bioeffects of multiple frequency nonionizing radiation fields. ${ }^{119}$ Solne researchers have suggested that the coinbimed action of inultifrequency fields is more dangerous than the mere addition of their power densities would imply. ${ }^{120}$ The question is very complex because of the possible frequency dependence of some effects. ${ }^{121}$ It is also important because, as the number of radiation sources increases, complex fields inay become the norn of general population

level of control over the exposed population is obviously nil. See text accompanying notes 127-45 infra.

112. 1977 Hearings 342 (statement of Maj. Lawrence Larsen, M.D.).

113. See id. 5 (statement of Dr. Stefen O. Schiff) (referring to ionizing radiation, but applicable to nonionizing radiation or chemical pollutants as well).

114. ANSI C95.1 (1974).

115. MARHA 43-44.

116. BARANSKI 93.

117. Id. 94.

118. Marha 44.

119. Tyler 12.

120. Marha 44.

121. BARANSKI 152. 
exposure conditions.

2. Interference Effects. The second sort of hazard posed by the presence of nonionizing radiation nit the atinosphere and by spectruin crowding is inutual interference between systems. Such intereference ranges froin the merely annoying, such as interference with television or radio reception from nearby radar installations, ${ }^{122}$ to the potentially fatal, such as interference with electronic cardiac pacemakers, sensitive life support systems in hospitals or critical communications systems such as aircraft guidance systems. ${ }^{123}$ Another possibility is that stray signals could trigger certaim systems-for example, radio-detonated explosives. ${ }^{124}$ Interference may occur at levels inuch lower than those accepted as necessary to produce bioeffects. ${ }^{125}$ Given these facts, some government staff nienibers at the Bureau of Radiological Health have suggested that "the interaction of electromagnetic radiation with sensitive electronic instrumentation, rather than directly with biosystems may be the primary factor in deciding if a specific level of radiation is hazardous."126

3. Environmental Measurements. In order to evaluate the extent of the health threat posed by a particular environmental pollutant and to determine the type of regulation, if any, that is needed, it is necessary to inonitor ambient levels and to define exposure patterns. Several agencies have small-scale projects inomitorimg the "environments" under their respective jurisdictions. These include the Federal Communications Commission (FCC), ${ }^{127}$ the Federal Highway Safety Com-

122. See BRODEUR 224.

123. Review of Radiation Protection Activities 1974, supra note 61, at 90.

124. Rowe, supra note 76, at 262. See Wilford, Stray Radio Signals Postpone Launching, N.Y. Times, Nov. 22, 1977, at 23, col. 1 (describing how stray radio signals from an unidentified source were received, prior to takeoff, on the command-destruct systein of a rocket at Cape Canaveral).

125. This may be true in the case of interference with pacemakers. A study conducted by the Food and Drug Admmistration's Bureau of Radiological Health (BRH) found that the inost sensitive pacemaker tested registered no output signal upon exposure to nonionizing radiation as low as $.015 \mathrm{~mW} / \mathrm{cm}^{2}$, which corresponds to the exposure level three feet from a microwave oven leaking at five $\mathrm{mW} / \mathrm{cm}^{2}$. A pulsed wave stopped the paceinaker as low as $.3 \mu \mathrm{W} / \mathrm{cin}^{2}$. Ruggera \& Swicord, Electromagnetic Compatibility, Electromagnetic Interference and Susceptibility as Related to Medical Devices, in ENvironmental ExPosure 74-75. Five $\mathrm{nW} / \mathrm{cn}^{2}$ at any point five $\mathrm{cm}$ or more from the oven is the maximum allowable post-purchase leakage for microwave ovens under the BRH standard. 21 C.F.R. $\$ 1030.10$ (c)(1) (1977). But see 1977 Hearings 213 (statenent of Dr. John M. Osepchuk) ("The potential for interference is a pacenaker susceptibility problem rather than a radiation lazard, is essentially nil for modern microwave ovens, is less for microwave ovens than many other legitimate radiation sources, is considered an insignificant problem by the medical profession, and is to be under effective control by FDA").

126. Ruggera \& Swicord, supra note 125, at 71-72.

127. 1977 Hearings 1153-54. 
mission ${ }^{128}$ (m the Department of Transportation), the Federal Aviation Administration (FAA), which is conductimg a joint project with the $\mathrm{Na}$ tional Bureau of Standards, ${ }^{129}$ and the National Institute for Occupational Safety and Health (NIOSH) in the Department of Health, Education and Welfare. It is EPA's Office of Radiation Programs (ORP) that is currently conducting the major environmental ineasurements work.

ORP's measurements are conducted froin a mobile van equipped with a coinputer controlled instrumentation system. The van has been travelling around the country simce 1975 measuring power densities im the broadcast frequency bands. These frequencies were chosen because radio and television broadcast antennas are considered to be the unajor source of ainbient levels of radiation in urban areas. By the end of 1976, EPA had completed measurements im more than two hundred locations in Boston, Atlanta, Miami, Philadelphia, New York, Chicago and Washington, D.C. ${ }^{130}$ The results of the preliminary analysis of data collected from seventy-two sites im Atlanta, Boston, Miami and Philadelphia indicated that the maximum power density at any site summed over all seven broadcast bands was $2.5 \mu \mathrm{W} / \mathrm{cm}^{2}$. Four sites (about six percent) fell within the range $1-2.5 \mu \mathrm{W} / \mathrm{cm}^{2}$. The inaximum value ineasured at any of the 200 sites was approximately $10 \mu \mathrm{W} / \mathrm{cm}^{2}$. Extrapolations from measurements unade im these four cities suggest that less than one percent of the population is exposed to ambient values greater than $1 \mu \mathrm{W} / \mathrm{cm}^{2131}$-well below the ANSI and OSHA advisory standards of $10 \mathrm{~mW} / \mathrm{cm}^{2}$ for occupational exposure.

128. The Regulations and Standards Branch of the Highway Safety Commission is measuring electromagnetic (EM) fields to evaluate the possibility of imterference with automobile safety devices, e.g., accidental triggering of a microwave operated air-bag mechanism. Personal communication with Janet Healer, OTP (Dec. 6, 1977).

129. The FAA project has two goals: first, to check measuring techniques and instrument calibrations; and second, to measure the levels of NEMR produced by air traffic control radars and present in airport environments and aircraft interiors. OTP, FOURTH ANNUAL REPORT 48-49. The project staff found severe limitations in some of the commercially marketed momitoring devices. Id. app., at $\mathrm{C}-16$.

130. Radiation Protection Activities 1976 at 95 . The project surveyed 15 to 30 sample sites per metropolitan area. Janes, Tell, Athey \& Hankin, Radiofrequency Radiation Levels in Urban Areas, 12 Radio Scl. 49-50 (Supp. 1977).

Since the completion of that portion of the study, EPA has conducted similar measurement surveys in Houston, Denver, Las Vegas, San Diego, Los Angeles, Seattle and Portland, Oregon. Measurements in San Francisco are scheduled to be completed soon. These measurements will complete Phase I of EPA's monitoring program, and the agency will then direct its attention to the areas with higher than average exposure levels. Personal communication with David Janes, Office of Radiation Programs, EPA (Oct. 2, 1978).

131. Radiation Protection Activities 1976 at 95 . The $1 \mu \mathrm{W} / \mathrm{cm}^{2}$ standard lias been recommended as a general population exposure standard for the U.S.S.R. Janes, Tell, Athey \& Hankin, supra note 130, at 50 . 
Various cautions are in order, however, with respect to these measurements and any conclusions drawn from them. First, the authors of the EPA analysis warn that there may be some bias in the data because the criteria for site selection were "qualitative and evolutionary," with selection based on such factors as "population and source density, site accessibility, and the time available for field studies." 132 The latter two criteria lack scientific merit, but it would be necessary to examine the site data itself to reach any conclusions regarding the nature and extent of the bias thus introduced. Second, power density values for the AM broadcast band ( 0.5 to $1.6 \mathrm{MHz}$ ), although collected, ${ }^{133}$ were not included in the analysis "simce current U.S. exposure standards do not apply to frequencies below $10 \mathrm{MHz}$."134 This seems a curious reason for excluding these results in view of the fact that the purpose of the measurement program is to determine the need for standards to control exposure. ${ }^{135}$ One possible explanation might be that these frequencies are thought harmless. ${ }^{136}$ Simce the data were collected, however, perhaps they will be included in future analyses. Third, the field measurements were conducted at a height of 6.4 meters above the ground. Knowledge concerning exposure levels at 6.4 meters may be of value since many people work on the second and third floors of buildings and consequently are subject to levels of exposure found at this height. ${ }^{137}$ The EPA authors also suggest that "barring constructive interference of reflected waves, one would expect ground level field intensities on the average to be somewhat less than those measured at 6.4 meters." 138 of course, there may well be constructive interference, and some potentially sigmificant sources of microwave and radio frequency radiation exposure operate closer to ground level. For example, power density equivalents very close to walkie-talkie and $\mathrm{CB}$ antennas can exceed 10 $\mathrm{mW} / \mathrm{cin}^{2} .^{139}$ Thus, in some places power densities may actually be higher at ground level. It would make more sense to make at least some of the measurements at five to six feet above ground level-the

132. Janes, Tell, Athey \& Hankin, supra note 130 , at 54.

133. Id. 49 .

134. $I d .50$.

135. Id. 49.

136. If these frequencies are beheved to be harmless, there would appear to be no reason for measuring thein. See note 107 supra for the contention that low frequency radiation may be at least as harmful as higher frequency (radio and microwave frequency) radiation.

137. The authors add that "[v]alues on the lower floors inside buildings should be lower still due to building attenuation. However, one cannot generalize that values inside buildings will be lower than those reported here." Janes, Tell, Athey \& Hankin, supra note 130, at 55.

138. Id.

139. $I d$. 
level of adult human heads. ${ }^{140}$

In some cases, the experimental team also carries the equipment to the top stories of tall buildings and measures exposure values in these offices. The results, while predictable, have been somewhat disturbing. Maximum power densities in these locations are as high as $97 \mu \mathrm{W} / \mathrm{cin}^{2}$ in one Miami skyscraper, with other measured values ranging well above the Soviet occupational exposure standard of $10 \mu \mathrm{W} / \mathrm{cm}^{2}$. These high values result from the fact that many FM radio and UHFTV transmitters are mounted on the tops of buildings. Consequently, persons working and living in taller, neighboring buildings inay find themselves in the main beam of these antennas. ${ }^{141}$

In conjunction with this field work, EPA, with the assistance of the Navy's Electroinagnetic Compatibility Analysis Center (ECAC), ${ }^{142}$ is perforining a nationwide source and frequency distribution analysis. The study is designed to test the value of the existing data base for determining the mipact of federal guidelines or standards and to identify sources with potential for producing certain radiation levels at various distances from source antennas. ${ }^{143}$ EPA's mitial analysis of the inost powerful sources in the country indicates that, as of early 1976, there were eighty-six sites capable of producing power densities of 10 $\mathrm{inW} / \mathrm{cm}^{2}$ at a distance of approximately one mile from the source. When they lowered the key value to $10 \mu \mathrm{W} / \mathrm{cm}^{2}$ (the Soviet occupational exposure standard), investigators found 2,368 sources with radiation capabilities of one mile. EPA identifies $10 \mu \mathrm{W} / \mathrm{cm}^{2}$ as the probable lower extreme of the "range of acceptable power densities for environmental criteria." 144

The results of the ineasurements in tall buildings and the preliminary high-powered source analysis indicate that a decision to set a general environmental exposure standard at $10 \mu \mathrm{W} / \mathrm{cn}^{2}$ would be disruptive if not accoinpanied by a systein of exemptions for existing sources. One EPA staff inember inade the following projection with respect to UHF-TV antennas, frequently nounted on tall buildings in

140. Because clothing serves to soine extent as an insulator against NEMR by decreasing the amount of body absorption, the head is usually the part of the body most vulnerable to radio frequency and microwave radiation. MARHA 25-26.

141. Radiation Protection Activities 1976 at 95.

142. The ECAC in Annapolis, Maryland is the most comprehensive data systein in the Umited States on radio frequency and microwave radiation sources. However, it does not cover equipment operating in the amateur, citizens, landmobile, aircraft or commercial maritime frequency bands. Id. 100 .

143. This study covers SATCOMS, radars and all CW communications except broadcast transmitters covered by the other EPA mourtoring project described in text accompanymg notes 127-41 supra. Radiation Protection Activities 1976 at 95.

144. Radiation Program Statement, supra note 31, at 16. 
urban areas:

In the case of UHF TV allocations with maximum effective radiated powers of $5 \mathrm{MW}$ [megawatts], a distance of 212 feet corresponds to an exposure of $10 \mathrm{~mW} / \mathrm{cm}^{2} \mathrm{~m}$ the main beam while if we relax the exposure level to the Russian standard of $10 \mu \mathrm{W} / \mathrm{cm}^{2}$ we find that the distance has increased to 1.2 miles. In crowded metropolitan areas such an increase in effective exposure area from something less than a square city block to $4 \frac{1}{2}$ square miles could mdicate that in some cases certain portions of the general population are routinely exposed to levels exceeding the Russian exposure standards. ${ }^{145}$

This projection assumes a 360 degree radiation. Furthermore, it does not deal with attenuation or attempt to estimate the number of persons exposed to such situations. Despite these shortcomings, it does point out the need for actual ineasureinents more extensive than the present random samples of tall buildings if such projections are to be evaluated. Similarly, fuller analysis is needed to determine the extent of the disruption that would result from setting a standard for general population exposure lower than the present $10 \mathrm{~mW} / \mathrm{cm}^{2}$. It is certain, however, that even though a lower standard might cause some disruption at the present time, that disruption will only increase with delay.

\section{Present Governmental Activities in Nonionizing Radiation Protection.}

In order to analyze the need for changes in institutional structures or authority to deal with the nonionizing radiation problem, it is important to understand the existing governmental activity in the field. These activities are summarized in order to define the mitial context in which any new legislation would have to be impleinented.

1. Federal Agencies.

(a) Agencies with coordination and oversight functions.

(i) Department of Commerce-The National Telecommunications and Information Administration (NTIA). NTIA is a new agency within the Department of Commerce that has taken over most of the functions formerly exercised by the Office of Telecommunications Policy (OTP). OTP, formerly located in the Executive Office of the President, served as coordinator of the bioeffects research effort in the United States from 1972 to 1977. In 1972 it adopted the "five-year plan" submitted by one of its advisory committees, the Electromagnetic Radiation Management Advisory Council (ERMAC). While the undertaking of this prograin clearly lay within the purview of OTP's au-

145. Tell, supra note 15 , at 60 . 
thority, it was not a necessary part of its functions. Those functions included the review, management and assignment of radio frequencies (including microwave frequencies) for government use, and service as presidential adviser on telecommunications matters and as haison between the government (as spectrun1-user) and the FCC. ${ }^{146}$ Examples of the sort of policy issues with which OTP concerned itself mclude interoperability, privacy, security and emergency readimess of the various government communications systems. ${ }^{147}$ Thus, OTP's "Program for Control of Electromagnetic Pollution of the Environment: The Assessment of Biological Hazards of Nonionizing Electromagnetic Radiation" was largely an ad hoc undcrtaking. ${ }^{148}$ The importance of this undertaking is put into perspective by the following description of the program:

Unlike the major space effort, which was inanaged by a single dedicated agency, the National Aeronautics and Space Administration (NASA), or even the national effort in pursuing the biologic effects of ionizing radiation, which has been conducted by several agencies, but predominantly funded and controlled by the Atomic Energy Commission (AEC), there is no single agency whose major responsibility is the support of research in the nonionizing radiation area. Therefore, our present research efforts are supported by 13 different federal agencies. ...

To help coordinate this inultiagency effort, the OTP established a Side Effects Working Group with members from each of the concerned agencies. . . . Each agency in the Working Group provides the Group with a complete list of their research activities, so that an overall picture of the entire federal program is available. This is probably one of the first times in history that there has been such a clear picture of the activities of all the different federal agencies that are working in a single area. ${ }^{149}$

This high-level coordination of the nonionizing radiation research

146. Reorg. Plan No. 1 of 1970, 3 C.F.R. 195 (1970 Compilation), reprinted in 47 U.S.C. $\$ 305$ note (1976); Exec. Order No. 11,556, 3 C.F.R. 158 (1970 Compilation), reprinted in 47 U.S.C. $\S 305$ note (1976).

147. Reorg. Plan No. 1 of 1970, 3 C.F.R. 195 (1970 Compilation), reprinted in 47 U.S.C. $\$ 305$ note (1976); Exec. Order No. 11,556, § 2(e), 3 C.F.R. 158 (1970 Compilation), reprinted in 47 U.S.C. $\$ 305$ note (1976).

148. A spokesman for OTP at the Senate Committee hearings noted OTP's mission to promote the use of telecommunications in the public interest and added that "[i]nsuring that the use of nonionizing electronnagnetic (EMR) energy does not harn unan or his environment is an mtegral part of this responsibility." 1977 Hearings 693 (statennent of William S. Thaler). While this is the responsible and, this author believes, the correct role for OTP or its successor to assume, it is not specifically mandated. The FCC, which has a parallel role with respect to nongovernmental use of the spectrum, lias not imterpreted its public interest responsibilities in the same manner. See text accompanying notes 214-16 infra.

149. Tyler 9 (footnote omitted). 
program was lost when a 1977 presidential reorganization plan ${ }^{150}$ abolished OTP. Under the plan, certain functions reverted to the President for redelegation as the President dcemed desirable; these functions imcluded "the preparation of Presidential policy options including, but not limited to those related to the procurement and management of Federal telecommunications systems."151 While under one interpretation this language would cover the OTP bioeffects researcli project, ${ }^{152}$ in fact the program was included among the OTP functions transferred to the Secretary of Commerce and delegated to the new NTIA under the Assistant Secretary for Communications and Information. ${ }^{153} \mathrm{Be}-$ cause the bioeffects research program was developed as an adjunct to OTP's spectrum management duties, there was some logic in transferring the two in tandem-it is NTIA that now controls government frequency allocations. ${ }^{154}$

Altliough the five years covered by the origmal research plan were over (and ERMAC's job arguably conipleted), ERMAC also survived the transfer to beconie an advisory committee to the new NTIA. ${ }^{155}$ ERMAC has not yet developed a new "five-year plan" for NEMR research, but the agencies are proceeding with their individual activities as outlined below.

(ii) Environmental Protection Agency (EPA). The nonionizimg radiation activities of EPA are divided between the Office of Research and Development (ORD) and the Office of Radiation Programs (ORP). ${ }^{156}$ The former office conducts bioeffects research at the Health Effects Research Laboratory in Nortl Carolina. This research supports the activities of ORP, which include the environmental nieasurements program discussed above ${ }^{157}$ and the exercise of other radiation protection authorities transferred to EPA at its creation. ${ }^{158}$ In the nonionizing radiation area, EPA claims no regulatory or enforcement authority; it does claim authority to issue "guidance" aimed at control-

150. Reorg. Plan No. 1 of 1977,3 C.F.R. 197 (1978).

151. Id. \& 5(B)(1), 3 C.F.R. 198 (1978).

152. See note 148 supra.

153. See Reorg. Plan No. 1 of 1977, § 4, 3 C.F.R. 197, 198 (1978).

154. The Office of Management and Budget, however, received the authority to "arbitrat[e] ... interagency disputes about frequency allocation." Presidential Message to the Congress Transmitting Reorg. Plan No. I of 1977, 13 Weekly Comp. OF Pres. Doc. 1009, 1011 (July 15, 1977).

155. See 44 Fed. Reg. 1442 (1979).

156. 1977 Hearings 91 (statement of Dr. William Rowe).

157. See text accompanying notes $127-45$ supra.

158. See Reorg. Plan No. 3 of 1970, 3 C.F.R. 1072 (1966-1970 Compilation), reprinted in 42 U.S.C. § 4321 note (1976). 
ling ambient levels of radiation and exposures thereto of the general population. EPA spokespersons say that this authority is derived from the former Federal Radiation Council (FRC) whose functions were transferred to EPA in 1970. ${ }^{159}$ These functions are set forth in a simgle section of the Atomic Energy Act of $1954^{160}$ that provides, inter alia:

The Administrator [of EPA] shall advise the president with respect to radiation matters, directly or imdirectly affecting health, including guidance for all Federal agencies in the formulation of radiation standards and in the establishment and execution of prograins of cooperation with States. ${ }^{161}$

EPA cites this provision as authority to issue guidelines for nonionizing, as well as ionizing radiation. ORP is presently evaluatimg the need to issue such guidelines. First, they must determine whether there is a need to provide such guidance im the area of environmental nonionizing radiation. ORP intended to make this decision, probably in the affirmative, in March, $1978 .^{162}$ Second, if the decision is affirmative, they will try to develop a workable standard for general population exposure. ${ }^{163}$ Finally EPA , will promulgate guidelines. In promulgation, EPA will probably try to track procedures of the old FRC. Simce FRC was made up of representatives from several different agencies, EPA will circulate their draft guidelines to the affected agencies for comment. EPA will then make any appropriate modifica-

159. Id. Nonionizing radiation at least arguably falls under the broad definition of the term "air pollutant" in the Clean Air Act as amended. "The term 'air pollutant' means any air pollution agent or combination of such agents, including any physical, chemical, biological, radioactive . . substance or matter which is emitted into or otherwise enters the ambient air." Clean Air Amendments of 1977, Pub. L. No. 95-95, § 301(c), 91 Stat. 761, 769 (codified at 42 U.S.C.A. $\S 7602$ (g) (West Supp. 1978)). EPA either does not think that this definition imcludes nonionizing radiation, or prefers to utilize its FRC-derived authority to deal with this pollution agent, or else simply has not considered the possibility of regulating radio frequency and microwave radiation under the Clean Air Act. In fact, it is probably not a good idea, for many reasons, to use the Clean Air Act for regulation of this pollutant. NEMR has too low a priority in EPA to receive treatment under the Clean Air Act in the near future. EPA's ORP is not equipped to handle such an undertaking, and governmental control of half of the spectrum makes NEMR particularly poorly suited for regulation through the state implementation plan system. $C f$. Stewart, Pyramids of Sacrifice? Problems of Federalism in Mandating State Implementation of National Environmental Policy, 86 YALE L.J. 1196 (1977). This Article discnsses many problems caused by the federalstate division of authority in the achieveınent of national environmental goals. Because the spectrum is federally controlled, many of these problems can probably be avoided in NEMR regulation if special legislation is passed for this pollutant-legislation that does not rely on state implementation plans of the Clean Air Act type.

160. Pub. L. No. 703,68 Stat. 919.

161. 42 U.S.C. $\$ 2021(\mathrm{~h})(1976)$.

162. 1977 Hearings 74 (statement of Dr. William Rowe). As of October 2, 1978, although the ORP staff had recommended proceeding with promulgation of guidelines, a decision had not yet been made at the administrative level. Personal communication with David Janes, ORP, EPA (Oct. 2, 1978).

163. 1977 Hearings 96 (statement of Dr. William Rowe). 
tions, ${ }^{164}$ following which the administrator will submit the guidelines to the President for his approval, and the guidelines will be issued over the President's signature. Once the guidelines are issued, individual agencies must promulgate regulations to impleinent and enforce the guidelimes within their own spheres of action, with EPA assuming the role of overseer of these operations. ${ }^{165}$

EPA has not yet tested this FRC-derived authority in action and it seeins likely to encounter difficulties on at least two fronts if and when it attempts to proinulgate nomionizing radiation guidelines im this inanner. First, such EPA action will probably coine under jurisdictional attack from the Departinent of Health, Education and Welfare (HEW) and perhaps from the Departinent of Labor and other agencies as well. In the past, HEW has contended that EPA's radiation protection authority applies only to nuclear inaterials and that EPA has no legal authority to provide guidance or advice on inedical $\mathrm{x}$-rays or on nonionizing radiation. ${ }^{166}$ This position is supportable because FRC was created to serve as a watchdog for radioactive fallout ${ }^{167}$ and was never used by the FRC to issue guidelines for norionizing radiation. Secondly, the location of the FRC provision within the Atomic Energy Act suggests that "radiation" was ineant to refer to ionizing radiation. Until recently, this was its usage, especially when speaking of hazards, since at the time the FRC was established, nonionizing radiation hazards were not a matter of general national concern. In short, it is the classic confrontation between the arguinent based on historical usage (and the intent implied from that usage) and the ineaning of the language, in this case the word "radiation." Each agency has assumed a position that suggests a desire to defend its turf. In general, however, EPA's interpretation can be seen as closing a inajor gap in regulatory functions, in that no other body possesses general environinental authority over this type of radiation.

164. Personal communication with David Janes, ORP, EPA (Dec. 8, 1977).

165. 1977 Hearings 95 (statement of Dr. William Rowe).

166. Radiation Proliferation 19. The title of this report and the report itself concur to some degree in the thesis of this Article that congressional action is needed to deal with the uncertainties that presently surround the question of government control of radiation. With respect to EPA, it is interestimg to note that an early draft of this report was entitled "Failure to Adequately Protect the American People from the Hazards of Radiation. Environmental Protection Agency."

167. The original Protective Action Guides of FRC concerned such substances as iodime 131 and strontium 90 and the institution of emergency procedures, for example, the protection of national milk supplies following a "contaminating event." See Federal Radiation Council Protective Action Guides: Hearings Before the Subcomm. on Research, Development and Radiation of the Joint Comm. on Atomic Energy, 89th Cong., 1st Sess. 3-5 (1965) (statement of Dr. Paul C. Tompkins). 
(b) Agencies with regulatory authority. Agencies with major regulatory and enforcement authority within their general spheres of action include HEW's Food and Drug Administration (FDA), operating through its Bureau of Radiological Health, and the Department of Labor's OSHA. The Department of Defense, although not usually considered a regulatory agency, does have an occupational-type regulatory authority over its own personnel and imstallations. The FCC conducts a major national (nongovernmental) source licensing program with other agencies liaving lesser programs. Two of these agencies with regulatory authority, $\mathrm{HEW}$ and the Department of Defense, also have substantial research programs; along with EPA, they account for about ninety percent of the funds devoted to bioeffects research. ${ }^{168}$

(i) Department of Health, Education and Welfare $(H E W)$. Nonionizing radiation activities of $\mathrm{HEW}$ are divided among several subdivisions. The National Institute of Environmental Health Sciences (NIEHS) conducts research into both basic mechanisms and bioeffects of NEMR. ${ }^{169}$ In addition, they serve as the United States coordinator for collaborative research conducted under a 1975 agreement witl the Soviet Union. ${ }^{170}$

Another HEW subsidiary with an important role is The National Institute of Occupational Safety and Health (NIOSH), which serves as a research and advisory arm for the Department of Labor's OSHA. NIOSH is responsible for conducting research and investigations into various toxic substances and other pollutants, including pliysical agents such as electromagnetic radiation, which may pose a danger in the workplace. NIOSH prepares criteria docnments on these liazards and then recommends occupational exposure standards and work practices for adoption by OSHA. ${ }^{171}$ NIOSH personnel also respond to requests fronı workers or management for "Health Hazard Evaluations"-inspections of individual workplaces where hazardous occupational environinents are suspected. ${ }^{172}$

NIOSH is currently preparing a criteria document on radio frequency and microwave radiation for the purpose of proposing an occu-

168. 1977 Hearings 698 (statement of Dr. William Thaler).

169. Id. 668 (statement of Dr. David Rall). This accounts for all of the National Institutes of Health (NIH) research in nonionizing radiation except for a small program in the National Cancer Institute (NCI) concerning the uses of radio frequency (RF) or microwave radiation in cancer therapy.

170. OTP, FOURTH ANNUAL REPORT 56.

171. See 29 U.S.C. $\$ \$ 669-71$ (1976) (establishing NIOSH and outlining duties with respect to promulgation of health and safety standards by the Secretary of Labor under 29 U.S.C. $\$ 655$ (1976)).

172. See 29 U.S.C. $\$ 657(f)$, (g) (1976); 42 C.F.R. $\$ 85.1-.12$ (1978). 
pational exposure standard for OSHA adoption. Present in-house research concentrates on the 10 to $40 \mathrm{MHz}$ frequency range, which is associated with inany industrial radiation sources, and on the 10 to 300 $\mathrm{MHz}$ radio frequency (RF) range in general. ${ }^{173}$ This range is considered critical for several reasons. First, NIOSH field studies showed that many employers (and thus employees) are not even aware that they are using RF radiating equipment. ${ }^{174}$ Second, the studies showed that seventy-five percent of all workers using RF sealing and heating equipment are exposed to radiation levels exceeding the guidelines, and that the majority of these workers are females of child-bearing age, who, if actually pregnant, may be one of the population groups most sensitive to this environmental hazard. ${ }^{175}$ Third, although the OSHA guidelines purport to apply to radiation between $10 \mathrm{MHz}$ and 100 $\mathrm{GHz}$, in fact they are inapplicable to the $\mathrm{RF}$ (10 to $300 \mathrm{MHz}$ ) range because measurement in terins of power density $\left(\mathrm{mW} / \mathrm{cm}^{2}\right)$ is "meaningless" in this range 176 and "because exposure monitoring techniques are not specified and electric and magnetic field nomitoring instrumentation [ $\mathrm{E}$ and $\mathrm{H}$ ineasurements being necessary in this range] has not been commercially available." 177 Finally, experimenters have concentrated their effort in the higher, microwave frequency range; therefore, there is little bioeffects information specifically concerning the radio frequency region. ${ }^{178}$ The techniques for extrapolation froun one range to the other are uncertain. ${ }^{179}$ NIOSH plans to publish this criteria document treating some of these problems by the end of fiscal year 1979.180

The other component of HEW active in this area is the Bureau of Radiological Health (BRH), under FDA, which exercises the regulatory authority assigned to HEW under the Radiation Control for Health and Safety Act of 1968. ${ }^{181}$ That act calls for: "the establishment ... of an electronic product radiation control program which shall include the development and administration of performance standards to control the emission of electronic product radiation froun elec-

173. OTP, FOURTH ANNUAL REPORT 23.

174. 1977 Hearings 586 (statement of Dr. Elliott Harris). Thus it is not at all certain how many workers nationally are exposed to RF and microwave radiation. One NIOSH study projected as many as 21 million "potentially exposed." Id. 637 (NIOSH Attachment C).

175. Id. 587 (statement of Dr. Elliott Harris). The guideline used was ANSI C95.1 (1974), modified to take account of $E$ and $H$ field strengths. See note 48 supra.

176. 1977 Hearings 589.

177. OTP, FOURTH ANNUAL REPORT 23.

178. 1977 Hearings 589.

179. See text accompanying notes 56-58 supra.

180. 1977 Hearings 583,589 (statement of Dr. Elliott Harris).

181. 42 U.S.C. $\$ \S 263 b-263 \mathrm{~m}$ (1976). 
tronic products." 182 To date, BRH has set performance standards for only two nonionizing radiation products-lasers ${ }^{183}$ and microwave ovens. ${ }^{184}$ It has issued proposed standards for sunlamp products ${ }^{185}$ and inercury vapor lamps, ${ }^{186}$ and is developing a standard for microwave diathermy machines. ${ }^{187}$

The microwave oven standard has generated considerable controversy. Maximuin emission or leakage levels were ultimately set at 1 $\mathrm{mW} / \mathrm{cm}^{2}$ before purchase, $5 \mathrm{nW} / \mathrm{cm}^{2}$ in use, measured at a distance of five $\mathrm{cm}$ froin the surface of the oven at any point. ${ }^{188}$ Industry contends that this emissions standard provides sufficient control to limit actual exposures to levels within the conservative U.S.S.R. exposure standards. At least one prominent Eastern European scientist has endorsed this position, statimg:

Emission standards limiting nonintended radiation leakage should ideally tend to eliminate any such radiation. This may be, $[$ sic $] \mathrm{im}-$ practicable, however, from the technical or economic poimt at the present timie. The tendency to eliminate all nonintended radiation is reflected in the U.S. Department of Health, Education and Welfare standard concerning microwave ovens .... The data presented ... indicate that microwave ovens which conform to this standard

182. Id. $\S 263 \mathrm{~b}$. '[T] he term 'electronic product' means (A) any manufactured or assembled product which, when in operation, (i) contains or acts as part of an electronic circuit and (ii) emits (or in the absence of effective shielding or other controls would emit) electronic product radiation, ...." Id. \$263c. Subscction (B) of that section includes any "coniponent" of an electronic product that neets the above-quoted definition. FDA's regulation interpreting the extent of their jurisdiction under this broad definition includes such microwave products as "dryers, ovens, and heaters [and] [r]adar devices"; "signal generators" are histed in both the "microwave" and "radio and low frequency" categories. 21 C.F.R. $\S 1000.15$ (1978). Although FDA had conducted surveys on 17 kinds of microwave equipnent, other than ovens and diathermy equipment, General Accounting Office, More Protection from Microwave Radiation Hazards Needed app. II, at 48 (1978), it has not proposed or promulgated performance standards for any of these 17 products, nor has it proposed such standards for any RF equipment it may have investigated, e.g., $\mathrm{CB}$ radios or radio and TV broadcast "signal generators" which may be significant sources of general population exposures to NEMR. Most miportantly, it has set no performance standards for any of the numerous RF heaters and sealers used in various industrial processes. There is documentation indicating that thcse hcaters and sealers cause high occupational exposures. FDA also has the authority to set standards for electromic cardiac pacenuakers and other similar devices under the Medical Device Amendments of 1976. See 21 U.S.C. § 360(d) (1976).

183. 21 C.F.R. $\S 1040.10$ (1978). (Part 1040 is designated "Performance Standards for LightEmitting Products.")

184. 21 C.F.R. $\$ 1030.10$ (1978) (Part 1030 is designated "Performance Standards for Microwave and Radiofrequency-Emitting Products").

185. 42 Fed. Reg. 65,I89 (1977) (Proposed 21 C.F.R. $\$ 1040.20$ ).

186. 43 Fed. Reg. 16,997 (1978) (Proposed 21 C.F.R. $\$ 1040.30$ ).

187. See 1977 Hearings 19 (statenent of Sherwin Gardner); Advance Notice of Proposed Ruleınaking-Performance Standards for Microwave Diathermy Equipment, 40 Fcd. Reg. 23,877 (1975).

188. 1977 Hearings 235-37 (statement of Dr. John M. Osepchuk). 
are . . . within the USSR safe exposure limits. ${ }^{189}$

Despite such assurances, environmental and consumers' groups continue to raise questions about the safety of this product. ${ }^{190}$ Even if the physics data are correct, several factors suggest a need for conservatisin-froin the uncertainties surrounding the biological data, to questions concerning the assumptions made regarding the way such products may be used by the unwary. Importantly, BRH has little control over these ovens once they leave the manufacturer. There is an inspection program involving federal agencies and some states that accounts for about 4000 ovens per year ${ }^{191}$-less than one percent of the ovens. ${ }^{192}$ The FDA does have a plan to make this testing more effective, ${ }^{193}$ but still only a fraction of the ovens can be reached. In the event that a product line is defective and this defect is discovered by $\mathrm{BRH}$, it may result in a recall, as was the case with 36,845 GE ovens found to be leaking in excess of the standard. ${ }^{194}$ In general, however, the private individual must simply trust that the standard is being met by his oven and that that standard is safe for him, provided he abides by the warning label, regardless of high temperature or humidity, or simultaneous exposure to other sources of radiation.

(ii) Department of Labor (DOL)—Occupational Safety and Health Administration (OSHA). OSHA administers the Occupational Safety and Health Act of $1970 .{ }^{195}$ This act authorizes the establishment of "inandatory occupational safety and health standards applicable to businesses affecting interstate commerce," 196 and provides for inspections and proceedings to enforce these standards. ${ }^{197}$ In an effort to have the program in operation at the earliest possible date, the Act required the adoption as an OSHA standard of "any national consensus standard and any established federal standard, unless [the Secretary of Labor] determines that the promulgation of such a standard would not result in improved safety or health for specifically designated einployees." 198 Under this authority, OSHA promulgated the

189. BARANSKI 185.

190. See, e.g., Consumers Union of United States, Inc., Is Microwave Leakage Hazardous?, CONSUMER ReP., June 1976, at 319.

191. 1977 Hearings 65 (statement of FDA).

192. See Radiation Program Statement, supra note 31, at 17 Table 5 (estimating number of microwave ovens in use in 1974 at one million).

193. 1977 Hearings 65 (statement of FDA).

194. Id. 240.

195. 29 U.S.C. $\$ \S 651-678$ (1976).

196. Id. $\$ 651$.

197. Id. $\S \S 651-678$.

198. Id. \& 655(a). 
1966 ANSI standard as a "Radiation Protection Guide" for NEMR frequencies between $10 \mathrm{MHz}$ and $100 \mathrm{GHz}$. The standard is 10 $\mathrm{mW} / \mathrm{cm}^{2}$ for periods of six minutes or longer, averaged over the sixminute period, including continuous or intermittent radiation, and whole or partial body exposure. ${ }^{199}$

This standard has many drawbacks. As was noted above, a standard expressed in terms of $\mathrm{inW} / \mathrm{cm}^{2}$ is impracticable for the radio frequency range, ${ }^{200}$ and further frequency differentiation inay prove desirable as well. ${ }^{201}$ It does not apply to frequencies below $10 \mathrm{MHz}$ at all-which may mclude AM broadcasts and industrial heating equipinent. Finally, an administrative law judge for the Occupational Safety and Health Review Cominission pronounced the standard "advisory" only in the Swimline Corporation ${ }^{202}$ case. The DOL takes the position that the standard is mandatory in its terms-that deviation is allowed only as long as "careful consideration" is given to reasons for the deviation; otherwise comphance is required. DOL specifies no criteria for "careful consideration," but it follows froin Swimline that the standard as written is legally unenforceable.

The legal question may be inoot for two reasons. First, the standard is unenforceable not only legally, but also practically in many or most workplace situations since inost imdustrial RF equipment (except ovens) ${ }^{203}$ operates below $300 \mathrm{MHz}$, generally in the ISM frequency bands below $50 \mathrm{MHz}{ }^{204}$ Second, enforcement activities are practically nonexistent in the radiation field (ionizing or nonionizing). Inspections specifically to examine radiation hazards are extreinely rare because radiation hazards have a very low priority in OSHA. Such hazards will be investigated during the general inspection, but general inspections by OSHA or state compliance officers can cover only a tiny fraction of the nation's workplaces each year. ${ }^{205}$ Thus, an OSHA spokesperson

199. 29 C.F.R. $\$ 1910.97(a)(2)$ (1977).

200. See text accompanying notes 176-77 supra.

201. See text accompanying notes 101-07 supra.

202. EMPL. SAFETy AND Health Guide (CCH) \20,379 (Feb. 17, 1976), affd, Empl. SAFETY AND HEALTH Guide (CCH) ๆ 21,656 (Apr. 12, 1977).

203. See text accompanying notes $174-77$ supra.

204. ISM stands for "Industrial, Scientific, and Medical." These frequencies include 13.56, 27.12 and 40.68 MHz. OTP, FOURTh ANNUAL RePORT 23-24.

205. There are 1435 federal compliance officers who can cover about two percent of the nation's places of employment per year. 1977 Hearings 580. In addition, there are 998 state inspectors in the 25 states or jurisdictions that have assumed OSHA implementation under 29 U.S.C. $\S 667$ (1976). 1977 Hearings 572, 580. OSHA reports that during fiscal year 1976 radiation compliance activities included only 25 microwave and four laser inspections, nationwide. These figures do not distinguish between inspections conducted specifically for nomionizing radiation hazards and those made during general inspections. Id. 574. 
concludes: "[I]t is clear that OSHA must rely heavily on voluntary compliance of employers to assure safe and healthful workplaces."206 Such compliance is unlikely if, as NIOSH field studies indicate, employers and employees are not even aware of the radiation sources in the workplace, ${ }^{207}$ or of the potentially hazardous nature of the sources.

(iii) Department of Defense (DOD). DOD, a pioneer in thermal effects research, now has a new Tri-Services Program locatcd in the Office of the Director of Defense Research and Engineering (ODDR \& E) that coordimates the research activities of the three major branches of the Armed Forces. ${ }^{208}$ Because of the proliferation of NEMR sources in the miliary environment, nomionizing radiation research lias a higher priority in DOD than im other agencies or departments and more funding is available. In fact, DOD consistently contributes between sixty and seventy percent of the total amount of federal funds spent on NEMR researcli each year. ${ }^{209}$ These funds go primarily for the study of the bioeffects of exposures to NEMR at those frequencies commonly encountered in the military environment. ${ }^{210}$

In addition to their research activities, the Arnned Services, like the states, have the authority to develop standards for their own use. These standards inust conform to OSHA criteria but may be stricter. The service standards generally conforn to the OSHA or ANSI standards. ${ }^{211}$ However, a recent Air Force standard, issued in November of 1975 , establishes exposure levels for lower frequencies- $1 \mathrm{kHz}$ to 10 $\mathrm{MHz}$ - than those covered by the OSHA guideline. The standard set for that range is $50 \mathrm{~mW} / \mathrm{cm}^{2}$ (average power density) for exposure periods longer than six mimutes and $3600 \mathrm{~mW}-\mathrm{sec} / \mathrm{cm}^{2}$ for exposures less than six minutes. ${ }^{212}$ Curiously, the standard is given im terins of power density ratlier than the $\mathrm{E}$ and $\mathrm{H}$ values, which, under current understanding, must be used for practicable standards at frequencies below $300 \mathrm{MHz}^{213}$

(iv) Federal Communications Commission (FCC). The FCC's responsibilities with respect to nongovernmental uses of the nonionizing spectrum are to some extent analogous to those of NTIA in

206. Id. 580 .

207. See text accompanying note 174 supra.

208. OTP, FOURTH ANNUAL REPORT 35.

209. 1977 Hearings 698 (statement of Dr. William Thaler).

210. Id. 310 (statement of Capt. Frank Austin).

211. See BARANSk1 171-73 for a more detailed discussion of the U.S. Army Standard.

212. AFM 161-42, cited in OTP, FourTh ANNUAL RePort 55.

213. See text accompanying notes $176-77$ supra. 
the governmental sphere. The FCC, too, must exercise its authority in the "public interest."214 This authority includes the right to determine the location of stations, to regulate the apparatus used, and to prescribe and enforce licensing standards. ${ }^{215}$ The FCC could conceivably require location, installation and operation of licensed equipment to conform to some standard for exposure levels beyond a posted and confined area to which the general public would not have access. Indeed, in 1968, the Commission acknowledged its authority to deal with radiation hazards and simultaneously repudiated a desire or imtent to do so:

The Commission has no primary responsibility in matters of health and safety. Our regulations with a few exceptions are directed toward ensuring an efficient, rehable and economic radio communications systen. . . . While I beheve we could concern ourselves with the question of radiation hazards, we have not found it to be a problem in the area of our responsibilities, and it is one which appears to be inore appropriately dealt with by the Department of Health, Education and Welfare both because the problem is one of health and because as the pending legislation [Radiation Control for Health and Safety Act of 1968] recognizes, it covers a broader field than that in which the Commission functions. ${ }^{216}$

Although health and safety matters still may not be its primary responsibility, the FCC, like other agencies, now has an additional duty to deal with environmental (imcludimg health) matters, delegated to it by the National Environmental Pohcy Act of 1969 (NEPA). ${ }^{217}$ Accordingly, the FCC has adopted NEPA regulations. ${ }^{218}$ However, despite the fact that EPA identifies broadcast transmitters as the most environmentally significant source of population exposure to nonionizing radiation, the FCC regulations do not even mention the nomionizing radiation liazard. An appendix to the extensive preamble that accompanied these regulations on promulgation does discuss the problem, but specifies nonionizing radiation for routime consideration im NEPA evaluations only im the case of satellite communications earth terminals (SATCOMS). ${ }^{219}$

Significantly, in defining major actions under NEPA, the FCC imcludes antennas and supporting structures of 300 feet or more, but exenipts from that category certain antennas mounted on existing buildings or antenna towers because "[t]he use of existing . . . build-

214. See, e.g., 47 U.S.C. $\$ 303(\mathrm{~g})(1976)$.

215. Id. \& 303 .

216. Hearings on S. 2067 at 942 (letter of R.E. Lee, FCC).

217. 42 U.S.C. $\$ \S 4331-4332$ (1976).

218. 47 C.F.R. $\S 1.1301, .1303, .1305, .1311, .1313, .1315, .1317$ (1977).

219. 39 Fed. Reg. $43,834,43,843$ (1974). 
ings and towers is an environmentally desirable alternative to the construction of new ... towers and is encouraged."220 While this statement inay be aesthetically correct, froin the health point of view the mounting of antennas on building roofs and the intensifying of radiation from the addition of antennas to existing towers may be the inost dangerous alternative if other tall buildings are located nearby. ${ }^{221}$ The FCC was aware of this fact at the tinne it passed its regulations, ${ }^{222}$ but evidently did not consider the problem serious in comparison with aesthetic values or migratory bird paths, values that it seeks to protect. ${ }^{223}$

In its Federal Register notice, the Commission did express the belief that it has a duty "to see that the OSHA standard and such other applicable official standards as may be established by the responsible Government agencies are inet by Commission licensees."224 The FCC recommends that licensecs review and correct their operations in compliance with the OSHA standard, but notes that it considers radiation levels under NEPA only where an applicant cannot practicably comply with "applicable official safety standards." 225

Commission positions and practices, however, make enforcement of even this limited policy difficult. First, the above-noted provisions do not appear in the official FCC regulations in the Code of Federal Regulations, and the FCC admittedly does not regularly review for OSHA compliance in NEPA or licensing proceedings, ${ }^{226}$ but will consider the question only if citizens enter such proceedings and object to soine project on grounds of radiation hazards. Such an eventuality depends, of course, on a citizenry informed of the impending project and of the radiation dangers. Second, the FCC has interpreted the Swimline Corporation decision differently from DOL, and does not consider the OSHA standard "applicable" for its own purposes, or enforceable by either the FCC or OSHA. Nor is the Commission willing to prescribe such a safety standard in NEPA proceedings on its own authority. ${ }^{27}$ The FCC position was well illustrated at a meeting among EPA, OSHA and FCC personnel that followed EPA's disclosure that it had ineasured field intensities on an FM tower at Mt. Wilson, Califorma at

220. 47 C.F.R. $\S 1.1305$ (1977).

221. See text accompanying note 141 supra.

222. 39 Fed. Reg. 43,843 (1974).

223. Id. $43,839-40$.

224. Id. 43,843 .

225. Id.

226. Id.

227. Personal communication with Mr. Will McGibbon, Acting Associate Chief Engineer, FCC (Aug. 17, 1978). 
greater than $180 \mathrm{~mW} / \mathrm{cm}^{2}$ :

EPA said that their concern was for the tower workers which would be controlled by OSHA. OSHA said they have no control over the source which is a [sic] FM broadcast station controlled by FCC. Our [FCC] position is that since OSHA does not have an enforceable standard . . . the inost FCC could do would be to advise the station owners of the condition that exists but here again, it is not the owner or general public who are $[s i c]$ in danger but the tower workers over whicl we have no control and very little contact. ${ }^{228}$

(v) Other agencies with regulatory power. Other federal agencies, though subject to FCC spectrum control, do have licensing or other regulatory authority over installations under their jurisdiction and could probably prescribe and enforce certam standards with respect to nonionizimg radiation hazards. These agencies include the Departnient of Transportation (DOT), through the Federal Aviation Administration (FAA); the Department of Energy ${ }^{229}$ (DOE); and the Nuclear Regulatory Commission (NRC). All three conduct small research projects as well.

FAA formally denies any regulatory power with respect to nonionizing radiation; ${ }^{230}$ however, FAA does have the power to set "minimum standards governing the design, . . . construction, and performance of aircraft" ${ }^{231}$ and to establish ininimum safety standards for the operation of the airports it certifies. ${ }^{232}$ These provisions arguably are broad enough to allow for radiation regulation, ${ }^{233}$ particularly im view of the fact that FAA apparently does take substantial safety precautions for the protection of the public and personnel within the airport environinent. $^{234}$

Both NRC ${ }^{235}$ and DOE have certam limited powers derived from the Federal Power Commission ${ }^{236}$ regarding the licensing of high volt-

228. FCC Internal Memorandum to the Chief Engineer from Mr. Will McGibbon, Acting Associate Chief Engineer 8 (Aug. 12, 1977). The author expressed his belief that the FCC must work closely with OSHA to resolve this situation. Id.

229. Department of Energy Organization Act, Pub. L. No. 95-91, 91 Stat. 565 (1977) (to be codified in 42 U.S.C. $\$ 7101)$.

230. 1977 Hearings 1102 (letter from Bruce Selfon, DOT, FAA).

231. 49 U.S.C. $\$ 1421$ (a)(1) (1976).

232. Id. $\$ 1432$.

233. See provisions for airport planning and developinent at 49 U.S.C. \& 1701-1742 (1976). NEPA should apply to the national airport system plan and revisions, im which case nonionizing radiation should certainly be treated therennder. See id. \$1712.

234. 1977 Hearings 1102-04 (letter from Bruce Selfon, DOT, FAA). See, e.g., DOT/FAA Advisory Circular No. 20-68A (Apr. 11, 1975) (an example of recommended safety precautionsconditions for ground operation of airborne weather radar).

235. 42 U.S.C. $\$ \$ 2131-2140$ (1976); 10 C.F.R. $\$ 50$ (1978).

236. 16 U.S.C. $\$ 797$ (1976); 18 C.F.R. $\$ 4$ (1977). 
age transmission lines from power plants within their respective jurisdictions. Those lines that are placed on nonfederal land, however, are subject to state regulation. ${ }^{237}$

(c) Other research-nonregulatory agencies and authorities. The ERMAC research program mvolves many other agencies whose efforts often provide important information and support for the activities of the regulatory agencies, as well as for their own activities. One of the most important of these agencies is the National Bureau of Standards (NBS) in the Department of Commerce. The National Academy of Sciences (NAS), though not an "agency," also cooperates in this research program.

NBS has a general responsibility to provide government agencies with advice on techirical and scientific matters and to develop imstrumentation to serve their particular needs. The Bureau also has specific authority to investigate radiation, which includes the means of transmission of radio waves, the uses of radiation and the means of protecting persons from its harmful effects. ${ }^{238}$ NBS has actively supported other federal agencies in their research on nomionizing radiation, developing important imstrumentation and sometimes performing the measurements and research. ${ }^{239}$

The National Research Council of NAS has performed some nonionizimg radiation research and review for the Navy. ${ }^{240}$ The Academy also plans to commence a two-year study that will involve a critical review of existing data on the bioeffects of nonionizing radiation, including recommendations for further research and for protection guides. This would be coupled with a three-year epidemiological study - an expansion and refinement of an ongoing study of Navy veterans exposed to radar during the Korean War. ${ }^{241}$ Additional proposals are also under consideration. One proposal is for a two-year study of the "impact on over-the-air communications systems and on other mierowave-utilizing systems that would result from taking regulatory action on nomionizing radiation." 242 Also under consideration is another two-year study, this one on energing teclinologies that produce nonionizing radiation and the potential health effects that may result from their contributions to ambient levels of EMR. ${ }^{243}$ Of course, the

237. See 1977 Hearings 94 (statement of Dr. William Rowe).

238. 15 U.S.C. \& 272(f)(9) (1976).

239. OTP, FOURTH ANNUAL REPORT 45-46.

240. 1977 Hearings 751 (statement of Dr. Richard Setlow).

241. Id. $762-63$.

242. Id. 752 .

243. $I d$. 
undertaking and completion of all of these studies is dependent on obtaining sufficient funding from agency budgets or through congressional appropriations. ${ }^{244}$

Other agencies with research projects include the following: National Aeronautics and Space Administration (NASA) - research on proposed solar power satellite; ${ }^{245}$ Central Intelligence Agency (CIA) international scientific literature review; 246 State Departınent-Project Pandora, monitoring of microwave levels, United States Embassy Moscow and follow-up inedical studies of embassy personnel; ${ }^{247}$ Veterans Administration (VA)-bioeffects research on behavioral and ocular effects of NEMR, ${ }^{248}$ as well as adjudications of claims for benefits for disabilities alleged to have been caused by military exposures to nonionizing radiation. ${ }^{249}$

2. State and Municipal Activities. In contrast to the control of ionizing radiation, for which many states have well-established programs, few states are active im the control of nonionizing radiation. Twenty-one states have specific statutes relating to the control of nonionizing sources. ${ }^{250}$ Some of these statutes are limited in terms of source or frequency range-for example, they may apply to lasers only. ${ }^{251}$ Other states may have broader health protection statutes, which could be used to regulate nonionizing radiation, but few of those states that have passed enabling legislation have adopted regulations. In many cases, the problem is one of limited resources which the states have felt would be better applied to ionizing radiation control. ${ }^{252}$ For example, New York (which may be typical of many states) has enabling legislation ${ }^{253}$ but has promulgated no regulations dealing with

244. Id. 756.

245. OTP, Fourth ANNUAL Report 35. See Glaser, supra note 36 (proponent's description of space solar power generation).

246. OTP, Fourth ANNUAL RePORT 35.

247. 1977 Hearings 268-278, 283-88 (statement of Dr. Herbert Pollack). The National Technical Information Service (Department of Commerce) has reproduced and released the recently completed report on the State Department sponsored epidemiological study of Moscow Embassy personnel. The report concludes that "persomel working at the American Embassy in Moscow from 1953 to 1976 suffered no ill effects from the microwaves beamed at the Chancery." The Johns Hopkins University, Foreign Service Health Status Study, Evaluation of Health Status of Foreign Service and Other Employees from Selected Eastern European Posts (July 31, 1978). See also BRODEUR 95-134 (a very different version of the story of the embassy irradiation).

248. OTP, FoURTH ANNUAL REPORT 50.

249. See generally 38 U.S.C. $\$ \S 301-362$ (1976); BRODEUR 65 n.17.

250. 1977 Hearings 703 (statement of Charles Hardim).

251. Id. 745 .

252. One significant exception exists; several states do have regulations establishing inspection programs for occupational exposure to nomionizing radiation. Id.

253. N.Y. Pub. Health Laws $\S \S 201(r), 225(4)(p)$ (McKinney Supp. 1977-1978). 
nonionizing radiation. The State does respond to requests froin individuals to monitor leakage from microwave ovens but does not generally survey such equipinent. 254

One of the inore advanced states in terms of nomionizing radiation control is Texas. In 1971 Texas annended the Texas Radiation Control Act to cover "electronic devices capable of stimulated emission of radiation to such energy density levels as to reasonably cause bodily harn." "255 Under the authority of this act, the Texas State Departinent of Health has proinulgated regulations controlling lasers ${ }^{256}$ and radio frequency (including microwave) radiation. ${ }^{257}$ The latter regulations are keyed to the 1974 ANSI standard and are for the protection of "inankind." They do not apply to the einployer-einployee relationship, but OSHA guidelines are applicable there; nor do the regulations apply to RF inedical treatinent. Otherwise, persons who possess RF products capable of einissions in excess of the ANSI standard are required to register those products and coinply with the applicable state regulations. There are special regulations for microwave ovens, which inust coinply with the BRH standard. Two miportant exemptions are of note. First, microwave ovens, except those used in commercial food vending service, are exeinpt froin registration. Second, and very m1portant, all telecommumications products or installations hicensed by the FCC are exeinpt from the regulations. ${ }^{258}$

The strictest and inost comprehensive regulatory proposal so far comes not from a state, but from the nation's largest city. New York City has recently proposed incorporation into the city Health Code of a general population exposure standard of $50 \mu \mathrm{W} / \mathrm{cm}^{2}$, a standard lower than the ANSI and OSHA guidelines by a factor of 200. If adopted in its present form, the New York City standard would apply to all sources operating from $10 \mathrm{MHz}$ to microwave frequencies "where such emissions may affect persons in uncontrolled or unregulated areas, including residential or recreational areas and areas open or accessible to the public," microwave ovens and mobile sources (including citizenband radios) excepted. ${ }^{259}$

254. Personal communication with George Kerr, Bureau of Radiological Health, N.Y. State Dep't of Health (Jan. 4, 1978).

255. Tex. Rev. Civ. Stat. ANN. art. 4590f, \& 3(b)(2) (Vernon 1971).

256. Texas Regulations for the Control of Laser Radiation Hazards. TRC Pts. 50, 66, 70 (Sept. 8, 1974).

257. Texas Regulations for the Control of Radio-Frequency Electromagnetic Radiation. TRC Pts. 80, 90, 100. 2 Tex. Reg. 3668-76 (Sept. 27, 1977).

258. Id.

259. Proposed amendment to the New York City Health Code, § 175.125, "Microwave and other radiofrequency power density standards" (June 22, 1978). ("Mobile units generatimg such radiation were exempted from the application of this section since their hazards to health are 
Another source of state and local guidance on radiation matters is the nine-year-old Conference of Radiation Control Program Directors, which meets annually and includes radiation control directors from all fifty states, certam territories and large municipahities. ${ }^{260}$ The Conference takes the position that the states have, and must mamtam, responsibility for the inspection of the use of radiation products and machines, the manufacture of which is subject to FDA control under the Radiation Control for Health and Safety Act. ${ }^{261}$ At the 1976 Conference, the members of one workshop supporting this position agreed that in the future states will have to become active in the nomionizing radiation area. Such activity would include Conference development of inodel state regulations in the nonionizing radiation area comparable to those already developed for ionizing radiation. ${ }^{262}$ The Conference already has developed such a draft regulation for lasers. ${ }^{263}$

In 1973 the Conference passed a resolution that was a topic of some discussion at the 1977 Senate Hearings on Radiation Health and Safety. ${ }^{264}$ The resolution, referring to radiation in general, both ionizing and nonionizing, read as follows:

Resolved that the Conference of Radiation Control Program Directors, urge the Congress of the United States to consider this serious problem of fragnentation and take the necessary legislative action to consolidate the various Federal responsibilities relating to radiation protection of the public and worker within one agency. ${ }^{265}$

Since the resolution was first adopted, the Conference has modified its position somewhat. It continues to support the general concept of consolidation but believes that perhaps a single agency would not be feasible. It now recommends "clear and concise 'memorandums of understanding' between the various agencies as to what their responsibilities are, and which is the 'lead agency' for a given area, when legislation requires more than one agency to be involved."266

incompletely evaluated at present.") Microwave ovens were also exempted presumably because, in contrast to all other sources, there is an applicable and enforcible federal (BRF) microwave oven standard. See 21 C.F.R. $\$ 1030.10$ (1978).

260. 1977 Hearings 702 (statement of Charles Hardin).

261. Id. 735.

262. State/Federal Relationship for Enforcement of P.L. 90-602, in HEW, 8TH ANNUAL NATIONAL CONFERENCE ON RADIATION CONTROL 417 (1977).

263. See Rogers, Report of the Task Force on Model Laser Regulations, in HEW, 6TH ANNUAL National Conference on Radiation Control 66 (1974).

264. 1977 Hearings 705 (statement of Charles Hardin).

265. Id. 742 (statement of Charles Hardin). See text accompanying notes 304-05 infra for further discussion of the regulatory confusion that prompted this resolution.

266. 1977 Hearings 705. 


\section{The NeED FOR Legislation}

After four days of Oversight Hearings on Radiation Health and Safety covering several hundred pages of testimony, Senator Adlai E. Stevenson, presiding over the Hearings of the Senate Committee on Commerce, Science and Transportation, reinarked:

I have never gotten into a subject on which there has been so much disagreeinent and so much confessed lack of knowledge. Everything is either being studied or hasn't even started to be studied or is just beginning to be identified as a possible problem.

If you could start froin scratch with a clean Federal slate, how would you organize the research and regulatory activities of the Federal Government with respect to radiation? ${ }^{267}$

These reinarks suggest that legislation may be needed in the field of radiation, specifically to sort out agency research and regulatory roles.

Before examining this stateinent further, one should note that the hearings, includimg Senator Stevenson's reinarks, concerned ionizing as well as nonionizing radiation. For policy purposes, however, the two types of radiation should be treated separately. The scientific and regulatory problems they pose are for the most part quite different. Furtherinore, when the two are tied together, nonionizing radiation tends to be subordmated to ionizing radiation. The liearings indicate that reforins are needed in radiation programs across the spectrum, but the nonionizing radiation problem is important and different enough that Congress slould accord it mdividual treatinent. ${ }^{268}$ There is an immediate and compelling need for comprehensive legislation concerning nonionizing radiation, not only to deal with agency conflicts, but also to provide much needed policy guidance. This section will docuinent the urgency of the need for this legislation and identify some of the deficiencies of the present program in the areas of poliey guidance, research and agency structure.

\section{A. Legislation for Prevention.}

The call for legislation for prevention in the area of NEMR incorporates botli a conclusion about timing-when to legislate-and a statement of policy. In both cases, the assertion that legislation is the best first step to solving the problem of prevention is grounded in an assessment of the present environmental and governinental reality and its implications for the future.

1. Timing. In 1971 ERMAC recommended an accelerated no-

267. Id. 671 (statement of Sen. Adlai E. Stevenson).

268. Id. 687 (statement of Dr. William Thaler). 
nionizing radiation research program and a resolution of agency responsibilities, based in part on the observation that

[t]his type of man-made radiation exposure has no counterpart in man's evolutionary background; it was relatively negligible prior to World War II.

Unless adequate momitoring programs and methods of control are instituted in the near future, man may soon enter an era of energy pollution of the environment comparable, in public health and ecologic implications, to the chemical pollution of today. ${ }^{269}$

ERMAC noted that decisions were already being made in the areas of diplomacy (compliance of American overseas radar and communications transmissions with the safety criteria of the host country ${ }^{270}$ ) and litigation (involving claims for radar or other microwave-related injuries and for property damages), even in the absence of agreed-upon safety standards or patterns of authority. ${ }^{271}$

Seven years later, the term "electromic smog" has been adopted by the mass media. ${ }^{272}$ In the past seven years, there has been a rapid proliferation of NEMR-emitting products. ERMAC's 1971 calculations, based on projected increases in output intensity froin existing VHF-TV transmitters, predicted that radiation levels might reach 2 $\mathrm{mW} / \mathrm{cm}^{2}$ or more in tall buildings adjacent to broadcast antennas. ${ }^{273}$ EPA has recently measured actual levels as high as $97 \mu \mathrm{W} / \mathrm{cm}^{2}$ in a small sample. ${ }^{274}$ The practical significance of this failure to develop the necessary monitoring and control programs becomes apparent when one compares these figures with the $1 \mathrm{~mW} / \mathrm{cm}^{2}$ figure, frequently suggested as a population exposure standard, and with New York City's proposed standard of $50 \mu \mathrm{W} / \mathrm{cm}^{2}{ }^{275}$ Legal and political actions in the area are also occurring more frequently, or at least the press is reporting thein inore often. ${ }^{276}$ These controversies are being resolved by

269. OTP, First ANNUAL Report app. A, at 1-2.

270. Id. app., at 5-6. This is the example of diplomatic problems given in the ERMAC report. It is possible, however, that some of the ERMAC members who drafted the report were also concerned with governmental actions and diplomatic problems involving the then-secret "Project PANDORA" investigation of the irradiation of the American Embassy in Moscow. At least one of the ERMAC ineinbers, Dr. Pollack, was aware of that problem at the time the report was prepared. 1977 Hearings 268-69 (statement of Dr. Herbert P. Pollack).

271. OTP, First ANNUAL RePORT app. A, at 5-6.

272. See, e.g., Browne, supra note 40; Palm, supra note 67.

273. OTP, FirSt ANNUAi REPORT app. A, at 2.

274. See text accompanying note 141 supra.

275. See note 259 supra and accompanying text.

276. See, e.g., BRODEUR 65 (successful suits for Veteran's benefits, microwave-related imjuries); Cape Cod Radar Base to Get Environmental Study, N.Y. Times, Apr. 13, 1978, at A18, col. 1; New York Disputes Coast Guard on Microwave Towers for Harbor, N.Y. Times, Mar. 27, 1978, at 
courts and agencies at both the state and federal levels without the benefit of legislative guidance.

The ineffectiveness of agency action in slowing or halting the process predicted by ERMAC suggests that the time has come for Congress to intervene. Seven years is a sufficient period of time to demonstrate that the current research and regulatory arrangements are inadequate to deal with the complex problems of NEMR. Admittedly, the implementation of new legislation will require a certain amount of "start-up time," particularly if it not only clarifies but also restructures agency roles. This makes legislation within the next year or so particularly desirable in order to prevent further loss of time and to provide guidance before NTIA and the agencies make their own nodifications in the research prograin. It would also be preferable to legislate before EPA promulgates its projected nonionizing radiation guidelines, ${ }^{277}$ in order to avoid or at least alleviate the problems such a situation could create. Prompt congressional action would ensure that any agency standards would be set in accordance with congressional policy.

2. The Logic of Prevention Policy. As the House Committee on Interstate and Foreign Commerce noted when it decided to legislate for nondeterioration in the 1977 Clean Air Act anendments: "[c]ommonsense dictates that it is substantially less expensive to prevent air pollution problems-and health problems-before they develop than it is to abate dangerous pollution levels."278 This conclusion regarding the necessity of prevention calls for legislation, botli to make the agencies act and to make then act in the most effective malmer.

In order to bring about agency action, nonionizing radiation must attain a higher position in the agencies' priority system. Agency priorities are generally determined by events. Because the health protection agencies, particularly EPA, generally have insufficient funds and manhours to deal with all problems, they can respond only to the inost urgent problems or crises. Such crises are either immediate and acute, like the kepone and vinyl chloride pollution imcidents, or recognized, that is, legislated, chronic problems like the "listed" chemical air pollutants such as particulates and photo-cheimical oxidants. ${ }^{279}$

Analysis of the priority problems suggests that inuch environmen-

B2, col. 1; Lawsuit Says Police Radar Poses a Health Hazard, N.Y. Times, Feb. 21, 1977, at 14, col. 6.

277. See note 162 supra and accompanying text.

278. H.R. REP. No. 294, 95th Cong., 1st Sess. 136, reprinted in [1977] U.S. CoDE CONG. \& AD. NEws 1077, 1215.

279. 40 C.F.R. $\S \S 50.7-8$ (1977). 
tal legislation to date has dealt primarily with problems of "clean-up" rather than prevention. Legislative action such as the Clean Air Act nondeterioration provisions indicates that Congress has learned the necessity of prevention, but the agencies still need prodding. A colloquy on nonionizing radiation control between Dr. Rowe of EPA and Senator Adlai Stevenson highlights the limited perspective of the agencies that inust implement this legislation:

Dr. Rowe: [W] have to bring two things together, the health effects levels and the ambient levels to get an idea of the scope of the problem.

Senator Stevenson: If I could interrupt right there. You are going to have to do more than that. You are going to have to project what the levels are going to be as a result of the decisions that are beimg made. It is not present levels I am concerned about as much as it is future levels.

Dr. Rowe: I think you are right, sir . . . If the problem is very large, there will be new requirements for institutional arrangements. If the problem is not too large then perhaps what we have now will be satisfactory with ouly minor changes. ${ }^{280}$

It is difficult to see how the problem could be other than very large, considering the unresolved controversy over low-level health effects, the increase in incidences of annoying and potentially dangerous NEMR interference, and the widespread and increasing dependence of American society on nonionizing radiation technology. Estimates made in 1976 placed the nation's depreciated capital investment in radio spectrum-dependent electronics equipment at over $\$ 100$ billion, divided roughly equally between public and private sectors. The 1977 estimate for the federal government sector alone was $\$ 55.2$ billion. ${ }^{281}$ This value mcludes the vast government communications systems and a huge array of electronics weaponry for national defense. One official aptly describes telecommunications systems as the "nervous system" of inodern society and concludes that the United States "has as much dependence on availability of radio frequencies as . . . [it has] on availability of energy resources." 282 The developing tension between the protection of health and the operation of these national electromics systems, be they government or private, presents a thorny problem. Spectrum crowding and imterference effects are another cause for concern. Congress must act, and act now, if it wishes to prevent these conflicts fron becoming crises.

Adoption of a principle of prevention demands that the legislative

280. 1977 Hearings 87.

281. Id. 699 (statement of Dr. William Thaler).

282. Jansky, The Management of the Radio Spectrum and Its Relationship to the Environmont, in ENVIRONMENTAL EXPOSURE 4. 
action be immediate. Immediate action would prevent the ERMAC predictions from coming to fruition, prevent the agencies from acting wrongly or inconsistently because they lack congressional guidance, and cause them to act preventively. The remamder of this Article will consider this policy problem and offer soine approaches to dealing with it through legislation.

\section{B. Legislation for National Policy Directives.}

When Congress passes comprehensive legislation on a subject, it usually begins by setting out its findings and purposes. It then formulates a strategy that it believes will achieve those purposes, imcorporating this strategy into legislative provisions for agency implementation. For example, im the 1970 Clean Air Act, Congress consciously chose protection of the public health as the guiding purpose of air pollution regulation. ${ }^{283}$ It chose ambient air standards, deadlines and "technology-forcing" as the strategy for achieving that goal, and determined that if industry did not meet the standards, the offending businesses would be closed. ${ }^{284}$ Then, im the 1977 amendments to the Clean Air Act, Congress, though it reaffirmed the health protection primciple, not only modified deadlines in the face of reality, but also bent the health protection principle to accommodate certaim other policies. For exainple, the amendments allow compliance extensions for stationary sources converting from natural gas or oil to domestic coal as a primary energy source. ${ }^{285}$

This description of Clean Air legislation illustrates two points: first, that we expect Congress to inake our inajor policy choices; second, that sometimes public health bows to other national objectives and preferences. As Congress has passed no comprehensive legislation aimed at the control of nomionizing radiation, it has not yet articulated national policy or chosen priorities in this area. The single brief provision allocating a very general radiation control function to $\mathrm{EPA}^{286}$ and even the Radiation Control for Health and Safety Act of $1968,{ }^{287}$ which has proven limited in relation to the nature and scope of the NEMR problem, contrast with the detailed provisions of the ainended Clean

283. See 42 U.S.C.A. \& 7401(b)(1) (West Supp. 1978).

284. S. Rep. No. 1196, 91st Cong., 2d Sess. 2-3 (1970).

285. 42 U.S.C.A. $\$ \S 7413$ (d), 7410(f) (West Supp. 1978). In another example, Congress bowed to the public opposition to parking surcharges and bridge tolls and legislated that states can neither be required to adopt such measures in order to gaim approval from EPA for their transportation control plans, nor can such provisions be included in an EPA-formulated state implementation plan under 42 U.S.C.A. $\$ 7410$ (c)(2)(B).

286. 42 U.S.C. $\$ 2021$ (h) (1976).

287. 42 U.S.C. $\S \S 263 b-263 n$ (1976). 
Air Act or of the Toxic Substances Control Act. ${ }^{288}$ Absent additional guidelines for implementation of their authority, EPA and the other agencies will be left to make policy choices that have the potential to affect American society significantly. This situation indicates a need for legislative clarification of policy. When the playing cards are public health, national communications and national defense, the legislature has a responsibility to the American public and to the principle of democratic accountability to define the rules of the game. Whatever policy goals are chosen will inform the legislative decisions on the proper institutional structure and implementation strategies needed to deal with the nonionizing radiation hazards.

\section{Legislation for Research.}

There are several reasons why legislation is needed to correct the deficiencies of the present governmental efforts in nonionizing radiation research. First, legislation is needed for its exhortatory value. That Congress is interested enough $\mathrm{m}$ an issue to pass legislation indicates that it is a matter of some priority with the majority of legislators. This symbolic value alone may be sufficient to prod the agencies into providing more funds and man-hours for NEMR research.

An important point about the present program is that, except for the drive to satisfy the curiosity of imdividual scientists or administrative personnel, there is no real imcentive for an agency to devote more funds to the problem of nonionizimg radiation research than its own prograins imght require. As one scientist poimted out:

It may be unfortunate that within the United States there is no single source of major funding for this research. While nany of us intiinately involved with electroniagnetic radiation research niay tend to look upon it as the alpha and oinega, each agency is faced with inany other research responsiblities of higher priority. ${ }^{289}$

Many problems - cancer, or toxic substances in our air, water and food, for example-may deserve preference from agencies concerned with these matters as well as with nonionizimg radiation. Nevertheless, many scientists, like the one quoted, conclude that NEMR warrants increasing national attention. ${ }^{290}$ The mere existence of legislation on nonionizing radiation, regardless of its content, should raise the visibility of the problem and serve as an incentive and a justification for devotimg more agency resources to NEMR research.

Second, legislation is needed to resolve questions concerning the

288. 15 U.S.C. $\$ 2601$ (1976).

289. Tyler 9 .

290. E.g., id,; 1977 Hearings 683 (statement of Dr. William Thaler). 
status and location of the research coordinating function. With its present ad hoc status, the program is subject to relocation as an adjunct to some other function, without consideration of the merits of that transfer for the research prograin itself-as in the recent transfer of research coordination froin OTP to NTIA. The prograin may lose stature and effectiveness by being operated from within a sister agency, rather than froin the Executive Office of the President (EOP). Furthermore, there is no guarantee that the Departinent of Commerce, in overseeing NTIA, will not atternpt to skew the program in line with its own agency purpose, ${ }^{291}$ which is primarily commercial development and not the protection of health. ${ }^{292}$ It is not clear that health research coordination and techirical spectruin inanagement should be controlled by the saine entity, regardless of whether that entity is an independent executive agency or a division of EOP. In any case, legislation should examine these questions.

Third, legislation could improve the research coordination role itself. The prograin as it now operates is not without its flaws. For example, the coordinator's authority over both the funding and the content of research projects is recommendatory only. The agencies accept or reject the advice of NTIA and ERMAC as interest and funds allow. As a result, significant gaps exist in some areas of research. ${ }^{293}$ Such a limitation of authority is probably desirable as long as the program is located in the Department of Commerce. However, should the research coordination role be relocated by legislation to a nore compatible environment, Congress could take steps to close research gaps and to create a new, more effective and more coherent research program.

Finally, any legislative mandate must be accompanied by appropriations of sufficient funds to conduct the necessary research. Without

291. OTP identified its program as having the dual goals of, first, insuring that man is not harmed by the use of energy froun nonionizing radiation; and second, avoiding unnecessary restrictions of spectruni use. Healer, Federal Bioeffects of EM Energy, in ENvIRONMENTAL ExPoSURE 123. If OTP has atteinpted to subordinate the first goal to the second, that is not apparent from program reports; the einphasis of the research seems to have been almost exclusively on bioeffects. The second goal, however, could probably await impleinentation in the treatment of the results of the bioeffects research, with respect to OTP's (now NTIA's) spectruln managenent policies. What action is taken by NTIA based on NEMR research (now that the "five year plan" is over and as more research results are reported) is as important as seeing that the research was done.

292. One way to limit the opportunities for such bias would be to contimue the practice of the present program-allowing research funding decisions to be nade by the individual agencies. See 1977 Hearings 688 (statement of Dr. William Thaler). This plan has drawbacks as well, however. The problem will be considered in more detail in text accompanying notes 387-427 infra.

293. 1977 Hearings 688. 
congressional mandates and imcreased budget authorizations, important research may not be performed. For example, the proposed NAS studies described above ${ }^{294}$ were the subject of the following colloquy between Senator Adlai Stevenson and Dr. Alvin G. Lazen (Associate Executive Director, Asseinbly of Life Sciences, National Academy of Sciences) at the recent Senate Hearings:

Senator Stevenson: How could we in the Congress move this process along? Is additional funding necessary? Is a congressional inandate necessary?

Dr. Lazen: We would hope that our process of touching bases with the various Federal agencies would elicit enougl interest from thein that they would be willing to support such a study. If, however, Congress mandates a study, it certainly facilitates matters.

Senator Stevenson: Should that mandate include additional funding or do you think the funds are already available?

Dr. Lazen: There are several new topics that have been introduced in the course of discussion. . . . It would require additional sums of inoney if that [einerging technologies and their potential health effects] were also to be studied. . . .

Senator Stevenson: In addition to those which might be available?

Dr. Lazen: That is correct. ${ }^{295}$

The fate of such important proposals cannot be left to the decisions of individual agencies in the context of their own agency needs and budgets. Even more important may be the need for more basic research in the field, ${ }^{296}$ particularly in order to set proper standards. Most researchers agree that nonionizing radiation is much more complex than ionizing radiation ${ }^{297}$ and that much less is known about it. ${ }^{298}$ Futherunore, this basic research (for example, into mechanisms of interaction) is not sufficiently funded because of the "mission orientation" of the agencies; nor do individual agencies currently have sufficient and stable funds to undertake inuch-needed long-term chronic exposure or epidemiological experiments. ${ }^{299}$

Perhaps the inost telling indication of the insufficiency of the pres-

294. See text accompanying notes $241-44$ supra.

295. 1977 Hearings 756.

296. One part of the proposed NAS studies would be a literature review accompanied by recommendations. As one expert testified:

When one reviews all of these various researcl recommendations, one is struck by their similarities. . . . This is not surprising, since it is obvious to anyone working in the field and familiar with the current literature, what is and is not known. There seem to be more people reviewing the problem and making recommendations than there are people doing the research.

Id. 368 (statement of Capt. Paul E. Tyler).

297. E.g., id. 358; Hearings on S. 2067 at 718 (statement of Dr. Susskind).

298. E.g., Hearings on S. 2067 (statement of Dr. Susskind); OTP, FIRst ANNuAL Report 3. See also 1977 Hearings 692 (statement of Dr. William Thaler).

299. 1977 Hearings 685 (statement of Dr. William Thaler). 
ent research is provided by a reexamination of the 1971 ERMAC report that became the basis for the OTP research program. That report recommended "[a]n immediate, integrated, and sustained research effort over a five-year period"300 and a "resolution of [agency] responsibilities"301 in order to meet a potentially serious pollution problem given the rapid and virtually uncontrolled proliferation of sources. Seven year later, the research effort that attempted to fulfill that recommendation has provided "more questions than answers."302 Nor has the second prerequisite, "resolution of agency responsibilities," 303 been met. This is another reason why legislation is needed.

\section{Legislation for Regulation.}

The previous description of agency regulatory roles identified some areas in which there are current conflicts as to the division of responsibility for nonionizing radiation control. Two of the most outspoken critics of the present regulatory system have been the states and NBS. The latter offers the following assessment of the situation:

There is some confusion about respective responsibilities of state and federal regulatory agencies. The variety of possible agreements, contracts and preemptions adds to this confusion. In addition, many regulations at the federal and state levels have boundaries or limitations which are not immediately obvious. . . . The confusion is confounded because of the several federal agencies involved and the sometimes apparent duphication of jurisdiction and imadequate coordination between federal agencies. ${ }^{304}$

This confusion suggests why the Conference of Radiation Control Program directors favor congressional consideration of some consolidation of federal agencies in the area of radiation protection or, at the very least, clarification of existing agency responsibilities. ${ }^{305}$ With respect to its own task of providing ineasurement support for the various regulatory programs, the NBS adds that "[a]t this time, appreciable effort is expended in coordination of activities with the various agencies, and serving as a comınunications link or referee among them." 306

\section{The Trouble with EPA. To the extent that there exists a single}

300. OTP, FIRST ANNUAL RePort app. A, at 6.

301. Id. app. A, at 5.

302. Tyler 11.

303. OTP, First AnNual Report App. A, at 6.

304. 1977 Hearings 1119 (letter from Ernest Ambler).

305. See text accompanying notes 265-66 supra.

306. 1977 Hearings 1119 (letter from Ernest Ambler). Reference is to radiation control programs in general, ionizing as well as nonionizing, but the discussion here will continue to deal only with the latter radiation problem. 
agency in the regulatory arena with a coordinating function, that agency is EPA, operating under authority derived from the old FRC. ${ }^{307}$ However, EPA has encountered considerable opposition, both from OSHA and HEW-FDA, to its assertions of authority to formulate and issue guidelines in the areas of occupational exposure and the healing arts. Both battles, which have recently come to tentative resolutions im interagency agreements, ${ }^{308}$ were fought $\mathrm{m}$ the context of ionizing radiation. The opposition promises to be even stiffer, at least from HEW, when EPA attempts to formulate general guidelines for nonionizing radiation. HEW has not yet conceded that EPA has any authority over this portion of the spectrum. ${ }^{309}$

Despite both the inefficiencies of the present system and the unresolved controversy surrounding its potential exercise of FRC authority (no guidelines have yet been submitted for presidential signature), EPA asserts that there is no need for legislative action with respect to federal agency coordination, its FRC authority being "adequate to assure coordination of radiation protection activities among Federal agencies." 310 Even assuming that EPA's own imterpretation of the scope of its authority is correct, and assuming that its position would be confirmed by presidential signature on the contemplated nonionizing radiation guidelines, it is questionable whether FRC authority alone is adequate to assure the level of imteragency cooperation needed.

First, legislative action may be necessary to assure that EPA's ORP will have the ability to exercise its authority, in the most basic sense of possessing adequate funding and inanpower for the task. ORP has suffered continual reductions in budget and personnel since its creation in $1971,{ }^{311}$ and, at the present time, "[r]adiation protection is the least funded of all EPA programs."312 In a recent study of EPA's radiation protection activities, the General Accounting Office noted that

[s] everal [EPA] officials said that further reductions of personnel will require that certain lower priority radiation control efforts be discontinued. The officials said that the program has been drastically reduced because the Office of Radiation Programs could not compete for EPA's limited resources with other major pollution control prograins. They explained that because the Congress has not specifically mandated that EPA provide radiation protection, radiation protec-

307. See note 159 supra and text accompanying notes 159-61 supra.

308. Radiation Protection in Healing Arts; Guidance to Federal Agencies-MOU: HEW, EPA, 42 Fed. Reg. 5123 (1977); Regulation of Toxic and Hazardous Substances, Interagency Agreement: OSHA, CPSC, HEW, EPA, 42 Fed. Reg. 54,856 (1977).

309. See note 166 supra and accompanying text.

310. 1977 Hearings 99 (statement of Dr. William Rowe).

311. Radiation Proliferation 21-22.

312. Id. 34. 
tion has not received the same priority in EPA as other congressionally authorized programs. ${ }^{313}$

Sorne agency officials also admitted that in the past radiation protection has been "crisis oriented," with shifts in resources to meet each publicly perceived crisis as it developed. ${ }^{314}$ To anyone familiar with other EPA programs, this admission is not surprising. The shifts occur at two levels. In response to legislation or national attention there may be resource reallocations at a departmental level (for example, from ORP to Toxic Substances) as well as within the department (for example, within ORP from nomionizing radiation to nuclear wastes). Because the health hazard posed by nonionizing radiation in terms of general population exposure levels appears to be primarily a potential problem, and, to the extent that it is a present hazard, cause-effect correlations are difficult to make, this particular pollution problem has not yet assumed the proportions of a "crisis." 315 When it does become a crisis and EPA allocates more resources of its own accord, the nation will have lost both the opportunity to undertake a program of prevention, rather than cure, and the time necessary to examine carefully the most cost-efficient and beneficial course for such a program. Thus, if EPA is to have an effective role in overseeing nonionizing radiation pollution in the environment, it will require a congressional mandate defining this role, accoinpanied by appropriate funding. ${ }^{316}$

2. Clarification of Agency Roles. Such a mandate addressed to EPA would necessarily resolve in its favor the question of EPA jurisdiction over nonionizing radiation. At a minimum, legislation could inerely affirm the application of FRC-derived authority to the nonionizing spectrun and leave to the agencies the questions of role clarification, such as how this broad authority meshes with responsibilities of BRH under the Radiation Control for Health and Safety Act of $1968^{317}$ or of OSHA under the Occupational Safety and Health Act of $1970 .^{318}$ This course of action is unsatisfactory for two major reasons.

The first reason is that the process of clarification at the agency

313. Id. 22

314. Id. 29.

315. See 1977 Hearings 683 (statement of Dr. William Thaler).

316. While the need for legislation may be greatest with respect to EPA because of its coordinating role, it is clear that the other regulatory agencies need a similar incentive im order to take action on NEMR-from OSHA, whose nonionizing radiation protection activities have been minimal, to the FCC, which has virtually ignored its potential to regulate the nonionizing radiation hazards created by its ticensees. See text accompanying notes 195-207 supra (OSHA); text accompanying notes 214-28 supra (FCC).

317. 42 U.S.C. $\$ \S 263 \mathrm{~b}-263 n$ (1976).

318. 29 U.S.C. $\$ 8651-678$ (1976). 
level is time-consuming and inefficient. Considerable agency time and inanpower have already been expended to resolve the jurisdictional dispute concerning federal guidelines on medical use of radiationspecifically x-rays-but the resulting Memorandum of Understanding (MOU) by no ineans solved the problem. ${ }^{319}$ During this process of resolution, agencies may continue to duphicate each other's regulatory efforts in some areas, each confident that it is fulfilling its delegated duties. The states and other agencies such as NBS inust face these inefficiencies on their own levels of operation in dealing with several different agencies regarding a single problem. Nor is the end result, a series of interagency agreements and MOUs dealing with various subject matters, the most desirable solution from the point of clarity.

The second reason that the clarification of roles should not be left to the agencies is that there are important policy questions that may be settled without adequate consideration. Once again, the EPA-HEW jurisdictional dispute over the healing arts serves as a paradigm for the problein of agency role clarification - particularly that of further definition of EPA's FRC authority.

At the 1977 Senate hearings on radiation control, both BRH and EPA deined the need for an act of Congress to settle this question. ${ }^{320}$ EPA's response was that the President would serve as referee in the dispute. ${ }^{321}$ The implication is that if he signs the EPA guidelines, this act constitutes recognition of EPA jurisdiction to formulate the guidelines. In one scenario, the President never considers the question of jurisdiction; his decision to sign or not to sign is based on his opinion regarding whether the guidelines are necessary and, if so, whether he approves the proposed guidelines. This scenario poses the question whether the jurisdictional issue should be decided in this manner, without independent consideration. A corollary question is, if a decision to sign the guidelines would signify acceptance of EPA's interpretation of the scope of its FRC jurisdiction, would the President's failure to sign nean that EPA lacks jurisdiction? Clearly this seems unreasonable if the President's decision not to sign is based on disapproval of certain provisions contained in the guidelines. In an alternative scenario, HEW and EPA argue the separate question of jurisdiction to the President, and he deals with the issue directly. This scenario focuses on the underlying question: Is the President the proper decisionmaker for this dispute? Should these jurisdictional issues be resolved piecenneal, in

319. See note 308 supra and accompanying text. See also 1977 Hearings 26, 68-69.

320. 1977 Hearings 27 (statement of Sherwin Gardner); id. 82 (statement of Dr. William Rowe).

321. Id. 82 (statement of Dr. William. Rowe). 
the context of EPA regulatory authority in the individual area of diagnostic x-rays, or should the whole question of the extent of EPA's FRC authority be confronted at once?

3. Reexamining the Federal Radiation Council Concept. The possibility that Congress would reexamine FRC authority in its entirety may lie behind EPA's insistence that no legislation is needed to facilitate agency coordination. Like all agencies, EPA is jealous of its allocations of responsibility, even when it lacks sufficient resources to implement thein. ${ }^{322}$ If, after due consideration of the problein, Congress were to enact legislation aimed at clarifymg agency roles, it is possible that EPA's FRC-derived authority might be circuunscribed, or even transferred.

Indeed, there was soine discussion in the recent Senate hearings of a possible revival of FRC itself. ${ }^{323}$ There was testimony to the effect that when FRC was formed in the late 1950s, the concept of placing general authority to set standards in a single agency was apparently studied in depth (the Cutler study) and rejected. ${ }^{324}$ Instead, FRC itself comprised the heads of departinents with radiation responsibilities. Each member in turn assigned one top radiation expert to a working group that inet weekly. ${ }^{325}$ In theory, it would be even more problematic to have this agency oversight authority (particularly in its broadest EPA interpretation) vested in a sister agency. In light of the problems that the EPA has encountered thus far, it is worth noting the conclusions of the Cutler study that led to the original decision not to locate FRC in a simgle agency:

(a) No one agency could provide the breadth of coverage needed for the development of radiation protection standards.

(b) No one agency could be assured, in the field of radiation protection of adequate cooperation by all other concerned agencies.

(c) Interagency committees in the normal sense were traditionally ineffective and frequently served only for window dressing.

(d) Bureaucratic necessities stimulate a kind of rivalry that is costly and inefficient. ${ }^{326}$

This analysis serves to highlight the question whether EPA has the authority necessary to ensure the coordination of radiation protection activities.

322. See text accompanying notes 311-14 supra.

323. E.g., 1977 Hearings 152 (statement of Dr. Lauriston S. Taylor); id. 482 (statement of Lee V. Gossick, NRC).

324. The 1959 "Cutler study" was the work of Dr. Robert Cutler, Bureau of the Budget. Id. 137 (statement of Dr. Lauriston S. Taylor).

325. 1977 Hearings 137.

326. $I d$. 
4. The Changing Picture. When the regulatory roles of all agencies are viewed together, it is notable that since FRC was formed and its duties defined in 1959 there has been an evolution, approaching a revolution, both of the radiation problem and of the structure of the federal bureaucracy in relation to that problem. $\mathrm{In}$ 1959, little was known about the health effects of nonionizing radiation; virtually nothing about nonthermal effects. Certainly the Council itself was not designed to deal with the nomionizing radiation problem. In 1968, when Congress passed the Radiation Control for Health and Safety Act of $1968,{ }^{327}$ the potential health problem of nonionizing radiation was just beginning to be considered seriously, but that act was designed to deal not with environmental levels of radiation, but with individual electronics products. The environmental "revolution" had not yet hit the federal government in sucl a way that Congress would have conteinplated enacting coinprehensive legislation of the sort typified by the Clean Air Act of $1970^{328}$-nor was the radiation problem perceived to be of a scope to require such attention. Congress delegated authority for the administration of the Radiation Control Act to HEW. OSHA and the Occupational Safety and Health Act $^{329}$ did not exist at that time, nor did EPA. In 1970, when the EPA was created, the FRC was dissolved and its authority was transferred to the new agency; ${ }^{330}$ that authority had never been used for nonionizing radiation control. Accompanying all these changes, since 1959 , there lias been a spiraling growth in the number of NEMR producing sources in this country and a fitful expansion of knowledge concerning the health hazards these sources inay pose. The result is the confused patchwork of authorities that exists today, prompting calls for clarification and consolidation. Only legislation can resolve the problem because only Congress possesses the perspective of an outside observer with a duty to define and delegate responsibilities, the voice of authority to which all the agencies will histen and the funds to meet the problem.

\section{Formulating a Legislative Response}

This section is divided into two major subsections. The first deals witl the issues of policy and strategy, the second with the creation of institutional structures. The intent is not to propose legislation in detail, but only to identify issues for consideration and suggest congressional approaches to the problems that energe.

327. Pub. L. No. 90-602, 82 Stat. 1173.

328. 42 U.S.C. $\$ 87401-7642$ (1970).

329. 29 U.S.C. $\$ \$ 651-678$ (1976).

330. See text accompanying note 159 supra. 


\section{A. Developing Policy and Strategy.}

1. Health Protection-Setting Standards. The complexity of NEMR as an environmental and health problem makes the setting of traditional ambient health protection standards-a simgle numberdifficult and perhaps misleading. Such standards are only one tool in pollution control, and other tools inay sometimes be more important; nevertheless, it is hard to imagine pollution control, ambient or occupational, without relation to soine standards. This subsection will first examine soine of the factors that should be considered in setting a health standard as they relate to the NEMR problem and then emphasize the importance of having a health protection standard for unicrowave and radio frequency radiation.

(a) The definition of health. One of the reasons for the general national concern with microwave and radio frequency radiation has been the wide discrepancy between the American and the Soviet (and East European) occupational exposure "standards," both of which purport to have the same goal-protection of the health of persons occupationally exposed to these radiations. Scientific commentators offer a variety of explanations for this discrepancy. ${ }^{331}$ The most notable is the identification of a philosophical basis for the difference in standards. The OTP staff discussed this matter at soine length at the 1977 Hearings and in follow-up written responses. They stressed the distinction between an effect and a hazard, pointing out that moderate exercise can cause physiological changes such as "imcreased heart rate, circulatory and respiratory effects, etc., which are not considered hazards under normal circuinstances." ${ }^{332}$ Relating this observation to the Soviet standard-setting philosophy as he understands it, Dr. Thaler, then Acting Director of OTP, explamed:

[T] he Soviets may use any physiological changes, even transient and subjective symptoms, as a basis for establishing safety criteria some appropriate order of magnitude below the lowest levcl at which such phenomena are found to occur. We generally look for objective signs and pathology and base our determinations of what constitutes a "hazard" on such objective criteria as a poimt of departure for the establishment of safety standards or criteria. ${ }^{333}$

This difference in the definition of safe levels raises some questions concerning the adequacy of American standard-setting philosophies that merit legislative consideration. First, the hazards-effects distinction is of questionable validity in a field such as norionizing radiation

331. See note 70 supra.

332. 1977 Hearings 701 (statement of Dr. William Thaler).

333. Id. 
where there are so many uncertainties. Before the hazards-effects dichotoiny can have any real meaning, the ability both to predict the changes that will occur in the body because of exposure to some agent and to distinguish between harmful and benign changes is required. The understanding of the biological activity of microwave and radio frequency radiation has not yet reached this stage. As long as scientists are uncertain as to the mechanisins producing some of the observed effects, they cannot predict the harmfulness of those effects. Researchers are still discovering possible new effects, and scientists have not yet fully investigated inany of those already reported. Thorough investigations are necessary since some effects may have deleterious implications that are not immediately apparent.

Second, even with additional knowledge, there are problems with the practical operation of the hazards-effects distinction when dealing with a national anbient standard for an extremely varied population. Different people react differently to the same stimulus. For example, even moderate exercise can cause hazardous physiological changes in sonie individuals. If their doctors have inforined them of this hazard, they inay choose not to engage in such activity, or to ignore the medical advice, knowing the possible consequences. It is well established that more stringent standards are needed for involuntary risks such as subjecting persons to high ambient levels of nonionizing radiation whenever they sit on a terrace or walk down a street.

In setting standards, the at-risk population to be protected inust be identified. For example, Congress has determined that in settimg ambient exposure standards under the Clean Air Act, "public health" ineans the health of the nost sensitive members of the population. ${ }^{334}$ In the present case, this group might include persons wearing electromc cardiac pacemakers or those having inetal bone pins. If these persons are included, then the general American population standard must be lower than that which protects the average healthy person, since some electronic cardiac pacemakers, at least, have been shown to be affected at very low levels of NEMR. ${ }^{335}$ Alternatively, it might be possible to redesign and better shield these pacemakers ${ }^{336}$ and to substitute other inaterials for bone pins, but some provision inust be made for the wearers in connection with setting health standards. In addition, research may point to other population groups who, for nonmodifiable physiological reasons, are likely to suffer from exposure to levels of nonioniz-

334. H.R. REP. No. 294, supra note 278, at 50, reprinted in [1977] U.S. CODE CoNG. \& AD. NEWS 1128.

335. See note 125 supra.

336. See 1977 Hearings 213 (statement of Dr. John Osepchuk). 
ing radiation that would not be hazardous to the average person.

Third, a standard inust account not only for those whom it protects, but also for the conditions under which that protection is effective. Since Congress cannot control the chimate, its definition of health should in some way encompass health under all ambient conditions, including high ambient teinperatures and humidity ${ }^{337}$ These factors alone would require a lower ambient standard than $10 \mathrm{~mW} / \mathrm{cm}^{2}$ because thermal effects occur at or below that level.

These observations hold true with respect to the failure of American standards to account for transient and subjective symptoms. This failure inay indicate inore serious problems or problems that are serious in soine situations. As OTP noted in one report: "[S]ubtle central nervous system effects, even if reversible, might disrupt or affect the judgment of individuals performing critical tasks,"338 such as pilots or autornobile drivers.

Such questions may or may not be resolved differently depending on whether an occupational or a general population exposure standard is under consideration. Sometimes a unore lenient standard can be used in the occupational situation if other workplace and individual controls such as shielding, protective clothing and regular medical checkups are available to augment the protection provided by the standard. ${ }^{339}$ On the other hand, prolonged exposure to a pollutant, especially if there is a potential for a cuinulative health impact, may offset other factors that might permit a less protective occupational standard.

(b) The benefits of nonionizing electromagnetic radiation (NEMR) and the need for a standard. Some persons involved with

337. See H.R. REP. No. 294, supra note 278, at 121-22, reprinted in [1977] U.S. CODE CoNo. \& AD. NEWS 1200-01; see text accompanying note 114 supra. In fact, OSHA at one point proposed to incorporate a temperature humidity index (THI) imto its standard, 29 C.F.R. $\S 1910.345$ (1978), for telecommunications workers. This proposed standard would have decreased the maximum safe power density progressively from $10 \mathrm{nW} / \mathrm{cm}^{2}$ at a THI of 70 or less, down to $1 \mathrm{~mW} / \mathrm{cm}^{2}$ at a THI of 79 or more. 38 Fed. Reg. 23,040, 23,046 (1973). Because of objections lodged as to the difficulty of administering such a graduated standard and the accuracy of the THI formulation, this provision was deleted from the final rule and the $10 \mathrm{~mW} / \mathrm{cm}^{2}$ standard was retained. 40 Fed. Reg. 13,436, 13,438 (1975). One of the comments cited as support for deletion of that provision caine from BRH, whose conclusion following its criticism of the THI was not implemented. BRH suggested that the Microwave Radiation Protection Guide (MRPG) should be lowcred to 1 $\mathrm{mW} / \mathrm{cm}^{2}$ averaged over any 0.1 hour period and added that "[p]ersons having dependence on the use of electronic inedical devices such as implanted cardiac pacemakers and other electromechanical prosthetic devices may need additional guidance for protcction." Bureau of Radiological Health, Comments on the Department of Labor, Occupational Safety and Health Administration's Proposed Safety and Health Standards for the Telecommunications Industry 2 (Oct. 19, 1973).

338. OTP, Ist ANNUAl Report app. A, at 4.

339. See Review of Radiation Protection Activities 1974, supra note 61, at 89. 
communications view with alarm the prospect of broad implementation of an ambient radio frequency/1mcrowave radiation safety standard, particularly one lower than $10 \mathrm{~mW} / \mathrm{cm}^{2}$, the present American occupational guideline. They suggest that any such limitation could affect the operating ability of certain communications systems. ${ }^{340}$ The possibility of such a conflict does suggest the need to consider other national interests in formulating a health-based nonionizing radiation standard for the protection of the general population. ${ }^{341}$

Congress recognized such a need for balancing conflicting interests in the legislative history of the Clean Air Act Amendments of 1977. It noted the findings of NAS that there are adverse health effects at lower ambient levels than was thought at the time the standards were set. This fact, coupled with the limitations on present scientific knowledge, caused NAS to conclude that, for the listed pollutants, the only standard protective of health would be zero. ${ }^{342}$ Congress rejected suggestions that it adopt zero as an aunbient standard for any of the listed pollutants. As the House Committee on Foreign and Interstate Coinmerce concluded: "[O]bviously this no risk philosophy ignores all economic and social consequences and is impractical." 343 Similarly, an EPA representative, speaking in connection with the setting of ionizing radiation standards, noted that "as individuals and as a whole population we accept risks when there are benefits from the activity which inore than offset the risks." ${ }^{344}$ In neither case, however, did Congress or responsible officials reject the idea of establishing some inviolable health standard, proposing instead to rely on cost-benefit analysis alone. Not only have standards been retained, but supplementary preventive primciples have been adopted, such as the "non-deterioration" policy of the Clean Air Act applicable to areas already cleaner than

340. Jansky, supra note 282, at 12. In general, present ambient levels of NEMR appear to be well below $10 \mathrm{~mW} / \mathrm{cm}^{2}$ and even below $1 \mathrm{~mW} / \mathrm{cm}^{2}$. RAdiation Protection ACTIVITIEs 1976 at 95. If some present systems would violate a proposed ambient environmental standard, it might be possible to modify either the systems or their siting so as to comply with that standard.

341. Critics of the Soviet and East European standards sometimes point out that the Departments of Defense and Interior in those nations are not bound by the strict standards, and that operation of a modern military while adhering to a $10 \mu \mathrm{W} / \mathrm{cm}^{2}$ occupational exposnre standard would be impractical. Jansky, supra note 282, at 16; 1977 Hearings 279 (statement of Dr. Herbert P. Pollack). Whether these foreign agencies have other standards is not discussed and is probably not known. Such practical problems deserve consideration in formulating occupational and ambient standards for the protection of health.

342. H.R. REP. No. 294, supra note 278, at 112, reprinted in [1977] U.S. CODE CONG. \& AD. News 1190.

343. H.R. REP. No. 294, supra note 278, at 127, reprinted in [1977] U.S. CODE CoNG. \& AD. News 1206.

344. See Rowe, supra note 76 , at 265 . 
national ambient standards. ${ }^{345}$ These actions represent a determination of the mappropriateness of including valuations of human life in costbenefit analysis. Our environmental health legislation assumes that death and life-crippling diseases are an unacceptable price to pay for whatever general societal benefits may accoinpany pollution, and that cost-benefit analysis can only cone into play below the level at which a health standard has been set.

The fact that the benefits of the pollution in question are so great-national defense, essential communications, first amendment values - may even enhance the need for such a standard confining the operation of cost-benefit analysis. One commentator analyzes the situation thus:

Society's historical empirical approach to arriving at acceptable balances of technological benefit and social cost by trial, error and subsequent corrective steps create in advanced societies today a critical situation for two reasons: 1) the difficulty in changing a technical subsystem once it has been woven into the economic, pohitical, and cultural structures and 2) the techniques for societal diffusion of a new technology and its subsequent exploitation are now so highly developed that widespread use of a new technological development may occur before its social impact can be properly assessed and before any empirical adjustment of the benefit-versus-cost relations is obviously indicated. ${ }^{346}$

The very fact that society places a high value on defense and communications makes them likely to develop more rapidly than other technologies and to becoune instantly "essential." Since traditional market mechanisms have failed to account for hcalth costs, hcalth protection requires special governmental attention. Other efforts may be made within the process of cost-benefit analysis to deal with this problem, but the liealth-based pollution standard serves as a necessary safeguard in a preventive program.

In determining what the ceiling should be, one should be aware of the important technologies and national functions potentially affected;

345. H.R. REP. No. 294, supra note 278, at 127, reprinted in [1977] U.S. CODE CONG. \& AD. NEws 1206; see 42 U.S.C. $\$ \$ 7470-7479$ (1976).

346. BEIR II REPORT 23. Such thoughts have been echoed in several court opinions in recent years. See, e.g., Ethyl Corp. v. EPA, 541 F.2d 1, 6 (D.C. Cir.), cert. denied, 426 U.S. 941 (1976) ("Man's ability to alter his environment has developed far unore rapidly than his ability to foresee with certainty the effects of his alterations. It is only recently that we have begun to appreciate the danger posed by unregulated modification of the world around us, and have created watchdog agencies whose task it is to warn us and protect ns, when technological 'advances' present dangers unappreciated—or unrevealed-by their supporters."); Soucie v. David, 448 F.2d 1067, 1080 (D.C. Cir. 1971) ("The public's need for information is especially great in the field of science and technology, for the growth of specialized scientific knowledge threatens to outstrip our collective ability to control its effects on our hives.") 
but one must reject the misguided suggestion that there must be "conclusive scientific evidence" of the threat before critical communications will be restricted. ${ }^{347}$ First, this suggestion ignores the realities of regulating on "the frontiers of scientific knowledge" where conclusive proof is probably impossible absent human experimentation or the occurrence of the very accidents a preventive policy seeks to avoid. ${ }^{348} \mathrm{Sec}-$ ond, this position adopts the traditional bias in favor of existing technology rather than human health. As Congress has recognized in recent years in its formulations of environmental legislation, our society needs a corrective bias in favor of health protection; those who support continued use of technologies harmful to health should have the burden of proof. Furthermore, certain absolute standards must be set, because merely imposing the burden of proof on industry has been shown insufficient. It has been necessary to resort to "technology-forcing" provisions ${ }^{349}$ to induce industry to do what it can (but claims that it cannot) do to reduce pollution. If, indeed, nonionizing radiation poses the case of a pollutant for which anibient levels are still safe, then this standard will help keep them so. It will be "technology controlling," channeling research and developnent efforts in communications and other affected industries into the creation of nonradiative alternative technologies. ${ }^{350}$

In fact, the American scientific community is not in full agreement regarding the "philosophy" of setting health protection standards. ${ }^{351}$ Practically, Congress should delegate to soine government agency the task of determining the standard, spelling out in the legislation the basis on which the standard is to be set and the ineaning, in policy terms, of such phrases as "protection of health" and "inargin of safety."

2. Welfare Policy. Congress nuust also provide guidance and sonie structure for controlling growth below the health-based pollution

347. Radio Frequency SPeCtrum A-7.

348. See generally Ethyl Corp. v. EPA, 541 F.2d 1 (D.C. Cir.), cert. denied, 426 U.S. 941 (1976); H.R. REP. No. 294, supra note 278, at 43-51, reprinted in [1977] U.S. CODE CoNG. \& AD. News 1121-29 (discussion of Ethy); Karstadt, Protecting Public Health from Hazardous Substances: Federal Regulation of Environmental Contaminants, 5 ENVIR. L. REP. 50165, 50169-76 (1976).

349. For an introduction to the concept of "technology-forcing," see, for example, International Harvester Co. v. Ruckelshaus, 478 F.2d 615 (D.C. Cir. 1973) (discussing the Clean Air Amendinents of 1970); Society of Plastics Indus., Inc. v. OSHA, 509 F.2d 1301, 1309 (2d Cir.), cert. denied, 421 U.S. 992 (1975) (interpreting the Occupational Safety and Health Act).

350. See text accompanying notes 373-74 infra.

351. See, e.g., Johnson, Research Needs for Establishing a Radio Frequency Electromagnetic Radiation Safety Standard, reprinted in 8 J. MICROWAVE POWER 367, 382 (1973) (later adopted as ANSI C95 Policy Stateinent).

352. See note 43 supra for a brief discussion of the margin of safety concept. 
ceiling-to provide for the public "welfare," as the Clean Air Act terms this area. ${ }^{353}$ There unust be some balancing of competing values, including the balancing of interference effects and any liealth effects not covered by the standard agamst national security, communications, and so forth. There must be a determination of the method and degree of control over growth needed in order to minimize costs and maximize benefits to the society.

(a) Determining the scope of the problem. On the national level, Congress can begin to ascertain the scope of the problem from the EPA survey of ambient radiation levels, ${ }^{354}$ and then compare this to proposed environmental healtli standards. Congress should also exainine, when completed, the proposed NAS study on emerging radiation technologies and their liealtlı effects. ${ }^{355}$ This report will be highly speculative, but optimally it will set forth ranges of calculated health effects froin projected growth. If it appears from the study that uncontrolled growth of nomonizmg radiation sources in populated areas will rapidly raise ambient pollution levels close to the level of the liealth standard, then congressional controls will have to be substantial.

In order to select the proper control strategy, several factors peculiar to the nature of this form of pollution sliould be considered. First, unlike chemical pollution and nost ionizing radiation (medical $\mathrm{x}$-rays excepted), the release of nonionizing radiation is generally intentional and necessary to the performance of some task. The radiation from a broadcast tower or a radar installation is not a waste or by-product, but is the very purpose for existence of the source. Sometimes there may be alternatives to microwave communications or radio frequency broadcasts, but when the airwaves are used in this manner, effective operation requires minimum power outputs, not maximums. This is also true of radar, for which no functional equivalent exists.

Second, unlike ionizing radiation that requires a long-term comunitment to cumulative pollution build-up from radioactive wastes, nonionizing radiation pollution would dissipate rapidly if its sources were "turned off." While this point is of some importance in calculating costs, risks, benefits and error costs of a wrong decision, it should be kept in perspective. Eliminating automobiles and stopping power production in fossil fuel plants would also quickly eliminate chemical pollution problems, but these technologies as well as national communications and defense systems are "technical subsystem[s] . . .

353. 42 U.S.C. $\$ 7602(\mathrm{~h})(1976)$.

354. See text accompanying notes 130-45 supra.

355. See text accompanying note 243 supra. 
woven into the economic, political and cultural structures" of American society. ${ }^{356}$ Our commitment to them may be, practically speaking, as irrevocable as our commitment to radioactive wastes from nuclear reactors. ${ }^{357}$

Third, the nonionizing or radio frequency spectrum is a curious type of "natural resource." Although its usable portion is limited, it is not exhausted by use. It can be squandered or polluted, however, in the sense that inefficient or sloppy management of transmissions can cause costly interference, limit the numbers who may use the spectrum and alter the quality of that use. ${ }^{358}$ To date there has been little quality control and spectrum nianagelnent per se in the government sector and insufficient FCC control in the private sector to eliminate interference and inefficiences. ${ }^{359}$ Because the spectrum is free and its use is controlled by regulation, not economics, there have been no private incentives to eliminate these interference probleins. ${ }^{360}$ Recognizing these failures in the face of spectrun saturation, OTP and related governinent bodies have recently sought to develop management plans to allow for more, and inore efficient, use of the spectrum. ${ }^{361}$ This muchneeded step, which should be helpful in dealing with interference hazards, will also vitiate the indirect control placed on ambient levels of nonionizing radiation by spectrum saturation and perhaps spur an increase in the already rapid growth rate of radiating sources and ambient levels of NEMR.

Finally, the spectrum's frequencies or airwaves are "owned" and allocated by the federal government. ${ }^{362}$ Consequently, every source that emits nonionizing radiation is subject to federal control-control

356. See note 346 supra.

357. The only relief in either case would be through the development of new technologies that can deal with these problems. On that score, at least soine alternatives to nonionizing radiation are available, while ultimate solutions for the elimination of the radioactive wastes problem are apparently beyond present capabilities.

358. RAdio Frequency SPECTRUM A-7.

359. Id. $\mathrm{E}-19$.

360. Id. A-7.

361. Id. $\mathrm{E}-20$.

362. See Federal Communications Act of 1934, 47 U.S.C. $\$ 301$ (1976). The main rationale for this government control is the physical scarcity of spectrum resources, a theory advanced by the Supreine Court in National Broadcasting Co. v. United States, 319 U.S. 190, 216 (1943). Whether this justifies nontechnological regulation, i.e., the conposition and content regulation for a "public interest, convenience, or necessity," is beyond the scope of this Article. See generally 1 N. Dorsen, P. Bender, B. Neuborne, Emerson, Haber \& Dorsen's Political and Civil RIGHTS IN THE UNITED STATES 588-91 (4th ed., law school ed. 1976), and sources cited therein. That source also cites public or government ownership of the airwaves as another possible justification for their regulation-a somewhat circular argument. Id. 590. A third justification might be that soine regulation is necessary and proper for national defense, which today is dependent upon exclusive use of certain frequencies free from interference of other channels. Fimally, the current 
that is to be exercised in the "public interest."

This latter factor, coupled with the fact that the federal government is the major user of the spectrum for services of national importance, suggests that the controls should be largely national in character.

(b) Weighing the costs and benefits-the limits of economic analysis. The most ambitious plan would be to build on the NAS studies and conduct a spectruin-wide cost-benefit analysis of major emissions sources; value all benefits accrumg from existing and projected uses and all health costs; examine control alternatives; determine the most cost-effective controls and the optmial cost-benefit mix; and have the agencies implement this program through spectrum management, NEPA and licensing standards. This plan is too ambitious either for cost-benefit analysis or for our pohtical system. The cost-benefit analysis would encounter formidable problems as a result of the very speculative nature of much of the information on both the costs and the benefits. It is difficult to value even the economic costs of untested new technologies. Scientific uncertainties make the health costs of additional emissions sources highly speculative and subjective. On the benefits side, one inust confront such questions as: What are the benefits of a new defense systein that allows detection of enemy attack five minutes sooner? How does one figure the discount factors in relation to the risk of such attack, or the risk of such attack tomorrow as agamst five years from now? Can such factors really be objectively converted into dollar values?

In the field of ionizing radiation where there seem to be fewer uncertamties on both sides of the equation, a committee of NAS has concluded that cost-benefit analysis can "only determine choices at technical levels where the technical information is available and cannot dictate choices or replace the ultimate responsibility of the decisionmaker at higher levels where pohcy decisions must inevitably include more value judgments."363 At these "higher" levels, NAS concluded that cost-benefit analysis could be useful as a "framework and a set of procedures to help organize the available information, display tradeoffs, and point out uncertainties."364

On the political level, the total control that the suggested plan might imply is ahen to our pohtical and economic system. It is hard to imagime some agency's notion of optimal welfare dictating how many

knowledge of the potential hazards of unrestricted use of electromagnetic radiation gives rise to a federal police power justification for regulation of the spectrum.

363. BEIR II REPORT 10.

364. Id. 70 . 
CB radios could be manufactured and sold in a certam area if that area were also to support $x$ number of television stations and $x$ number of microwave ovens. Yet prevention requires planning for the future, and some method must be devised to assure that the planning is rational and also accounts for social and political values. Because sucli valuation is subjective, there should be public involvement on this matter. How to allow for this involvement in a program that requires a high level of national uniformity is a difficult problem to resolve.

In its recent report concerning ionizing radiation, NAS confronted a similar problem. The Academy identified two value systems-the traditional cost-benefit analysis that "seeks to maximize human welfare primarily through increasing economic well-bemg"365 and another system that considers future generations. It concluded that "the problem of incorporating both of the traditionally separate value systems into the decisionmaking process is perhaps the major quesiton of the coming decades. The short- versus long-term trade-offs depend on the mamier of incorporation of the traditionally separate value systems into the decision-making process." ${ }^{366}$ NAS's suggested solution for this problein is to use weighting factors in the cost-benefit analysis for factors traditionally undervalued by the marketplace and to have these factors "established by society in general, whether through the political process, public survey, or other means."367

The prospect of Congress actually voting on multiphers for the factors on each side of a traditionally constructed cost-benefit equation suggests that such action may be neither rational nor helpful. As an alternative, Congress might establish a structure of agency review procedures, veto powers and so forth. The process of political compromise should produce an agency structure that "weights" the cost-benefit analyses performed so as to reflect the preferences of the people as voiced by their congressional representatives.

Proposals for such a structure will be offered below. The following subsection will first examine some specific strategies for preventive action in NEMR pollution control.

\section{Policy Implementation-Choosing Pollution Control Strategies.} It seems unlikely, given the numerous uncertainties, the complexity of the radiation problem and the important national political imterests at stake, that the first attempt at legislation will be wholly satisfactory. A question of some importance, then, is how far-reaching the new legisla-

365. Id. 69.

366. Id. 70.

367. Id. 
tion should be. The uncertainties mvolved may suggest the need for somewhat cautious initial legislation accompanied by vigorous research:

[T] he need for alternative technologies and the extent of any such use would be influenced by what electromagnetic field exposure conditions-frequency, waveform, power density, time, etc.-might be found to be responsible for any harmful effects. For example, a finding that such affects [sic] occur only under certain conditions (of frequency, ete.) would affect any such considerations. ${ }^{368}$

As a counter to this position, it is worth reemphasizing the commonsense position that health uncertainties call for more controls not less. Since the agencies seein to have a natural tendency to imertia, that is, to wait for the resolution of all uncertainties before acting, it would probably be wiser to provide them with this counter position as a guiding principle. Whatever its extent, the program should concentrate on control of those sources that may contribute most to the exposure levels of the general population. These would probably include the highpowered government sources (some defense radars and SATCOMS and the proposed solar satellite power systeins) and broadcast transmitters.

(a) Control of government sources. An important first move would be to require consideration of NEMR in the preparation of environmental inipact statements under NEPA. ${ }^{369}$ Specifically, the definition of "major Federal actions"370 should mclude radiation output levels as a standard for requiring an impact statement. It might be possible to key the standards to regional variations on a scale correlating emissions levels with ainbient levels to determine when the impact statement process would be triggered. To facilitate the impact statement process, Congress should legislate several other strategies, such as government organization of regional spectruin inanagement centers; ${ }^{371}$ extensive use of a data bank showing anbient radiation levels as an aid in selecting sites, particularly for defense installations; formulation of "new source performance" standards for individual agencies to minimize and control NEMR emissions from their projects.

The government should carefully examine the alteruatives to its own uses of NEMR. President Carter recently announced his intention to transfer sensitive government cominunications fronı microwave relay to cables in order to avoid the possibility of capture of signals by

368. 1977 Hearings 700 (statement of Dr. William Thaler).

369. 42 U.S.C. $\$ 84321-4374$ (1976).

370. Id. $\$ 4332$.

371. Cf. 47 C.F.R. $\& 0.38$ (1978) (FCC regional spectrum management). 
foreign intelligence sources. ${ }^{372}$ The government might take analogous actions with respect to other, more significant radiation sources for health protection reasons. For example, it has been suggested that a "substantial part of satellite communications could be replaced by cables, fibers and millimeter waveguide" and that it is only the economic advantages that prevent the use of these alternatives. ${ }^{373}$ Utilization of these options would limit the need for some sources of potential radiation health hazards. It would also provide improved communications, just as cable television provides improved reception, because of the elimination of interference from atmospheric and topographic conditions that affect microwave and radio frequency communications. ${ }^{374}$ When these factors are included in the calculation, the alternatives may even prove to be advantageous in the classical economic sense. Considering the health question involved, the government should examme the available options, implement some of them on a trial basis and im other ways encourage the development of alternatives.

(b) Control of private broadcast sources. FCC regulation of the channels delegated to private use is in some respects more advanced than governmental use in its development of decentralized spectrum inanagement and the use of data banks and processing systems. ${ }^{375}$ However, the FCC also should imcorporate nonionizing radiation health costs imto its NEPA and licensing standards and its concept of regulation in the "public imterest."

Congress should require the FCC to pay particular attention to broadcast stations and should inandate the development of siting criteria for transnritters. Siting criteria should take imto account the possibility of exposure to the near field of the antemia (as with persons on the top floors of tall buildings for antemras located on the roof of their building or nearby buildings) and also the ainbient levels of NEMR in the area to which the far field radiation of the antemra may contribute. Such criteria could be supplied to the local zoning boards that make the mitial decisions with respect to the location of antennas. It is already technically feasible to replace airwaves broadcasts with coaxial or fiberoptics cable systems that provide improved service and nore channels for programming. ${ }^{376}$ Congress might also mclude provisions specifically designed to encourage the switch to cable, particularly for

372. Burnham, Carter Approves Plan to Combat Phone Spying by Other Nations, N.Y. Times, Nov. 20, 1977, at 34 , col. 1 .

373. 1977 Hearings 699 (statement of Dr. William Thaler).

374. Id.

375. See 47 C.F.R. $\$ 0.38$ (1978).

376. 1977 Hearings 699. 
television, where transmissions are to fixed locations.

The FCC could accomplish this by limiting the amount of the spectrum that is allocated to television broadcast use. This move would be very difficult politically for several reasons. First, to date, the FCC has not even adopted technically achievable standards for airwaves broadcasts that would require upgrading to conserve spectrum space. It lias not taken such action because of an expressed "reluctance to risk disturbing so large an investment." 377 Given the strength of the television lobby, Congress may be equally reluctant to act $\mathrm{m}$ this area. Although recent actions of Congress and the FCC suggest that the current regulations that protect broadcasters im both the cable and the broadcast industries may be revoked, there is no indication that the health advantages of cable television are being given any consideration. Perhaps with a different perspective imparted by a legislative mandate to the FCC and other agencies to control radiation health hazards, accompanying changes im attitude in support of the cable industry would be forthcouning; however, the political clout of the broadcast networks should not be underrated. ${ }^{378}$

It is also possible that there would be adverse public response to a congressional inandate for change on first amendment grounds. In fact, a properly engineered transition from broadcast to cable television across the board should improve rather than limit service and at the same time help to limit the most pervasive source of elevated ambient levels of nonionizing radiation. The real problem is that cable television costs money and the per-household costs might be higher in sparsely populated areas. ${ }^{379}$ Since urban areas would generally benefit most im terms of health from the limitation on the numbers and power outputs of broadcast transmitters, it might be reasonable to equalize what would otherwise be disproportionate rates and spread the costs. Public opposition to any cliange at all, however, might be considerable. One can rationalize the fee cliarged for cable as a sort of tax for health

377. Radio FREQUeNCY SPECTRUM D-37 to 38.

378. In June 1978, the Communications subcommittee of the House Committee on Interstate and Foreign Comnerce unveiled its plans for general revision of the 1934 Communications Act. The bill provides for the complete deregulation of the cable television industry. Coupled with proposed charges to television broadcasters for spectrunt use, see note $386 \mathrm{infra}$, this could result through market forces in a gradual reduction in broadcast facilities because of cable competition and therefore in a reduction in radiation pollution from this source. Of course, these provisions may not survive lobbying and conference procedures. Even if they should, market-forced reduction in broadcast emissions is at best speculative and the time-frame for the process is uncertain. Furthermore, until Congress addresses the health question explicitly and consciously attempts to limit electromagnetic pollution levels, any frequencies unused by broadcasters will simply be reallocated to other sources, inaking net reduction in ambient nonionizing radiation levels unlikely.

379. See 1977 Hearings 699. 
protection; consumers would only be paying the true costs of this protection, which is not provided by traditional airwaves broadcasterscosts that were formerly externalized. Nevertheless, there are solne prices that people are unwilling to pay for improved health and longer hives. ${ }^{380}$ Congress should certainly investigate this possibility.

Alternatives are also available for AM and FM broadcasts that reach both mobile and fixed radio receivers. One possibility is to limit antenna power output and substitute several antennas with lesser outputs broadcasting from various local points on the same charmel. ${ }^{381}$ Another inethod for reducing environmental radiation and alleviating interference probleins in urban areas is to use a combination of relay towers and cables. ${ }^{382}$ This method could be used by the rapidly growing land-nobile communications systems as well. A third possibility, when there is no alternative to urban siting, would be to have the broadcaster purchase development rights froin neighborimg lot owners to prevent construction of tall buildings close to and in the inain beam of the antenna. Legislation should require research into and consideration by the hicensee of all these alternatives, leading eventually to their cost-effective impleinentation.

(c) Control through expanded spectrum management. Adoption of the control inethods suggested, particularly increased use and enforcement of spectrum inanageinent techniques, has the potential to all but eliminate interference effects, an inportant aspect of the pollution problein. Particularly if conversion to cable television is effectuated or if changes are made in anterma siting (including revision of the present FCC policy favorimg the mounting of antennas on existing structures in urban areas), this legislation would also reduce or at least retard the growth in ambient levels of radiation. In anticipation of future growth, however, and in search of rational control strategies, Congress should consider mandating investigation of other, nore comprehensive methods of control. One possibility is the use of spectrum management as a tool not only for assuring spectrum purity, but also for ambient level control. The proposal to limit frequency allocations for television broadcast is one example of such a control. In general, limiting the size of the frequency band assigned to a particular use is an indirect, though partially effective, way of controlling the NEMR pol-

380. See note 285 supra and accompanying text.

381. This, apparently, is the practice in some European countries, e.g., West Germany. Personal communication with Norbert Hankin, Electromagnetic Analysis Branch, ORP, EPA (Jan. 19, 1978).

382. 1977 Hearings 699. 
lution contribution from that category of sources. However, one undesirable response to the spectrum saturation inherent in this system inay be for licensees to increase power outputs (as in the case of broadcast stations) in an effort to overcome interference.

Such a regime would be more effective if supplemented by output ceilings for each band. This proposal faces a major problem, however, because the present FCC decentralized spectrum inanagement presuinably reflects deinands for spectrum use in that area. The establishment of ceilings would make desirable more systematic public involvement than is afforded by individual and essentially ad hoc licensing hearings. If all potential spectrum users could not be accommodated, it would be necessary to ensure that those services nost desired by the community were allowed, but local communities would probably lack the resources to generate their own growth scenarios. Neither do public referenda (vote for spectruin inanagement plan one, two or three) seem feasible. As the FCC or federal government presently allocates frequencies, has the expertise and, to the extent available, the infornation for this task, public hicensing hearings may be the best vehicle for public participation in the decisionmaking process. Local governments should have the option to petition the FCC for reallocation of frequencies withm the established radiation ceiling.

This system would have to be coordimated with federal government usage of the spectrum. In the context of ambient levels, it seems unreasonable simply to exempt government uses, as is done in some parts of Eastern Europe. ${ }^{383}$ Given the heavy governmental use of the spectrum in some areas, with concomitant contributions to radiation levels, a government exemption could render the established pollution ceiling ineaningless. Nor should these important national systems be subjected to local control, as is the case with most governmental installations under the Clean Air Act. ${ }^{384}$ Rather, certain localities would be required to limit their own radiation output to accommodate federal sources in the area. Government should attempt to minimize this adverse local impact by sitmg in areas with low ambient levels and by striving to reduce emissions.

It still seems inevitable, under such a regime, that some areas will pay disproportionately in teruns of local spectrun space (though not in terms of health) for benefits that accrue to the nation as a whole (for example, a defense installation). In addition, in contrast to the Clean Air Act's nondeterioration policy, this policy would contribute to the

383. See note 341 supra. The nondeterioration provisions of the Clean Air Act also include potentially substantial exemptions. 42 U.S.C. $\$ 7473(c)(1)$ (1976).

384. 42 U.S.C. $\$ 7418$ (1976). 
equalization of ambient levels of NEMR pollution nationwide, unless the ceilings under the spectrum zoning plan were differentially set. If the health ceiling itself is low enough to provide substantial health protection, this fact may not be cause for much concern. Nonionizing radiation pollution produces no visibility problems nor other adverse aesthetic effects as does, for example, particulate air pollution. If, however, the ceilings designed to prevent adverse consequences to human health were found not protective of wildlife, causing death, fetal defects or other adverse effects in plants and animals, ${ }^{385}$ and if ambient radiation were rising to damaging levels on farmlands or in wildlife habitats, it would be necessary to revise the equalization policy accordingly. Such a scheine seeins to offer a means for adequate coinprehensive control, if political barriers can be overcome. ${ }^{386}$

385. While the linear dose hypothesis underlying ionizing radiation protection policy is based on the accepted scientific premise that "other constitutents of the biosplere . . . are no more radiosensitive than lumans," EPA Policy Statement on Relationship Between Radiation Dose and Effect, in Radiation Proliferation app. I, at 38-40, this premise does not hold for nonionizing radiation. As a result of the phenonienon of resonance, see text accompanying notes 101-07 supra, and to nian's superior thermoregulatory capabilities, see text accompanying notes 52-53 supra, it is probable that most other organisms are nore radiosensitive than man at many nomionizing frequencies. See MARHA 2 (attributing the recent resurgence of interest in nonionizing radiation bioeffects research to "the discovery that animals and plants decline and die in electromagnetic fields of a certain minimum power density in the centimeter (cm) band.")

386. Another possible method of controlling electromagnetic radiation levels would be the institution of a pollution cliarge or pollution rights control strategy. Environmental analysts have advocated the use of sucl cliarges before as solutions to air and water clean-up problems, but these proposals have not been adopted in practice. See, e.g., B. ACKERMan, S. Rose-ACKERMaN, J. SAWYer \& D. Henderson, THE UnCERTAin SEARCh FOR ENVIRONMENTAL Quality 260-81 (1974). One reason is that such proposals always face pohtical opposition from powerful industrial interests. Broadcasters and other spectrum users are no exception. Fierce opposition to any clrange in the status quo- "free" use of the airwaves for licensed equipment-is to be expected. In spite of this fact, and undoubtedly with the federal budget and spectrum saturation rather than radiation levels in mind, the newly introduced Commumications Act of 1978, H.R. 13015, 95th Cong., 2d Sess. (1978), "[e]stablishes a hicense fee that would refiect both the cost of processing the hicense apphication and the value of the spectrum occupied by the user (applies to broadcasting and nonbroadcasting services)." 124 CoNG. REC. H5231 (daily ed. June 8, 1978). "Value" will be computed on the basis of local frequency demand and, for broadcast stations, on the basis of the ratio between the number of stations im the area and the number of households served during prime time.

This is a radical proposal that nuay not survive the political process. If it is to be implemented, the computation of "value" sliould include the lealth costs imposed by the spectrum use in question. This requirement would render these calculations even more difficult.

In addition, some environmentalists have in the past objected on philosophical grounds to the concept of awarding "rights" to pollute and awarding thein on the basis of willingness or ability to pay. Market mechanisms seen particularly ill-suited to control in an area characterized by a tradition of lieavy governmental regulation, heavy governmental use of the resource in question (spectrum space) and possible strong public preferences aniong pollution sources on the basis of values not accounted for in the marketplace. While it may be possible to overcome these hurdles, legislators should examine all proposals fron the perspective of lealth protection and consider the 


\section{B. Restructuring the Institutions.}

One of the most difficult problems in this area is to determine the proper administrative structure and the proper allocation of responsibilities among the agencies in order to ensure effective implementation and enforcement of the proposed radiation control legislation. The keys to the problem are clarification, coordination and some consolidation of agency roles to close gaps, eliminate duplication and create an administrative system as free as possible from agency in-fighting and jealousies. At the outset, it should be reemphasized that nonionizing radiation is a nultiagency probleın. While this makes it administratively difficult to handle, it may in the long run make it a stronger and better program. It cannot be allotted to a single agency, seemingly giving other agencies a license to ignore the problem. ${ }^{387}$ The task, then, is to ensure that all agencies involved with this problenı are encompassed in a structure that encourages communication and allows critique of the proposed programs from the various agency viewpoints and scientific backgrounds. This goal nust be accomplished in both the research and the regulatory fields, without unnecessary disruption of ongoing programs.

1. The Research Program-Choosing a Coordinator. Two of the most basic problems with the radiation research progranı as it now stands are the location of the program in NTIA within the Department of Commerce and the inadequate allocation of funds. The obvious solution to the former problem would have been to keep the research coordination function in EOP. Since the President recognized that some OTP functions properly belonged within EOP, he did not transfer thein to Commerce, but to himself, for reallocation within EOP. Those functions that reverted to the President may be reasonably interpreted to include coordination of the bioeffects research program. ${ }^{388}$ Given the inappropriateness of locating this program in the Department of Commerce $^{389}$ and the available alternative, it is not clear how or why

need for the sort of spectrum management proposed above as either an element of, or an alternative to, the marketplace scheme of the new communications bill.

387. See 1977 Hearings 781-82.

388. See text accompanying notes 151-52 supra. Adoption of this interpretation would have effected a divorce of frequency allocation (now clearly in NTIA) and research coordination. This would not necessarily be an undesirable result. Some commentators have criticized the lack of objectivity in research conducted by regulatory agencies. E.g., Karstadt, supra note 348, at 50106. Although OTP performed no research, its role as regulator of governmental spectrum use subjected to bias its exercise of research coordination and advisory functions. If the coordinating role were strengthened to allow the coordinator to provide more direction, such a combination of responsibilities would become more problematic.

389. See 1977 Hearings 677 (statement of David P. Rall) ("We believe this [OTP] coordination 
the program was transferred to NTIA.

Had the program remained in EOP, the President would have found it necessary to allot it to one of the offices that survived the reorganization. ${ }^{390}$ Of these offices, only three have functions that are sufficiently related to telecommunications or environmental effects problems to make them logical choices: the Office of Management and Budget, the Office of Science and Technology Policy, and the Council on Environmental Quality.

(a) Office of Management and Budget (OMB). In his "Message" accompanying Reorganization Plan No. 1, the President allocated to OMB most of the functions reserved to EOP by the Plan, including responsibility for "telecommunications procurement and management policy and arbitration of interagency disputes about frequency allocation." ${ }^{391} \mathrm{He}$ transferred all other functions to NTIA except "developing Presidential policy options." 392 The last Acting Director of OTP identified the radiation research program as one of "the major pohicy-making functions" 393 of OTP, so logically it might be viewed as a part of OMB's new telecommunications functions.

OMB might have certain advantages as a research coordinator over the old OTP administration. First, it can help resolve the funding problem. On its face, that problem is simple. Several existing research plans similarly define the critical needs in the area and make recommendations for concentration of research efforts; these plans represent the consensus of the scientific community. ${ }^{394}$ OTP has suggested that funding at two to three times the present level of $\$ 9$ million would support such a program. ${ }^{395}$ Congress must merely authorize the appropriation. Such a general appropriation, however, would be a dramatic departure from the previous practice; formerly, mdividual agencies allocated the funds from within their own research budgets. The total size of that budget was determined by OMB. The congressional appropriation would require a new structure for funding allocation that OMB can provide. The past Director of OTP expressed concern that authorizing OTP to allocate funds might create tensions in an otherwise amicable and cooperative effort, producing a feeling in the agen-

function is needed and should be maintained at some locus at an appropriately high level in the Executive Branch.")

390. Presidential Message, supra note 154, at 1011.

391. Id.

392. Id.

393. 1977 Hearings 687 (statement of Dr. William Thaler).

394. See note 296 supra.

395. 1977 Hearings 700 (statement of Dr. William Thaler). 
cies that "we were imposing our will on their efforts." 396 However, this problein is less likely to materialize under OMB allocation because that office controls agency funding in any event.

OMB could rely on recommendations from ERMAC, an NAS committee, or some other organization with expertise in the field, as a basis for granting the inoneys. The projects could be assigned according to agency mission, but should mclude much-needed basic research and long-range research projects not undertaken under the existing regine. OMB would then be able to accomphish the goal of providing more priority, direction and supervision for the program. In order to maintain some agency autonomy and in recognition of the fact that individual agencies may be the best judges of their own research capabilities, OMB's role should be limited to the assignment of NEMR research priorities, leaving to the agencies the choice of specific research project design.

Allocation of the prograin to OMB clearly has some attractive aspects, but there are potential problems as well. The inain problem concerns OMB's general orientation. In analyzing OMB's failure to oversee and support the NEPA process, one commentator noted that "[i]n many respects OMB shares the perspective of development-oriented agencies whose emphasis on economic growth overlooks important social values which are usually neglected in traditional economic analysis."397 Similarly, in the controversy over OMB's Quality of Life Review of EPA regulations, OMB was criticized for its delay of and opposition to EPA proposals for strong environmental controls. ${ }^{398} \mathrm{Be}-$ cause the prograin in question involves research coordmation rather than regulation and because OMB would be administering on the basis of the recommendations of scientists knowledgeable in the field of bioeffects of nonionizing radiation, these problems might not prove too serious; but recognition of their potential does suggest the desirability of assuring the scientific objectivity of the advisors and fornulators of any plan that $\mathrm{OMB}$ would administer. ${ }^{399}$

396. Id. 688.

397. Anderson, The National Environmental Policy Act in Federal ENVIRONMENTAL LAW 238, 251 (E. Dolgin \& T. Guilbert eds. 1974).

398. See generally [1976] 7 ENVIR. REP. (BNA) 693, 1197, 1243, 1443.

399. Because nuany of the specialists im the nonionizing radiation field coine from defense or industry, both of which have a strong interest in promoting radiation technologies and a history of supporting the "thermal effects only" position, there is danger that these biases will creep into advisory council analyses and recommendations, compounding the problem of OMB orientation. Thus, it night be wise to rely on CEQ or the health-oriented agencies to suggest advisory council or panel menibership. An established rotation of membership would also be a useful principle to assure fresh ideas and a balance between policymakers (who may change with administrations) and experts. 
(b) Office of Science and Technology Policy (OSTP). Under the language of the Reorganization Plan. OMB may have the strongest claim to the bioeffects research program, but there is no reason that Congress could not allocate it to another division of EOP. On paper, OSTP appears to be a likely candidate to serve as coordinator of the research program. That Office was established to advance the national policy for science and technology, which imcludes among its first principles:

(1) The continuing developinent and implementation of strategies for determining and achieving the appropriate scope, level, direction, and extent of scientific and technological efforts based upon a continuous appraisal of the role of science and technology in achieving goals and formulating policies of the United States, and reflecting the views of State and local governments and representative public groups.

(2) The enlistinent of science and technology to foster a healthy econoiny in which the directions of growth and innovation are compatible with the prudent and frugal use of resources and with the preservation of a bemign environment. ${ }^{400}$

OSTP also possesses substructures that to some extent correspond to the IRAC-ERMAC Side Effects Working Group structure and could easily take on these functions. ${ }^{401}$ There is even a specific statutory mandate for the development of five-year outlook and analysis reports on "current and emerging problems of national significance that are identified through scientific research," 402 which could be adapted to deal with a new five-year plan for nonionizing radiation research. This authority, formerly exercised by OSTP, was recently transferred to the National Science Foundation (NSF); 403 thus NSF could, through a committee or panel, perform the ERMAC functions for OSTP.

The idea of mtegrating environmental and health considerations mto science and technology decisionmaking is the ideal. It is the idea behind NEPA. It is the idea that prompted OTP, as regulator of government use of the spectrum, to start investigating the possible ill effects associated with its activities. In general, however, organizations do not conform to the ideal of integrated activity and often are not really designed to do so. Thus, industries designed to earn a profit may lose sight of questions related to the means used in pursuit of that end. OSTP, as successor to the Office of Science and Technology, probably has as much of a developmental orientation as OMB. While it may

400. 42 U.S.C. $\$ 6602(a)(1),(2)(1976)$.

401. 42 U.S.C. $\$ \S 6601-6618$ (1970), as modified by Reorg. Plan No. 1 of 1977, supra note 150;

Presidential Message, supra note 154.

402. 42 U.S.C. $\$ 6615(a)(1)(1976)$.

403. Reorg. Plan No. 1 of 1977 , supra note $150, \S 5$. 
resemble an Office of Technology Assessment on paper, OSTP basically serves as a research and development arm of the government with strong ties to the Department of Defense, the largest user of the spectrum and of nonionizing radiation technologies in the government. From this standpoint, OSTP may offer an even more inhospitable environment for bioeffects research coordination than the Commerce Department.

In fact, however, OSTP has been looking into the nonionizing radiation problem and has prepared a report ${ }^{404}$ that includes an assessment of the biological hazards associated with radio frequency and microwave technologies. That report may give some clues as to the ability of OSTP to transcend the inherent conflict between support for technological advances to meet certam national goals (its traditional role) and full and objective examination of the possible environmental and health problems of new technologies.

(c) Council on Environmental Quality (CEQ). In terms of its general orientation, CEQ is the entity within EOP that is best suited to administer the research program. Its duty is to "review and appraise the various programs and activities of the Federal Government in the liglit of the policy set forth in subchapter I"405 which recognizes "the profound influences of ... new and expanding technological advances" 406 and the responsibility of the government to ensure "that the Nation may . . . attam the widest range of beneficial uses of the environment witlout degradation, risk to health or safety, or other undesirable and unintended consequences."407 Although serving as coordinator of an ongoing program would be a deviation from the norm of CEQ activities, it is not very different from oversiglit of NEPA. Of course, the Council would need an infusion of resources, primarily personnel. Another possible problem, applicable to OSTP as well, concerns the proposal for independent funding for the program. Neitler OSTP nor CEQ has OMB's advantage in this area, and since CEQ must work closely witl the agencies, notably NEPA, on numerous environmental matters, it would be unfortunate if its control of the purse strings adversely affected its relationship with the federal agencies. This might not prove a serious issue in practice, and if it did, a reversion to the present pattern of individual agency funding would be pos-

404. Office of Science and Technology Policy, A Technical Review of the Biological Effects of Non-Ionizing Radiation (May 15, 1978).

405. 42 U.S.C. $\$ 4344(3)$ (1976).

406. Id. $\S 4331$ (a).

407. Id. $\S 4331(\mathrm{~b})(3)$. 
sible.

Congress should carefully examine all the advantages and disadvantages of each of these executive offices as coordinator of the interagency nonionizing radiation bioeffects research program. It should also consider the possibility of creating a new office whose functions would include administration of the program. An alternative would be to coinbine program administration by CEQ, OMB and OSTP. Congress should then incorporate its decision into a clear legislative nandate to administer such a program, so that it will no longer be unrecognized in EOP reorganizations. This mandate should include increased power to determine research priorities. It should also include appropriation of sufficient funds earmarked for this bioeffects research, including provisions for funding long-term and basic research projects that are currently not undertaken because research and funding decisions are made on the individual agency level. ${ }^{408}$

2. The Regulatory Program. One of the most basic criticisms of the proposal to create a single radiation control agency was that the agency would be an anomaly in the existing executive structure, which is organized along functional rather than subject-matter lines. A consolidated agency would have to duplicate, in all areas, the tasks carried on by other agencies-such as inspections for occupational hazards, protection in the healing arts or environmental monitoring-rather than utilizing the existing expertise in the area. ${ }^{409}$ In the present format, a similar charge could be made against EPA, with its proposals to issue guidelines in the healing arts and occupational safety. Whether in the ionizing or the nomionizing context, these are not areas of EPA expertise. Given the inadequacies of its present Office of Radiation Programs, ${ }^{410}$ high quality results would be a minor miracle. One possible solution to this problem would be a redefinition of EPA's role and a revival of the FRC.

(a) A new Federal Radiation Council for nonionizing radiation. The advantages of the FRC structure as derived from the Cutler study are breadth of coverage (nultidisciplinary); cooperation of all involved agencies (multiagency); permanence and participation of top agency experts and administrators, which are not generally found in interagency cominittees; and elimination of wasteful bureaucratic rival-

408. See, e.g., 1977 Hearings 677 (identifying the need for a "focal point for determining the direction of the total research effort"); see text accompanying note 289 supra (recommending centralized funding allocation).

409. 1977 Hearings 1101-02 (statement of Dr. William Thaler).

410. See text accompanying notes $311-14$ supra. 
ries. ${ }^{411}$ When coupled with a redefinition of EPA's role, this structure would allow recognition of the superior knowledge of BRH or OSHA in certain areas and ensure their cooperation, ${ }^{412}$ which EPA cannot presently compel.

The revived Council as proposed here would deal only with nonionizing radiation natters. Membership in the Council would be modified from that of the old Council to eliminate any agencies with interests solely in the ionizing radiation spectrum and to account for the fact that other agencies now have regulatory authority that encompasses nonionizing radiation sources. Agencies with a strong research mterest im NEMR should also have a representative attend these meetings. The Council should meet on a regular basis. The major responsibility of the Council would be to develop general guidelines similar to the CEQ guidelines for environmental impact statements. ${ }^{413}$ The preliminary task of devising a health standard should be assigned to EPA. The proposed standard should be pubhished in the Federal Register for public comment, then subjected to review by the Council, with EPA, however, having the final say. In hight of this standard, the Council should then proceed to develop general standards for the agency members. This guidance should include specification of uniform measureinent techniques to be used in development of the mdividual agency standards. The guidelines, mcluding the EPA standard, would be issued under the President's signature, as is presently the case. The agencies would then proceed to develop and promulgate standards for their own spheres of operation in accordance with the guidelines. These standards would again be subjected to public comment procedures and then, accompanied by environmental impact statements, subjected to review by other Council members.

In commentimg on the general process of environmental impact statement review, one analyst of environmental law and pohicy noted that in practice there was a reluctance of agencies to divert resources to commentimg on the projects of others, adding that: "[ $t]$ his attitude of benign neglect will be transcended only when an agency perceives that another's project is threatening its own programs. In this case an agency's comments will be primarily those of an advocate. Such advocacy will often be extremely valuable."414 The proposed Radiation Council process is designed to encourage just this sort of valuable criti-

411. See text accompanying note 326 supra.

412. See 1977 Hearings 481-82 (statement of Lee Gossick).

413. CEQ Guidelines, 40 C.F.R. $\S 1500$ (1977).

414. B. ACKerman, S. Rose-ACKerman, J. SAWYeR \& D. HENDerson, supra note 386, at 155. 
cism, because the agencies will essentially be competing for spectrum space and radiation allotinents. The standards would then be incorporated into the spectrum inanagement prograins of the FCC and the new NTIA in the Department of Commerce.

The individual agencies would be responsible for the implementation and enforceinent of their own standards. An already existimg structure, the NEMR Commitee of the Interagency Regulatory Liaison Group (IRLG), ${ }^{415}$ might be enlisted to undertake health standards oversight duties, including recommendations for adjustinent in standards and notifications of the need for enforcement to agencies who are remiss in their duties. These tasks would be accomplished through coordination among these agencies on the regional level, through an IRLG representative at EPA or FDA regional offices and through the regional spectrum management centers. ${ }^{416}$ There would be a presumption in favor of modifications and enforcenent actions in line with the IRLG recommendations, which should be made on a principle of unanimity. If an agency failed to respond, procedures would have to be established for adjudication of the issue. If an agency failed to enforce its own standards, citizens should have the right to sue for enforcement. It would be possible to grant EPA standing to sue the recalcitrant agency for failure to enforce, but this would have the drawback of creating animosity between EPA and the other agency, with whom friendly cooperation is essential. In addition, this procedure would be far from optimal in the case of a recommended standard adjustment, because choosing between two scientific standards may be beyond the competence of even the most conscientious of our courts.

The Council would have to set up its own review procedures or arbitration system to deal with these problens. It is hoped that instances of agency failure to accept IRLG recommendations would be rare, but if some compromise could not be worked out, then it would be necessary to resort to such procedures. In that case, perhaps a simple inajority vote of the whole Council would be sufficient, based on IRLG's recommendation. The agency and IRLG would each have the

415. This group is composed of representatives from EPA, OSHA, FDA and the Consumer Product Safety Commission (CPSC). CPSC's role on the NEMR committee of IRLG is necessarily limited becanse, under present legislation, CPSC has no authority over the radiation aspects of electronic products; it is preempted in this area by FDA's authority under the Radiation Control for Health and Safety Act of 1968, 42 U.S.C. $\$ \S 263 b$ (1976); 15 U.S.C. $\$ 2080$ (1976). Although new legislation could change this division of responsibilities, given HEW's substantial overall involvement and expertise in the area of nonionizing radiation, there is good reason to allow HEW's BRH to continue its role in emissions control-even though it has not been as vigorous as one might wish in its implementation of its authority over radio frequency and microwave radiation emitting products. See text accompanying notes 182-87 supra.

416. See text accompahying note 371 supra. 
opportunity to present its case, through either written submissions or oral argunient. The agency would then be obligated to comply with the decision, which would be final. Sanctions would probably not be in order in such a situation.

Although this could create problems of reluctant enforcement of the standard objected to by the responsible agency, such a problem would probably exist to an even greater degree if the standards theinselves were promulgated by EPA rather than by the individual agency. Resolution of this problem may be possible only at the expense of creating other problems.

(b) Redefinition of the EPA role. Certain of EPA's inost important functions under the new system are outlined above. Congress should also, of course, confirm EPA's jurisdiction to carry out its general functions in the area of nonionizing radiation, such as environmental noonitoring. ${ }^{417}$ The monitoring program should be made a part of the general legislative package. Outside of its Council and nonitoring duties, EPA's ORP would be concerned primarily with the setting of ambient environmental standards. Given the complexity of the nonionizing radiation problem, this would be a difficult task, because it would require the setting of a series of standards to account for frequency variations, near and far field problems, and so forth. In addition, EPA's Office of Research and Development would continue to be a niajor component of the research program. Such a redefinition of EPA duties should enable ORP to overcoine its serious deficiencies and devote to its more limited duties the quantity and quality of attention they deserve.

(c) Other agencies-OSHA. Other agencies would also require some infusion of funds to accompany their redefinition of roles. The FCC would require additional personnel to accomplish its new duties, but in general, agency adjustments could be confined largely to internal reorganizations.

OSHA, however, presents another major problem. The agency seems to be lraving trouble fulfilling its legislative mandate. Inspections for radiation hazards are apparently at the bottom of its hist of priorities, ${ }^{418}$ perhaps with solne justification, since many toxic chennical substances appear to pose more serious occupational hazards than nonionizing radiation, and these chemicals are also under controlled. The result, however, is that there is virtually no enforcement of radiation

417. See text accompanying notes $127-45$ supra.

418. See text accompanying note 205 supra. 
standards and guidelines in the workplace. ${ }^{419}$ Congress should devote particular attention to OSHA, giving it a strict and specific mandate and allocating the funds necessary to hire trained personnel to deal with this hazard and to purchase the necessary equipment to monitor hazards at the lower RF frequencies at which most industrial equipnient operates. ${ }^{420}$ Since BRH assumes authority over full compliance for some electronics products in the medical environment ${ }^{421}$ and for microwave ovens, it is possible to learn from its experience when upgrading OSHA's program in this area. OSHA and BRH might develop a cooperative agreement covering field inspections. Such cooperation offers, among other advantages, the opportunity to cut costs and improve the prograins of botll agencies.

(d) Federal-state relationships. Close cooperation between OSHA and BRH in the field inspection area would be particularly valuable in the awarding of enforcement contracts to the states. Both agencies engage in this practice when the states' own imspection programs neet certain standards. ${ }^{422}$ This allows the agencies to operate with fewer inspection personnel of their own and to cover more ground. If BRH and OSHA cooperated in the awarding of these contracts for nonionizing radiation imspections, it would streamline the bureaucratic and funding processes for some states, thus making the contract prospect nore attractive to states with limited finances to devote to inspection personnel and equipinent.

Indeed, this seenis to be the kind of consolidation the states have been requesting. ${ }^{423}$ This, coupled with the establishment of regional spectrum committees coinposed of FCC, NTIA and EPA representatives, would limit to two the number of federal entities witl which the states would have to deal on NEMR problems. Maintenance of a joint conputer file by these two entities for the reporting of radiation imcidents would be another way to facilitate interagency coordination.

419. See text accompanying notes $174-75$ supra.

420. See text accompanying note 204 supra. Better cooperation with NIOSH is also high on the list of reforms needed at OSHA. Although a close relationship between the two agencies is contemplated by the Occupational Safety and Health Act, 29 U.S.C. $\$ 671$ (1976), Grover Wrenn, Director of OSHA's Health Standards Programs, expressed his ignorance of the existence of very important NIOSH studies of the NEMR occupational environment. 1977 Hearings 578. Furthermore, OSHA is not obligated to take any action in response to NIOSH criteria documents. If NIOSH does present OSHA with a docnment supporting the establishment of a radio frequency/ microwave occupational lealth standard, OSHA nnay choose not to act on it.

421. See 1977 Hearings 735 (statement of Conference of Radiation Control Program Director).

422. 29 U.S.C. $\S 667$ (1976) (OSHA); 42 U.S.C. § 263m (1976) (BRH); see 1977 Hearings 65 (OSHA); id. 579-80 (BRH).

423. See text accompanying note 265 supra. 
(e) Adjudication of agency jurisdictional disputes. If these proposals are adopted, or if other attempts are made to define agency roles more clearly, particularly that of EPA, and to eliminate overlapping authorities, then the frequent agency disputes over "turf" should greatly diminish. Disagreements are unlikely to disappear altogether, however. There should be some structure to allow parties to a dispute to resolve the problem quickly. Although the parties will probably be reluctant to submit the dispute to adjudication or arbitration, each fearing to lose some function it beheves rightfully its own, it seems unlikely that such a disagreement could fail to affect the FRC. It is hoped that the cooperative atmosphere of the Council would be such that other ineinbers might informally advise the parties and help mediate the dispute. If all efforts should fail to resolve such a disagreement within soine time period, such as six months, the Council should require that the parties submit notification of their failure to resolve the problem. The Council could then discuss the inatter and, if it determined that the problein was a significant one, vote on a resolution that it be submitted to adjudication. (The parties should, of course, have the option to submit the question to adjudication voluntarily.) But adjudication in this instance does not mean resolution by the federal judiciary-there should be soine executive structure to resolve such disputes. In the past, both $\mathrm{OMB}^{424}$ and $\mathrm{CEQ}^{425}$ have sometimes assumed this function. Because of its general environmental oversight functions, CEQ is probably the more logical choice for arbitrator of interagency disputes over pollution control functions. OMB already has official appeal jurisdiction of interagency disputes over NTIA's frequency allocations, ${ }^{426}$ a function in line with its general duties. However, if either of these offices is assigned a role in radiation research management, ${ }^{427}$ this could potentially affect the impartiality of that office as arbitrator of the disputes in question. Congress should consider the situation and allocate dispute resolution responsibilities to an appropriate component of EOP.

424. See 1977 Hearings 92.

425. The duties of CEQ, as revised by the President's Reorg. Plan No. 1 of 1977, supra note 150 , and the accompanying "Message of the President," supra note 154, at 1012, are to "provide an independent assessment of our pohicies for improving the environment. Towards this end, it will analyze long term trends and conditions in the environment. It will advise OMB on the reorganization of natural resources functions within the Federal government." Id. See B. AcKERMAN, S. Rose-ACKerMaN, J. SAWYER \& D. HeNDERSON, supra note 386, at 161 .

426. See note 159 supra.

427. See, for example, proposals at text accompanying notes $388-99$, $405-08$ supra. 


\section{Conclusion}

When confronted with the complexities and uncertainties of the scientific enterprise, and with a bureaucracy that is in some ways disorganized, often inefficient, and always overburdened, even explaining the radiation problem, let alone proposing how the bureaucracy might control it, seems overwhelming. Congress has confronted the problem several times over the past decade, patiently questioning scientists and policymakers, private and public, in an attempt to find a path through the morass. The purpose of the examination of the problem undertaken by this Article has been first, to try to convince the reader that it is now time, or past time, to start making concrete legislative proposals for dealing witli a problem that is growing with each day of delay. Second, this Article has inade such proposals-proposals for adapting existing agency structures, for creatimg some new institutions and for opening new channels of communication among the numerous agencies, each with an important role to play in confronting and resolving the probleins of controlling nonionizing radiation.

It is important to emphasize here what has not been proposed. What has not been proposed is delegating all, or even most, of the responsibility for nonionizing radiation control to a single agency. By conparison, controlling air and water pollution may begin to look easy. The regulators here are being asked to regulate themselves, as well as private industry, because here the government is as inuch a polluter as the private sector. If nonionizing radiation is to be controlled, the Departinent of Defense cannot be given carte blanche simply because it is the Departinent of Defense, for it accounts for one quarter of spectrum use. The multiplicity of agency concerns must be integrated and coordinated into sonie sort of uniform approach. NEPA points in the right direction, but it is much too weak a tool to deal with the complex problein of nonionizing radiation. This Article only introduces the problems and proposes a structural framework for confronting them. It is hoped that Congress will take some of these suggestions and, through legislation, provide the agencies with the direction they need to deal with the probleins effectively. Nonionizing radiation pollution presents to Congress a clear challenge to translate the concept of technology assessnient into practice on a national scale, assuring that the health and environmental perspectives gain their rightful place. First Congress and then the agencies nuust nieet the challenge of making difficult choices and decisions creatively and forcefully-and without delay. 
